\title{
Characterization of ovine monocytes in response to Haemonchus contortus larvae in vitro and a novel role of Interleukin-13 inducing larval paralysis
}

\author{
Elizabeth Shepherd \\ eashepherd@mix.wvu.edu
}

Follow this and additional works at: https://researchrepository.wvu.edu/etd

Part of the Immunology of Infectious Disease Commons, Parasitology Commons, and the Sheep and Goat Science Commons

\section{Recommended Citation}

Shepherd, Elizabeth, "Characterization of ovine monocytes in response to Haemonchus contortus larvae in vitro and a novel role of Interleukin-13 inducing larval paralysis" (2019). Graduate Theses, Dissertations, and Problem Reports. 3814.

https://researchrepository.wvu.edu/etd/3814

This Dissertation is protected by copyright and/or related rights. It has been brought to you by the The Research Repository @ WVU with permission from the rights-holder(s). You are free to use this Dissertation in any way that is permitted by the copyright and related rights legislation that applies to your use. For other uses you must obtain permission from the rights-holder(s) directly, unless additional rights are indicated by a Creative Commons license in the record and/ or on the work itself. This Dissertation has been accepted for inclusion in WVU Graduate Theses, Dissertations, and Problem Reports collection by an authorized administrator of The Research Repository @ WVU.

For more information, please contact researchrepository@mail.wvu.edu. 
2019

Characterization of ovine monocytes in response to Haemonchus contortus larvae in vitro and a novel role of Interleukin-13 inducing larval paralysis

Elizabeth Shepherd

Follow this and additional works at: https: / /researchrepository.wvu.edu/etd

Part of the Immunology of Infectious Disease Commons, Parasitology Commons, and the Sheep and Goat Science Commons 


\title{
Characterization of ovine monocytes in response to Haemonchus contortus larvae in vitro and a novel role of Interleukin-13 inducing larval paralysis
}

\author{
Elizabeth Anne Shepherd
}

Dissertation submitted to the Davis College of Agriculture, Natural Resources and Design at West Virginia University in partial fulfillment of the requirements for the degree of

Doctor of Philosophy in Animal and Food Science

Scott Bowdridge, Ph.D., Chair

Janet Tou, Ph.D.

Jianbo Yao, Ph.D.

Rosana Schafer, Ph.D.

Anne Zajac, DVM, Ph.D.

Keywords: ATP, Haemonchus contortus, interleukin-13, macrophages, monocytes

Copyright 2019 Elizabeth Shepherd 


\section{Abstract \\ Characterization of ovine monocytes in response to Haemonchus contortus larvae in vitro and a novel role of IL-13 inducing larval paralysis}

\section{Elizabeth Anne Shepherd}

Haemonchus contortus is a hematophagous, gastrointestinal parasite affecting small ruminants. Parasitism by $H$. contortus is the greatest concern of sheep producers in the United States and accounts for billions of dollars in economic loss worldwide. However, different breeds of sheep display differences n natural resistance to $H$. contortus. St. Croix hair sheep have a remarkable ability to clear $H$. contortus without the aid of anthelmintics and develop a robust T helper type 2 (Th2) immune response, preventing establishment of infective stage 3 larvae (L3), when compared to susceptible Suffolk sheep. However, the mechanism of development of immune response and differences between resistant and susceptible breeds is not fully understood. In these studies, response of ovine monocytes, from resistant and susceptible breeds of sheep, to whole L3 were evaluated in vitro. Monocytes were isolated from peripheral blood mononuclear cells and cultured with L3 over 6 to 15 hours to measure gene expression and effector function, by measuring larval ATP and motility. Separation of peripheral blood mononuclear cells (PBMC) into monocytes and lymphocytes demonstrated a clear effector function of monocytes against L3. Monocyte and macrophage activation state have been associated with helminth infection and play an important role in induction of Th2 type responses for overall host protection. Inhibition of inducible nitric oxide synthase in Suffolk monocytes rescued susceptibility, whereas inhibition of alternative pathways reduced effector function in both breeds, and thus, monocytes required arginase-1 for full effector function. Though St. Croix derived monocytes up-regulated genes associated with classical (M1) activation, early activation of alternative markers (M2) were present compared to Suffolk derived monocytes. Interleukin-13 (IL-13) is a cytokine critical to Th2 type immune response and promoting alternative activation of monocytes in context of helminth infection. Inhibition of IL-13 in monocyte culture dampened effector function in St. Croix derived cells. However, larval morbidity was not IL-13 dependent. Independent of cellular mechanisms, IL-13 was observed to cause larval paralysis, reducing larval speed and distance, identifying a previously unknown role of IL-13. Overall, St. Croix displayed increased paralytic activity of from monocyte culture supernatant, in conjunction with heightened monocyte-mediate larval morbidity, and therefore may be reflective resistance to $H$. contortus infection and development of full host protective immunity. 


\section{Acknowledgements}

First and foremost, I'd like to thank my advisor, Dr. Scott Bowdridge, for taking a chance on me and accepting me as a graduate student. Not only did he provide an opportunity to pursue my interests, but he continually challenged me, pushing my development as a scientist and also to become a stronger, more confident person. I am incredibly grateful for my experience, the growth he has promoted and the encouragement I have received throughout my academic career.

I would not be successful without the help of the numerous individuals in the Division of Animal and Nutritional Sciences at West Virginia University. The faculty and staff have provided endless support and promote student success. Secretaries Bonnie Wood, Kim Mouser, Lindsay Tripplet and Gretchen Riggs were always there to help answer questions, deal with paper work or help with the smallest of issues. Ben Groover helped me recover data files more than once and has changed the course of anxiety inducing situations. Each of them has helped make the stress of graduate school much lessened. Additionally, a special thank you goes to Dr. Robert Taylor, Jr. for his genuine care about students and his willingness to help problem solve.

Having students exemplify hard work and dedication have not only been mentors, but also exceptional sources of support throughout the graduate experience. I have to thank Jesica Jacobs for always being willing to help no matter what, someone to brainstorm with, a model of success, and moreover an incredible friend. Lab mates Crista Crawford and Taylor Harrison taught me how to handle sheep and were always available to help at the farm. Denzel Middleton, Brynnan Russ, Cameron Maierle, Andrew Weaver and Reese Tuckwiller shared many long days, but together taught me how to have fun on long days at the farm and work together in the lab.

Finally, I would like to thank my family for their unwavering support in my graduate pursuit. My parents, Don and Mary, have shown patience and love through all my endeavors. Throughout my life they have demonstrated the value of hard work and persistence that I believe has gotten me to where I am today. My brothers, Andrew and Stephen, have been my greatest source of inspiration and motivation to achieve my goals. Each of them have pushed me to progress, do more, follow my interests and strive to excel at whatever I choose to do. I am truly grateful for their love and guidance. Living in West Virginia has also meant I have had the support of my extended family. They have fed me countless times and have been a source of refuge when Colorado was too far away. Lastly, I would be remiss if I didn't especially thank my uncle, Mark Teets. Without him and his belief in me, I would certainly not be here today. 


\section{Common Abbreviations}

$1400 \mathrm{~W}=(\mathrm{N}-(3-[$ Aminomethyl $]$ benzyl $)$ acetamidine $)=$ iNOS inhibitor

$\mathrm{APC}=$ antigen presenting cell

Arg1 = Arginase -1

$\mathrm{ATP}=$ adenosine triphosphate

$\mathrm{BEC}=(\mathrm{S}-(2$-boronoethyl)-I-cysteine hydrochloride $)=\operatorname{Arg} 1$ inhibitor

$\mathrm{CSF}=$ colony stimulating factor

$\mathrm{DC}=$ dendritic cell

ELISA = enzyme-linked immunosorbent assay

$\mathrm{FEC}=$ fecal egg count

GIT $=$ gastrointestinal trichostrongylid

$\mathrm{Hc}=$ Haemonchus contortus

HcLA = Haemonchus conotortus larval antigen

$\mathrm{HT}=$ heat treated

IFN $\gamma=$ interferon gamma

$\operatorname{Ig}=$ Immunoglobulin

ILC = innate lymphoid cell

IL- = interleukin

iNOS = inducible nitric oxide synthase

JAK = Janus Kinase

$\mathrm{KO}=$ knockout

L3 = infective third stage larvae

$\mathrm{LEV}=$ levaminsole

M1 = classically activated macrophages

M2 = alternatively activated macrophage 
$\mathrm{NO}=$ nitric oxide

PBMC $=$ peripheral blood mononuclear cells

$\mathrm{PCV}=$ packed cell volume

$\mathrm{RAG}=$ recombination activating gene

$\mathrm{RT}=$ room temperature

$\mathrm{RT}$ qPCR = real time quantitative polymerase chain reaction

STAT $=$ signal transducer and activator of transduction

$\mathrm{STC}=$ St. Croix sheep

SUF $=$ Suffolk sheep

Th1 $=$ T helper type 1

Th2 $=$ T helper type 2

$\mathrm{TNF}=$ tumor necrosis factor

$\mathrm{WT}=$ wild type 


\section{Table of Contents}

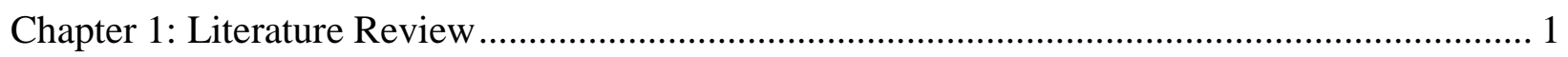

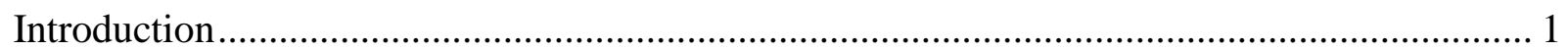

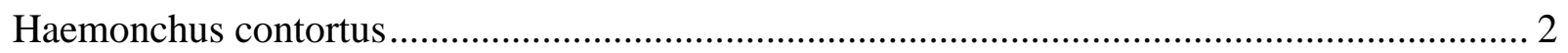

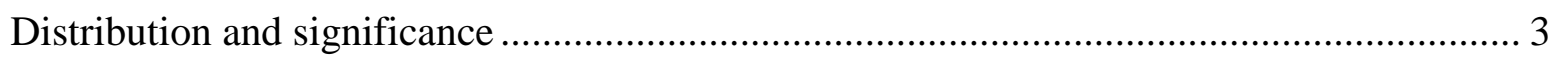

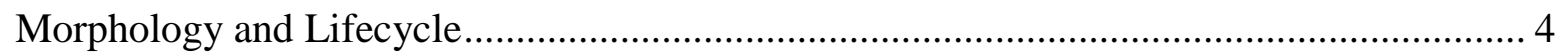

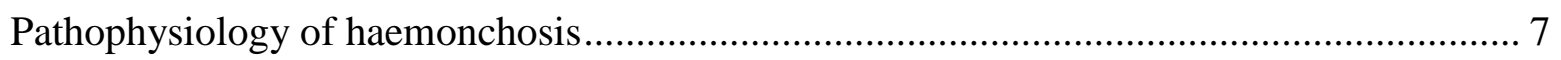

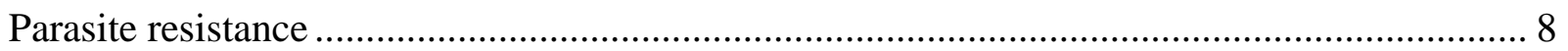

Immune response to Haemonchus contortus ........................................................................ 10

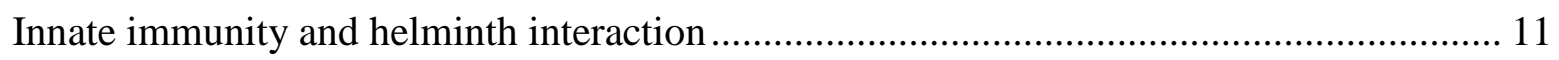

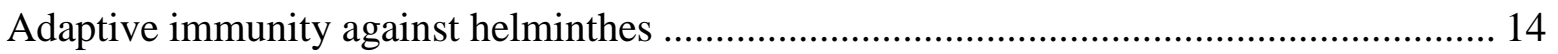

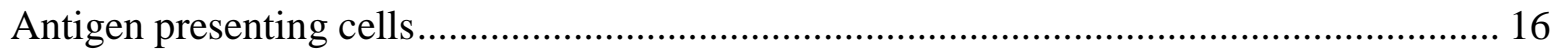

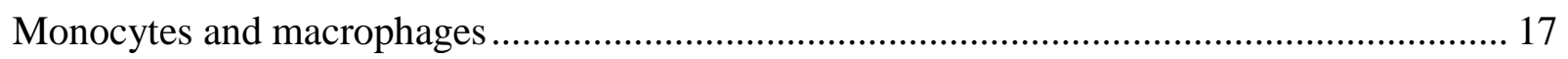

Development of monocytes/macrophages ........................................................................ 17

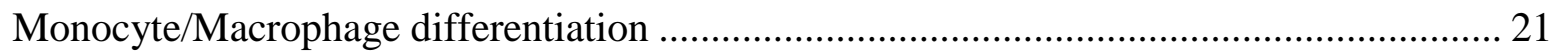

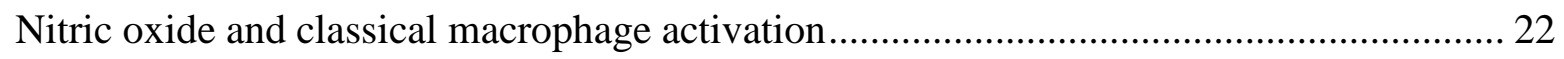

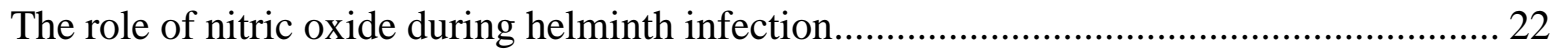

Arginase and alternative macrophage activation ........................................................ 23

Alternatively activated macrophages are critical during helminth infection ......................... 24

Macrophages are plastic cells and display a spectrum of phenotypes .................................. 27

Cytokine interleukin-13 is critical during helminth infection.................................................. 28

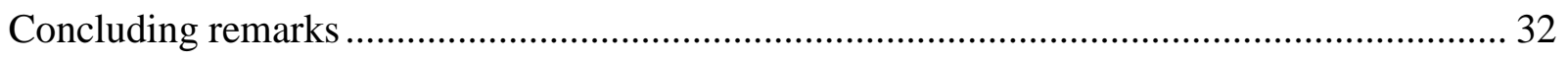

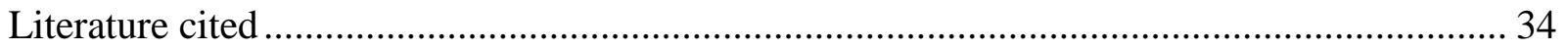

Chapter 2: Common methodologies …………………....................................................... 53

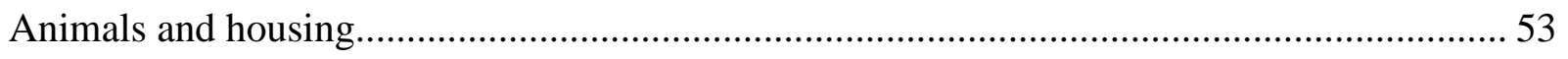

Experimental Design........................................................................................................ 53

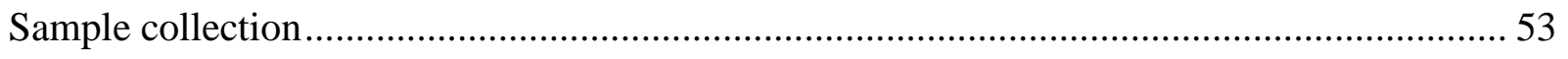

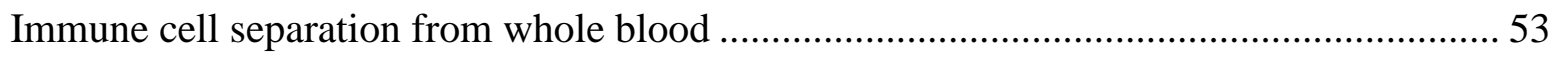

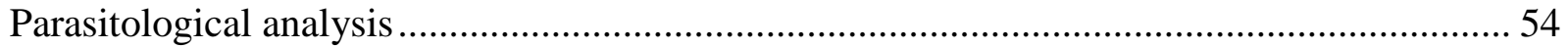

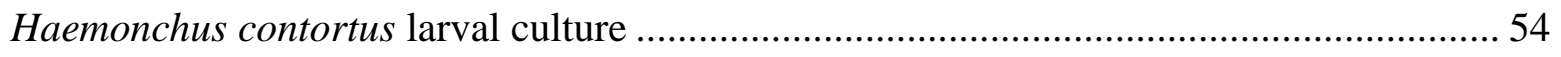

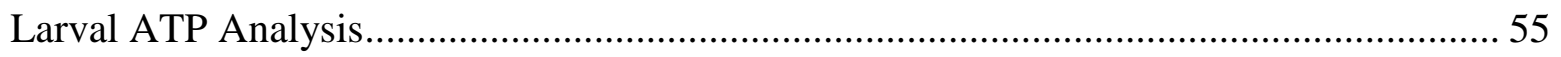




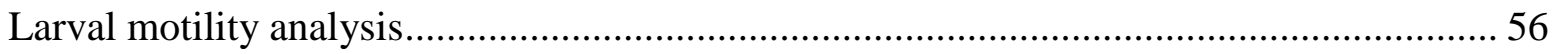

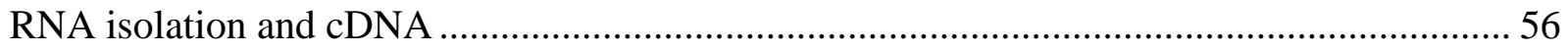

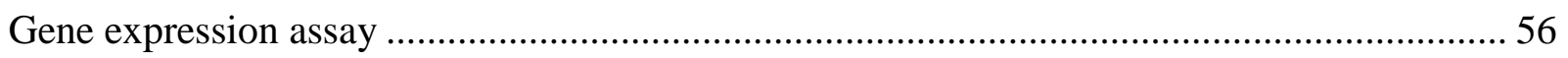

Chapter 3: Characterization of ovine monocyte activity when cultured with Haemonchus

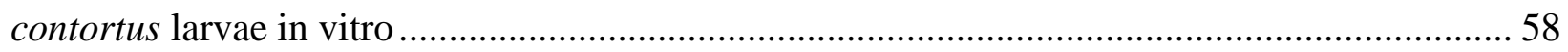

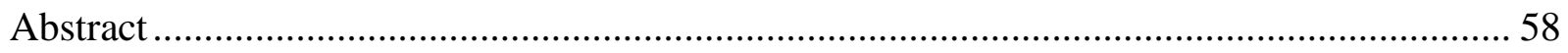

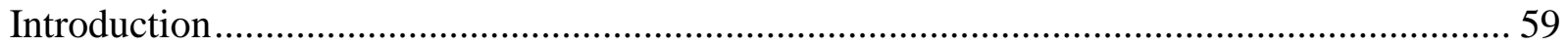

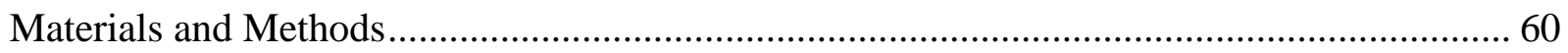

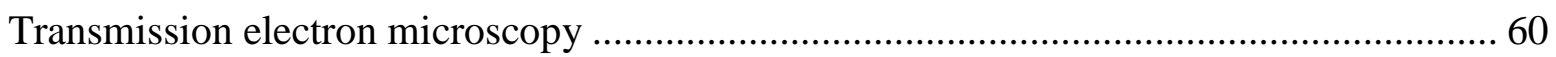

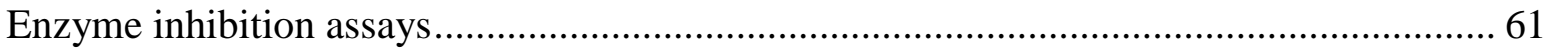

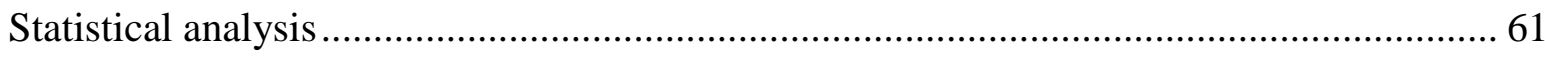

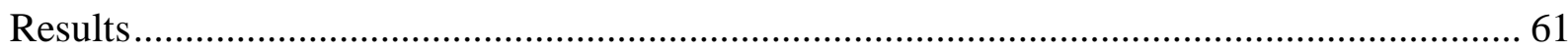

Effect of mononuclear cell subset on $H$. contortus motility and morbidity........................... 61

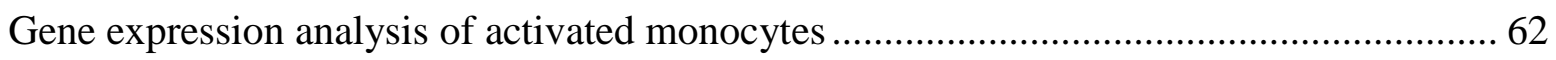

Effect of arginase and nitric oxide inhibition in monocytes during culture with $H$. contortus

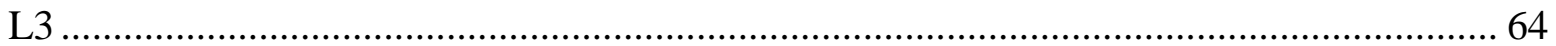

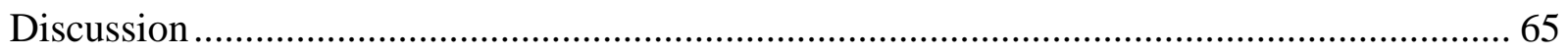

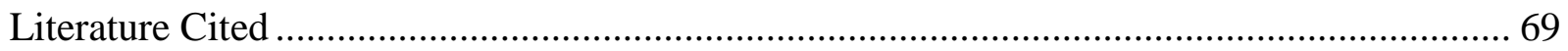

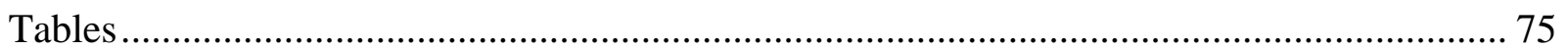

Table 3.1: Gene expression of monocytes at 6 hours of cultures with L3 ……….................. 75

Table 3.2: Gene expression of monocytes at 9 hours of cultures with L3 ................................. 76

Table 3.3: Gene expression of monocytes at 12 hours of cultures with L3 ……...................... 77

Table 3.4: Gene expression of monocytes at 15 hours culture with L3 …………………........ 78

Chapter 4: A novel role for Interleukin-13 inducing paralysis in Haemonchus contortus larvae 79

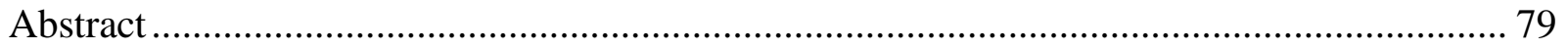

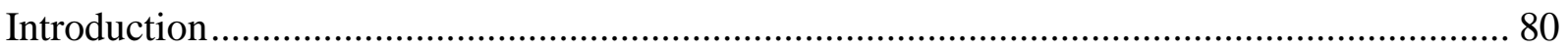

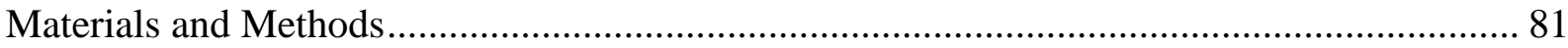

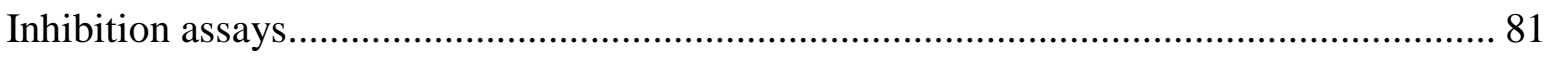

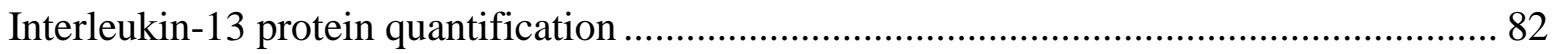

Larval antigen preparation ....................................................................................... 82

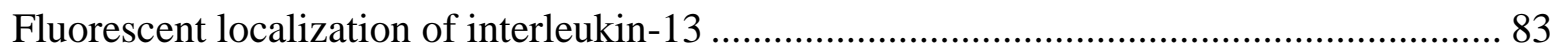




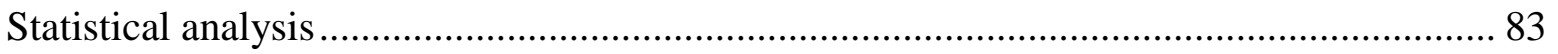

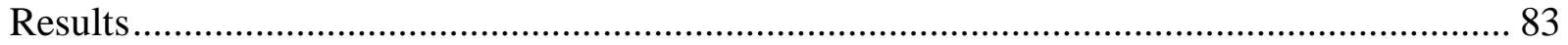

Larval motility following treatment with recombinant interleukin-13 ........................... 83

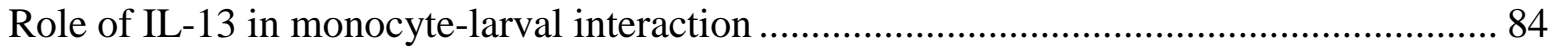

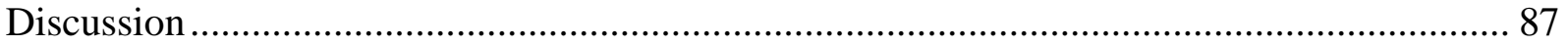

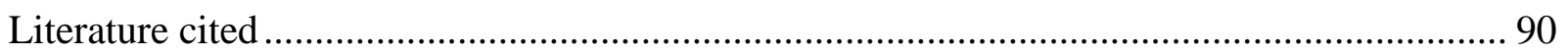

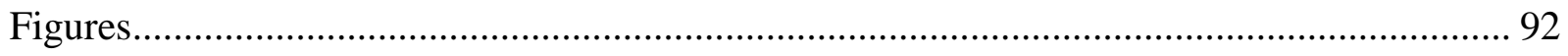

Figure 1: Larval motility measured after cytokine treatment in vitro.............................. 92

Figure 2: Role of IL-13 in monocyte-larval interaction............................................. 95

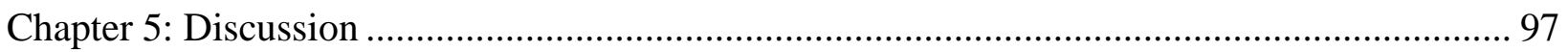

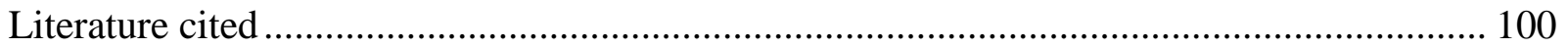




\section{Chapter 1: Literature Review}

\section{Introduction}

Gastrointestinal trichostrongylid parasites present a global animal health challenge, causing reduced growth rate, illness and even death in severely affected animals. In the United States alone, producers report gastrointestinal parasitism as the most prevalent health concern among sheep operations (1). Of these parasites, Haemonchus contortus is the most pathogenic species affecting commercial sheep and has become resistant to all drug classes due to the overuse of anthelmintics as a primary means of parasite control (2). The rise of resistant worm populations now requires development of alternative control methods for livestock production of parasite-resistant sheep, such as St. Croix hair sheep.

Due to their slow growth rate, small carcass size and lack of wool, St. Croix hair sheep are not typically considered desirable commercial sheep. However, these sheep have a welldocumented ability to clear $H$. contortus infections without the aid of anthelmintic drug treatment (3-6). Therefore, St. Croix are considered parasite resistant sheep (5). Compared to parasite-susceptible breeds, St. Croix produce a rapid and greater cellular immune response, preventing establishment and development of adults (3). Driven by T helper 2 (Th2) type immune response, interleukin (IL-) 4, IL-13 and IL-5 are increased, along with recruitment of innate cells such as eosinophils and mast cells in abomasal lymph nodes and mucosa $(3,7)$. T cells are also increased during infection, indicating strong adaptive immunity in control of $H$. contortus. Increased cellular innate and adaptive responses suggest that differences between parasites resistant and susceptible breeds may hinge on their ability to recruit cells and produce the proper signals early during infection, recognizing $H$. contortus before establishment. 
Previous studies have demonstrated a role of peripheral blood mononuclear cells (PBMC) contributing to reduced larval motility, as measured by path-length, velocity and acceleration in vitro (8). Larval death is commonly described as immobility, with outstretched bodies and nonrefractive internal structures (9). However, a more precise measure of larval morbidity can be quantified using larval ATP. Culture of $H$. contortus infective third stage larvae (L3) with PBMC revealed significantly reduced larval ATP, suggesting these cells contribute to and is also a valid measure of larval morbidity (10). Therefore, experiments in this dissertation are aimed to characterize and further understand the mechanisms contributing to observed larval morbidity. To date, little is known about the role of ovine monocytes during $H$. contortus infection. Thus, the elucidation of cellular responses in larval morbidity in parasite-resistant sheep is important for development of alternative strategies to manage haemonchosis.

\section{Haemonchus contortus}

Haemochus contortus is a haematophagous nematode parasite, belonging to the order Strongylida and the Trichostrongyloidea superfamily. While there are 12 species of Haemonchus, only three species spread globally - H. contortus, H. placei and H. similis however, $H$. contortus is considered one of the most significant parasites of sheep and goats worldwide, causing anemia and severe complications in susceptible hosts. Production losses due to control of $H$. contortus account for billions of dollars in Australia (11) and in the United States

(12). Gastrointestinal trichostrongylid parasitic infections are reportedly the most prevalent concern for producers in the United States (2). Though there are a number of GIT parasites affecting ruminants, trade of livestock has led to a cosmopolitan distribution of $H$. contortus (13), where its virulence, egg-laying capacity, widespread distribution and resistance to 
anthelmintics have made it one of the most important parasites to address in small ruminants (14).

\section{Distribution and significance}

Geographic distribution of $H$. contortus depends largely on climate, requiring warm, moist conditions for free-living stages. With continually high temperatures, tropical and subtropical climates around the world support development of $H$. contortus, including much of Africa, South-East Asia, Pacific Island countries, Central America and part of South America and the Caribbean (15). Variation in rain fall within these regions drives seasonality of haemonchosis, whereas persistent year-round haemonchosis is observed in wet tropic regions, making it a significant constraint on production of small ruminants (16). Ecological adaptation and biotic potential, however, have allowed $H$. contortus to spread over a wide range of environments beyond the tropics and into more temperate regions (17).

Seasonally dry or cold conditions restrict free-living stages of $H$. contortus, as larval stages are susceptible to desiccation and freezing. However, these regions experience increases in outbreaks during wet season and summer months. These regions extend north and south of the tropics, including southern Africa, eastern Australia, United States, South America, southern Asia and Mediterranean zones (15). Though, a smaller risk, the range of $H$. contortus has been observed affecting small ruminants in regions with longer periods of cold and thus experience very brief haemonchosis. Short summer months permit establishment of $H$. contortus in Canada, northern Europe, and Scandinavia, where increasing global temperatures contribute to these expanding presence of $H$. contortus $(17,18)$.

Of producers in the U.S., $62 \%$ reported intestinal nematodes as a major concern (1). Areas of greatest economic concern in the United States include much of the southeastern 
regions and gulf coast, where climate is favorable to development of $H$. contortus. Spreading from Alabama, Arkansas, Georgia, Florida, Kentucky, Louisiana, Mississippi, Maryland, North Carolina, South Carolina, Tennessee, Virginia and as far north as West Virginia, nematode infections have established large populations (12). In these regions, 75\% identified intestinal nematodes as a major problem effecting their sheep (1) and a significant economic concern.

Establishment of $H$. contortus in a new geographic location is dependent on the development of L3, which is influenced by many factors including fauna, biota and climate. Of these, climate is critical in driving persistence and the ability of $H$. contortus to spread to new geographic regions, favoring warm, moist environments. Eggs and L3 cannot withstand colder climates, such as northern latitudes, or overwinter. In the same regard, eggs and L3 cannot withstand xeric regions with higher temperatures and less rainfall. As such, H. contortus has developed mechanisms to survive periods unfavorable to development. To overcome extended dry or cold conditions, L4 undergo hypobiosis within the host, which arrests development until more suitable conditions permit development and reproduction (19). These mechanisms permit widespread establishment and increased geographic range, especially as climate change broadens favorable environments. These adaptations and increased geographic spread have made $H$. contortus more difficult to control and one of the biggest threats to small ruminant populations .

\section{Morphology and Lifecycle}

Adult worms live in the abomasum and have a small, specialized buccal lancet used to pierce abomasal mucosa, permitting blood feeding. Their common name, the "barber-pole" worm, is due to the female worm's appearance, as the female's white ovaries are wrapped around their blood-filled intestines. Adult female worms measure $18-30 \mathrm{~mm}$, where are male worms are much smaller, measuring $10-20 \mathrm{~mm}$ in length (20). Male worms also possess an 
asymmetric dorsal copulatory bursa. Mature adult worms sexually reproduce and females release up to 10,000 eggs per day, which are shed with feces into environment. Individual worms feed for up to 12 minutes, detaching and causing hemorrhage, which may last up to 7 minutes (21). Additionally, each worm can consume up to $0.05 \mathrm{ml}$ of blood per feeding (22), where high worm burdens can cause up to $30 \mathrm{ml}$ of blood loss per day (23), which can quickly result in severe blood loss, leading to anemia of the host.

Free-living stages must withstand changes in temperature, moisture and other potential hazards. A multilayered proteinaceous structure referred to as the cuticle or sheath, surrounds juvenile stages of $H$. contortus and functions to protect it from environmental threats. Not only does it function to protect larvae, the cuticle serves as an exoskeleton, which helps generate force permitting larval locomotion (24). This structure is important in both nematode survival as well as host evasion, as the molecular biochemistry of the cuticle varies between life stages and species.

Cuticles are thin, flexible and composed largely of collagen-like proteins, with trace amounts of lipids and carbohydrates (25). Structurally, the cuticle consists of a medial layer and basal layer made-up of collagen. Epicuticular and external cortical regions are made up of noncollagen proteins. Surface proteins are non-structural and exposed on the external surface of the cuticle. Glycoproteins make up the majority of surface proteins (25) and may contribute to the composition of excretory-secretory products. Furthermore, surface proteins contribute to the evasion of host responses, as they may shed antigen-antibody complexes. While surface proteins shed are immunogenic, immune responses may be inhibited by release of antigen-antibody complexes that prevent host immunoglobulin, complement and immune cells from binding or recognizing the worm $(25,26)$ and also encourage turnover of surface molecules $(27)$. 
Acting as an important interface between parasite and host, each life stage expresses a different and unique chemical signature. Each stage - L3, L4 and adult worms - express different patterns of surface proteins, thus, when shed, act as a method of immune evasion. Additionally, the cuticle surrounding L2 is retained during its molt into L3, but is shed once it is ingested by the host when transitioning to the L4 stage (25). Not only do surface proteins differ, but collagen-like proteins are associated with specific life stages and can vary between species as well (25). Therefore, the cuticle is critical to survival of $H$. contortus, and may be involved in both immune recognition and evasion of the host immune response.

The life cycle of $H$. contortus is direct, with no intermediate host. Eggs are shed with host feces into the environment, contaminating pastures. In the environment, eggs develop and molt twice before becoming infective L3. This development occurs five to eight days after eggs are shed, under optimal conditions. Sheep acquire an infection through ingestion of L3 while grazing on contaminated pasture. Larvae travel via water movement up grass blades during morning and evening dew, transported to the tips of grass, ensuring ingestion by actively grazing sheep. Once ingested, larvae molt and exsheathe within 48 hours as digesta passes through the rumen, forestomachs and arrives at the abomasum (28). Larvae develop from L3 into L4, shedding their protective cuticle within seven days after establishment in the abomasum and develop L4 cuticle. Fourth stage larvae form a buccal lancet, which is used to pierce abomasal mucosa and permit blood feeding from the host. Three days later, L4 undergo a final molt into fully mature adults. Patent infection occurs 14 to 21 days after initial ingestion, where mature adult worms mate, producing eggs that are subsequently shed in feces of the host.

Epidemiology of haemonchosis depends on parasitic larvae reaching their infective stage, permitting proliferation and spread. While $H$. contortus possesses a protective cuticle and can 
withstand a wide range of temperatures, larvae are still subject to desiccation and freezing. Both temperature and adequate moisture are essential for survival. While mechanisms triggering both hypobiosis and resuming maturation of arrested larvae remain unknown, transient peaks in eggs shed have been observed and documented corresponding with changes in climate. Unfavorable conditions during autumn and winter in the northern hemisphere, as well as hot, dry conditions between wet seasons at more arid latitudes, can trigger hypobiosis. Hypobiosis refers to arrested larval development of L4 within the abomasum of the host. Up to $35 \%$ of larvae recovered from the abomasum of sheep after 30 days of an experimental infection showed larvae arrested in L4 stage (29). Another study demonstrated that larvae recovered from sheep during winter months revealed two distinct populations of larvae, either early L4 or mature worms, despite having been infected for more than 21 days (30). The accumulation of L4 over winter leads to a resultant increase in fecal egg count during spring months, referred to as "spring rise" or "post-partrurient rise" (31), as it peaks following lambing of ewes and corresponds to a new generation of lambs susceptible to infection. In semi-arid regions of Africa, a study demonstrated a higher proportion of hypobiotic larvae recovered from sheep during dry months, compared to those recovered during wet months (32). The ability to establish in the host in an arrested state prevents excessive loss, where L3 left in the environment will likely die off. Thus, it is suggested that hypobiosis is the primary means of over-wintering, or survival of $H$. contortus during winter conditions, and similarly survival through dry months in xeric regions.

\section{Pathophysiology of haemonchosis}

Pathophysiology of haemonchosis is due to blood-feeding activity of L4 and adults during infection, leading to anemia, edema, hypoproteinemia and intestinal disturbances. Evidence of infection is observable by packed cell volume (PCV) 10-12 days after ingestion of L3, as L4 begin blood feeding causing blood loss (33). Blood loss due to hematophagy leads to 
anemia, characterized by reduced PCV and paleness of mucosal membranes. Adult worms can deplete nearly one fifth of total circulating erythrocyte volume in a lamb daily, whereas adult sheep may lose up to one tenth of their erythrocyte volume (34). Severity of pathology is wormburden dependent, meaning there is a strong correlation of worm-burden to amount of host blood loss (35). Continued intake of larvae increases worm burden, thus hosts can quickly accumulate severe infections.

In addition to anemia, pathology due to haemonchosis can lead to poor growth, body and wool conditions. Larvae in the abomasum induce glandular hyperplasia and inflammatory cell infiltration (14). Increased $\mathrm{pH}$ in the abomasum reduces digestion of protein and increases mucosa permeability, resulting in reduced nutrient absorption (14). Edema, or hypoproteinemia, results as an accumulation of fluid in tissues in interstitial spaces and reduced levels of circulating proteins (36). Grazing sheep lower their heads, allowing fluid to pool in the neck, resulting in a condition referred to as "bottle-jaw." Excessive collection of fluid in extremities can ultimately lead to tissue damage (36). In heavy infection, where the host cannot regenerate red blood cells enough to compensate for blood loss, hemorrhage can quickly lead to iron deficiency and inability to deliver oxygen to tissues, ultimately leading to death. Alternatively, animals that are able to fight off infection can develop immunological memory, clearing an infection and reduce severity of subsequent infection. Variation in susceptibility occurs both within and between breeds of sheep, leading to differences in resistance and tolerance.

\section{Parasite resistance}

Parasite resistance refers to the host's ability to resist establishment of a parasite and modifying reproductive capacity and egg production (37). Resistance can be assessed by fecal egg count (FEC), measuring eggs per gram (epg) of feces. However, FEC is limited, as it does 
not always accurately measure host worm burden. Exposure to pastures with different levels of parasitism can alter selection for FEC in sheep. Fecal egg count must be measured multiple times over a grazing season and across generation to be used in genetic evaluation $(38,39)$. Similarly, PCV is often associated with $H$. contortus infection in sheep, though heritability of PCV is lower than FEC, due to greater impact of environment (40). While PCV and FEC provide insight into the response and nature of infection, these measures fail to completely elucidate underlying mechanisms reflected by differences in numeric values.

Immunity varies between and within breeds of sheep, depending on factors such as antigenic stimulus, nutrition, size and age of an animal (41). Relative maturity compares mean live weight when an animal has developed immunity, along with mature weight, to determine a sheep's metabolic age rather than chronological age. Thus, regardless of breed, susceptible animals will establish some resistance with maturity and continued antigenic exposure to $H$. contortus (4). However, natural resistance occurs in some breeds of sheep $(4,42)$ such as St. Croix hair sheep, of tropical origin. With higher temperatures and wetter year round climate these tropical breeds have evolved mechanisms to mitigate infection with gastrointestinal nematodes. Alternatively, breeds common in cooler climates that have been selected for more economically valuable traits, such as carcass and wool quality, display increased susceptibility to H. contortus. Lack of selection pressure for resistance to gastrointestinal nematode parasitism or selection for economically important traits has perhaps resulted in higher susceptibility to parasitism.

Greater resistance to gastrointestinal nematodes has been observed in hair breeds of sheep such as Florida Native, Barbados Blackbelly and St. Croix, when compared to conventional wool breeds based on FEC data (4). Both Barbados Blackbelly and St. Croix have consistently higher 
blood PCV and lower FEC after exposure to $H$. contortus when compared to Dorset or Rambouillet wool breeds $(5,40)$. Following both natural and artificial infection with $H$. contortus, St. Croix have been reported to have $99 \%$ fewer worms recovered from the abomasum when compared to Dorset lambs (40). Along with marked differences in worm burden, PCV and FEC, immunologic responses in hair sheep are more robust, preventing establishment of adult $H$.

contortus (3). Abomasal lymph nodes from infected hair sheep have higher weight, with a significant increase in the number of immune cells present than those of infected wool sheep (42). Following a priming infection, resistant sheep displayed increased expression of genes related to tissue repair and cell migration in abomasal tissue and local lymph nodes, with higher recruitment of granulocytes, macrophages and CD4+ T cells (43). Furthermore, St. Croix hair sheep expressed high levels of markers of early inflammatory responses, whereas parasitesusceptible sheep showed delayed response and expression of markers consistent with chronic inflammation (44). Thus, with consistently higher PCV, lower FEC and quicker resolution of infection with $H$. contortus, St. Croix sheep are an ideal model for evaluating immune mechanisms of resistance.

\section{Immune response to Haemonchus contortus}

Host protective responses are critical in expulsion and impairment of helminth infection. Immunity to $H$. contortus relies on both innate and adaptive immune responses to effectively clear the parasite. Generally, helminth infections elicit Th2 type responses, producing key cytokines such as IL-4, IL-13, and IL-5, which influence downstream effector function, shape immunopathology and ultimately confer protection against disease (45). Recognition and localized wound repair mechanisms drive an influx of peripheral and tissue immune cells. Group 2 innate lymphoid cells (ILC2) and other innate cells such as eosinophils, neutrophils and mast 
cells produce high levels of type-2 cytokines, driving an overall Th2 response (46). Macrophages respond to cytokine signaling and are key cells in polarization of $\mathrm{T}$ helper cells, bridging adaptive and innate responses. Additionally, cells migrating through local lymph tissue and exchanging antigen drive $\mathrm{B}$ cell class switching, with increased production of immunoglobulin (Ig)E and IgA (45). In contrast to Th2 responses, T helper 1 (Th1) responses are associated with parasitic survival and increased host susceptibility (47), with increased production of cytokines such as tumor necrosis factor (TNF) $\beta$ and interferon (IFN) $\gamma$, downregulating Th2 responses (48). Breeds of sheep displaying higher levels of resistance to $H$. contortus express genes associated with Th2 responses in cells recovered from abomasal lymph nodes $(49,50)$ and thus, immune mediated resistance suggests breeds of sheep that naturally expel $H$. contortus are reliant on a greater cellular immune response $(3,39)$.

\section{Innate immunity and helminth interaction}

While it is not clear exactly which mechanisms first recognize helminths, resistant hosts demonstrate early recognition that ultimately leads to expulsion of larvae, preventing establishment and development into adult worms. Once ingested, gastrointestinal parasites incite changes to mucosal tissue, which acts as both a mechanical barrier and first line of immune modulation. Innate cells recognize invading pathogens through pathogen associated molecular patterns (PAMPs) produced by or located on the surface of the pathogen. However, parasites express different surface molecules at different stages of their life cycle. These relatively quick changes in expression between parasite life stage can make it difficult for the host to respond appropriately and aid in immune evasion by the parasite $(7,14)$.

Innate lymphoid cells (ILC) are of lymphoid lineage, but unlike T cells they lack a T cell receptor (TCR) and B cell receptor (BCR), thus foregoing thymic selection and are not antigen- 
specific. Alarmins IL-25, IL-33, and thymic stromal lymphopoietin, produced by epithelial cells in the lumen, stimulate innate lymphoid cells (ILCs) (51-53), as well as production of IL-5 and IL-13 in gut-associated lymphoid tissue during helminth infection (52). In the absence of IL-25 and IL-33, ILC population expansion was significantly inhibited during Nippostrongylus brasiliensis infection in mice, and increased worm burden (51). Mice deficient in IL-25 also showed delayed cytokine production, when infected with $N$. brasiliensis and were also unable to expel worms (54). Adoptive transfer of ILCs into IL-13 deficient mice restored cellular responses and worm expulsion (51), and administration of IL-25 restored ILC populations, leading to rapid parasite clearance (54). Furthermore, an early accumulation of ILC have been observed before expansion of adaptive Th2 responses (46) and thought to be a dominant source of polarizing cytokines $(46,55)$. Thus, ILCs are critical in development of protective immunity, which has recently been recognized as contributors to the clearance of gastrointestinal nematodes.

Often associated with helminth infection, eosinophils infiltrate injured tissues to aid in tissue remodeling and debris clearing (56). Accumulation of eosinophils around larvae has been associated with decreased larval establishment and direct damage, suggesting a targeted response by innate cells $(57,58)$. Degranulation of eosinophils, which occurs in the presence of parasites, releases histamine, peroxidase, ribonuclease, deoxyribonuclease, lipase and plasminogen, aiding in expulsion (59). Together, recruited eosinophils and mucosal mast cell hyperplasia lead to increased mucus production by goblet cells in the intestinal lumen (60), which may physically impair larval motility and help flush larvae out of the gastrointestinal tract. Eosinophils have also been found in greater densities in abomasal tissues of resistant lambs when compared with 
susceptible lambs (61), occurring as early as three days and as late as 42 days after infection with H. contortus (62).

Despite the ability of eosinophils to directly immobilize and kill infective $H$. contortus larval in vitro (58), eosinophils are not required for parasite expulsion (63). Depletion of IL-5 and inhibition of eosinophils had no effect on adult worm burden or expulsion during infection with Trichinella spiralis in mice (63). Additionally, depletion of eosinophils did not alter development of Th2 responses in a mouse model of shistosomiasis (64).

Neutrophils are rapid responders to infection, phagocytizing pathogens such as bacteria, viruses, and clearing the body of cellular debris resulting from pathogenic invasion. During helminth infection, neutrophils infiltrate tissues within 12 hours (65) and are one of the most abundant cell type during early infection of $H$. contortus (39). Additionally, St. Croix sheepdisplay higher numbers of neutrophils in abomasal tissues compared to susceptible sheep (3). Neutrophil accumulation and recruitment were inhibited when signaling through IL-4 receptor $\alpha$ (IL-4r $\alpha$ ) was blocked, which led to mice experiencing more severe pathology associated with $N$. brasiliensis infection in the absence of neutrophils (66). However, it is unlikely that neutrophils directly mediate clearance of worms, but rather contribute to recruitment of effector cell populations. Neutrophils activated during parasitic infection interact with macrophages, up-regulating anti-helminth macrophages and increase expression of adhesion molecules (9). Depletion of neutrophils greatly impairs effector macrophage function, suggesting that neutrophils prime macrophages (9), shaping overall Th2 environment.

Activation of mast cells by type- 2 cytokines or by binding of $\operatorname{IgE}$ to mast cell high affinity receptor for the Fc region (FceR1) triggers degranulation, releasing nitric oxide (NO) and 
histamine. Mast cells also release cytokines IL-13 and IL-33, which increase permeability in gut epithelium during infection. During $H$. contortus infection, mucosal mast cells increase (67), and repeated infection results in mast cell hyperplasia, inducing mucosal mastocytosis and inability of larvae to establish in the abomasal mucosa due to release of granule-specific sheep mast cell proteinase (68). Treatment with anti-IL-3 and anti-IL-4 monoclonal antibodies in mice decreased mastocytosis, however the reduction in mast cell hyperplasia did not impair worm expulsion (69).

\section{Adaptive immunity against helminthes}

Resistance to gastrointestinal nematodes relies on a network of host responses, including immune cell proliferation and production of antigen-specific antibodies. Developing in the thymus, $\mathrm{T}$ cells are distinguished by their cell surface expression of a $\mathrm{T}$ cell receptor, each having distinct function. $\mathrm{T}$ cells include two main subsets $-\mathrm{CD} 4+$ and CD8+. Additionally, gamma delta $(\gamma \delta) \mathrm{T}$ cells represent a small subset of T cells in peripheral blood, expressing an invariant $\mathrm{T}$ cell receptor, but function in recognizing lipid antigens. CD8+ $\mathrm{T}$ cells are typically involved in intracellular pathogen mediation through interaction with major histocompatibility complex (MHC)-I, however little evidence suggest CD8+ T cells contribute to clearance of gastrointestinal nematode infection. CD4+ T helper cells differentiate into different phenotypes, including Th1 and Th2 cells, depending on the cytokine environment during antigen presentation (70) and function as aids in the amplification of immune response. Development of Th2 cells primarily occurs through IL-4 and IL-13 cytokine signaling from innate cells, and induces IL-4ra signaling on both immune and non-immune cells.

Infection with $H$. contortus resulted in increased CD4+ T cells expressing MHC-II in abomasal lymph nodes of sheep as early as day 3 after infection, increasing through day 5 (49). 
Lymph nodes were also heavier in infected animals, indicating increased antigen presentation in secondary lymphoid tissues (49). Depletion of CD4+ T cells in resistant lambs had no effect on globule leukocyte or eosinophil counts, however, lambs were unable to eliminate $H$. contortus, abrogating host protective response (71). Similarly, H. contortus worm burden was higher in lambs following CD4+ T cell depletion, compared to IgG antibody control treated lambs (72), demonstrating a requirement of adaptive responses. Depletion of CD8+ T cells had no effect on FEC or worm burden in resistant lambs (71). Similarly, loss of CD4+ T cell function inhibited M2 differentiation and arginase-1 (Arg1) function during infection with Heligomosomoides polygyrus in mice, ablating host protective immunity and parasite expulsion (73). While $\gamma \delta \mathrm{T}$ cells were present during infection with $H$. contortus, cell numbers remained steady and did not increase (49), thus are not thought to be major contributors in resistance. Thus, loss of CD4+ T cell responses during infection led to an impaired development of Th2 immunity, resulting in increased susceptibility, emphasizing the importance of immune polarization.

Not only are CD4+ $\mathrm{T}$ cells critical in activating $\mathrm{Th} 2$ responses, these lymphocytes are also important activators of $\mathrm{B}$ cells, inducing antibody generation. Hallmark cytokine IL-4 enables IgG class switching to IgE. Release of IgE antibody amplifies immune responses during infection, triggering mast cell degranulation and recruiting effector cells to the site of infection (56). When B cells are absent during helminth infection, $\mathrm{T}$ cell phenotypes have been shown to become altered, shifting from Th2 to Th1 cells (74).

Antibody production has been shown to be associated with defense against $H$. contortus infection. Serum levels of $\operatorname{IgA}, \operatorname{IgE}$ and $\operatorname{IgG}$ were elevated in parasite resistant sheep $(7,75,76)$. Production of antibody was observed in both priming and challenge infection, but these data 
demonstrated antibody isotype was parasite life stage dependent. Larvae elicited an $\operatorname{IgA}$ response, whereas adult worms increased levels of IgG1 and IgG2 in resistant sheep (77).

Mouse models of helminth infection show differences in antibody contribution to parasite clearance. B cell deficient mice infected with $H$. polygrus were unable to expel parasites after challenge infection (78). Antibody was critical during the tissue-dwelling phase of $H$. polygrus infection, providing protection during secondary infection (66). Conversely, mice depleted of B cells challenged with $N$. brasiliensis did not display impaired responses and were able to clear infection (78). Differences in parasitic infection may be due to life-cycle and tissue niches of each parasite, where $H$. polygrus is strictly enteric and $N$. brasiliensis follows hepato-tracheal migration before establishment in the gut. Nevertheless, these studies indicate B cells contribute to both parasite expulsion (78) and support development of full protective immunity in resistant sheep (42).

\section{Antigen presenting cells}

Antigen present cells (APC) bridge innate and adaptive branches of the immune system. Dendritic cells (DC), monocytes or macrophages, and B cells are considered APC, as they are sentinel cells sampling the environment for pathogens and maintaining tolerance to self-antigen. Processing and breaking down foreign antigens into peptides allows for generation of antigenspecific responses and the development of immunologic memory. Peptides are presented on MHC-II, where T cells can interact before undergoing a rigorous selection process. Their ability to stimulate and promote activation of adaptive responses makes them vital effector cells in immunity. 


\section{Monocytes and macrophages}

\section{Development of monocytes/macrophages}

Monocytes are a heterogeneous population of cells with potent, yet plastic roles in immunity. These cells are critical in development of host protective responses, as well as maintaining tissue integrity and homeostasis. While an innate cell, monocytes are specialized with complex functions, having phagocytic activity, antigen-presenting capacity and produce an array of cytokines. Monocytes have been considered evolutionarily ancient and represent a dynamic system (79), both specialized within tissue microenvironments and found in peripheral circulation. Rapidly changing their function in response to environmental signals, monocytes are flexible cells, mediating diverse protective and pathogenic functions. These characteristics are important in influencing the development of adaptive immune responses and effecting overall host protective immunity.

In 1883 Elie Metchnikoff first described an accumulation of phagocytic cells after bacterial infection in frogs. Due to their abundance, he suggested these cells served as the first line of defense against invading pathogens (80). Not only did these cells respond to infection, Metchnikoff indicated these cells were involved in elimination of dead or dying cells that were remnants of metamorphosis from tadpole to frog (80). Observations of specialized phagocytic cells clearing apoptotic cells and responding to pathogens in the same host became one of the earliest descriptions of innate immunity, distinguishing self from non-self (80). Around the same time, in the early 1900s, Paul Ehrlich began classifying white blood cells into mononucleated leukocytes, describing some as large mononuclear cells with kidney shaped nuclei (81). Ehrlich first called these cells "Uberganagszelle", or transitional cells, but would later be renamed monocytes (81). Together, Ehrlich's and Metchnikoff's work described cellular interaction with 
pathogens and would become the foundation of innate immunity and remains so in modern immunology.

Understanding of monocyte ontology has evolved throughout recent history. Mononuclear phagocytic cells were once regarded as a continuum of differentiation from monocyte to macrophage, where circulating monocytes replenished tissue-resident macrophages throughout adulthood. Now monocytes are considered a heterogeneous population of cells, classified based on tissue location and origin. Macrophages can be separated into two groups of cells: circulating monocytes, giving rise to macrophages, or tissue-resident macrophages, established during embryogenesis (82,83). Transcriptional evidence, however, suggests that macrophages from different origins do not differ significantly (84). Adoptive transfer of bonemarrow derived and yolk sac-derived macrophages into macrophage-depleted mice demonstrated functional attributes could be acquired regardless of tissue origin, but these data do not include potential for epigenetic change due to cellular origin (84). Despite advancements in characterization, monocyte development and identification remains complex, as phenotype and function often overlap.

Peripheral circulating monocytes, or infiltrating macrophages, originate in bone marrow from a rapidly proliferating pool of hematological precursors of myeloid lineage, called monoblasts. When matured, monocytes enter the blood circulation where they can be recruited into tissues. Of circulating leukocytes, monocytes are the largest and are estimated to make up an estimated $5 \%$ in blood, constituting $2-10 \%$ of all leukocytes in the body $(83,85)$. The spleen is a reservoir for peripheral monocytes, storing the majority of undifferentiated monocytes, to be released to regulate inflammation during injury or infection (86). Lymphoid tissues can also yield myeloid precursors cells during embryonic and adult hematopoiesis. Circulating monocytes 
recruited to tissues can either remain steady state monocytes or differentiate into macrophages. However, monocytes can also develop within tissues during embryogenesis, seeded by hematopoietic progenitors from the fetal yolk sac (in mice and humans) and hematogenic endothelium (Wynn et al., 2013), representing a separate subset of cells called tissue-resident macrophages. Interestingly, during early gestation, yolk sac progenitors are restricted, only giving rise to red blood cells and macrophages (88). While transcription factors and surfacemarker expression differ between the two types of monocytes during embryonic development, cell surface-markers can vary with maturation, making precise identification difficult (88).

Macrophage subsets can be delineated by monocyte function, as monocytes and monocyte-derived macrophages are key mediators of inflammation, whereas tissue-resident macrophages are critical in maintaining tissue homeostasis and resolving inflammation $(83,89)$. Monocytes are found in all adult tissues and are highly organized. In the liver these cells are Kupffer cells, microglial cells in brain tissue, alveolar macrophages in lungs, and splenic monocytes are found in red pulp (89). Originally it was thought that circulating monocytes replenished tissue-resident macrophages and remained a dogma in immunology as the Mononuclear Phagocyte System. However, more recent studies have contributed to a greater understanding of monocyte and macrophage development in different tissues.

Establishment of tissue-resident macrophages persists into adulthood, independent of circulating monocytes. Tissue-resident macrophages develop during embryogenesis and are maintained by a process of self-renewal $(90,91)$. Fate mapping was used to define monocytes and tissue-macrophages based on their site of localization in mice, which demonstrated tissueresident macrophages could generate independently of both monocyte and adult hematopoietic progenitors (91). Ablation of tissue-resident macrophages in mice also indicated local 
proliferation repopulated tissues, with little input from circulating progenitors (91). Furthermore, proliferation and accumulation of tissue macrophages was observed when stimulated with IL-4 and during Th2 driven infection (92). Accumulating monocytes recruited from blood along with tissue-resident macrophages together are essential mediators in response to tissue damage and infection. Alone, tissue-resident macrophages reveal a potential for wound repair and pathogen response mechanisms without recruitment of other pro-inflammatory cells (92).

Hematopoiesis of monocytes is regulated by colony stimulating factors (CSF) $(93,94)$. Macrophage lineage function and population numbers during inflammatory conditions are regulated by cytokines granulocyte-monocyte CSF and monocyte-CSF (93). Bone marrow derived precursor cells stimulated with either GM-CSF or M-CSF, then treated with lipopolysaccharide (LPS), demonstrated different and competing responses, with potential suppressive capacity (93). Monocytes stimulated with GM-CSF preferentially produced proinflammatory cytokines TNF $\alpha$, IL-6 and IL-23, and M-CSF stimulated monocytes produced IL10 and chemokine CCL2 $(93,95)$. Pro-inflammatory phenotypes are preferentially expressed by monocytes stimulated with GM-CSF, whereas anti-inflammatory phenotypes can be stimulated with M-CSF (94). Despite the impact of CSF, hematopoiesis and lineage commitment is regulated by multiple factors, many of which are similar or with overlapping actions $(96,97)$.

Macrophages may further differentiate into a spectrum of phenotypes, where function depends on local signaling from the environment and can be distinguished based on surface expression of cell surface markers. Bacterial infections promote classically activated macrophages (M1), producing antimicrobial molecules, pro-inflammatory cytokines and increased antigen presentation capacity. During helminth infection, alternatively activated macrophages (M2) are activated through IL-4 signaling pathways, producing anti-inflammatory 
cytokines and molecules associated with wound healing. Mediation of alternative activation occurs through signal transducer and activation of transcription (STAT)-6 activation when IL4r $\alpha$ expressed on macrophage cell surfaces is stimulated by IL-13 and IL-4 (98). STAT-6 is required by $\mathrm{Th} 2$ cells to maintain their activation status, and is also an essential regulator of class switching recombination in B cells from IgG to IgE (99). Despite distinctive function between M1 and M2, macrophages display an overlap in surface marker expression between different subsets. Nevertheless, owing to their dynamic and multidimensional role in immunity, macrophages are an essential component during development of full host protective response.

\section{Monocyte/Macrophage differentiation}

Macrophage differentiation has been used to describe phenotype and characteristics associated with specific infection status, from bacterial, viral and protozoa to helminthes and allergy. Classically activated macrophages were first described following enhanced antimicrobial activity observed towards bacteria in an antigen-dependent, but non-specific manner, during secondary infection with Listeria (100). Later, M1 would be associated with Th1 responses and production of IFN $\gamma$ by activated immune cells (100). Opposing Th1 inflammation, M2 macrophages activated by IL-4 and IL-13 increased expression of major histocompatibility complex (MHC)-II, reducing production of pro-inflammatory cytokines (100). This phenotype was markedly different from macrophages activated by IFN $\gamma$, and became associated with Th2 responses (100). Further distinguishing activation states, downstream products and effector function of M1 and M2 macrophages were delineated, emphasizing a pivotal role of enzymes competing for the substrate L-arginine. 


\section{Nitric oxide and classical macrophage activation}

L-arginine is converted to NO, which is regulated by enzyme nitric oxide synthase (iNOS). Macrophages activated by inflammatory cytokines, such as IFN $\gamma, \mathrm{TNF} \alpha$ and bacterial pathogens can release high levels of NO. Conversely, Th2 type cytokines, such as IL-4 and TGF $\beta$, suppress iNOS expression through their effects on TNF $\alpha$ (101). Macrophages producing NO have functional roles in the immune system, which are involved in acute and chronic inflammation, as well as host defense mechanisms. During innate responses, toxic NO can be released against pathogens, but also acts to regulate function of host immune response (102). Effector functions of NO can inhibit pathogen replication by preventing cell division (103) and NO-producing macrophages can restrict T cell expansion, inhibiting MHC-II expression (104). Reactive nitric oxide intermediates can also cross bacterial and fungal walls, reacting with specific pathogen targets (103). Downstream responses are also influenced by NO production, such as IL-12 signaling in response to protozoa. In the absence of NO, natural killer (NK) cells were unable to induce IFN $\gamma$ and phosphorylation of STAT-4 was inhibited, failing to signal IL12 and induce cytotoxic function (101). However, if unregulated, too much NO can become toxic to host cells and thus, immune responses are mediated by timing and amount of NO released during infection $(101,104)$.

\section{The role of nitric oxide during helminth infection}

With its antimicrobial toxicity, NO has been linked with mediation of malaria, toxoplasmosis, leishmaniasis, and trypanosomiasis. However, little is known about the role of NO during gastrointestinal helminth infection. Because helminths typically induce type-2 responses and produce anti-inflammatory cytokines that are suppressive of iNOS, NO during infection has been overlooked and its role remains unclear. 
Eggs released from schistosomes incite tissue inflammation in the liver, where NO produced by macrophages aids in regulation of tissue damage (101). Despite heterogeneous macrophage phenotypes in the liver during schistosome infection, alternative activation was dominant, despite high iNOS and TNF expression (105), suggesting other pathways may be involved and NO may play a role in mediation of helminth infection. Other helminth models demonstrate a role for type 1 inflammatory responses to clear nematode infection. Infection with Taenia crassiceps, a tapeworm of canids, demonstrated a requirement for iNOS and NO. In absence of Th2 responses, STAT-6 knockout (KO) mice infected with $T$. crassiceps maintained macrophage populations producing high levels of iNOS, which controlled tissue-invasive larval stages (106). Mice with significantly lower levels of NO displayed higher parasite burdens (106). Furthermore, during infection with Strongyloides stercoralis in mice, macrophages producing NO were found, along with increased iNOS expression (107). These data are suggestive that NO is involved of mediation of helminth infection, however it also highlights that little is known about its exact role. Furthermore, these studies highlight different tissue niches and host interaction than gastrointestinal nematodes, which either may not be relevant or may be disparate from the functionality of NO during $H$. contortus infection.

\section{Arginase and alternative macrophage activation}

Arginase-1 (Arg-1) is an enzyme that competes with iNOS for the substrate L-arginine, serving a pivotal role in macrophage phenotype differentiation. Monocytes deficient in Arginase1 up-regulate iNOS, resulting in increased inflammation (108). Just as the iNOS pathway inhibits Arg-1 driven activity, Arg-1 inhibits iNOS and Th1 cytokine driven pathways of inflammation. Arginase-1 activity hydrolyzes L-arginine, which produces L-ornithine and urea (109). L-ornithine is a precursor for polyamine synthesis, where polyamines are involved in cell growth and differentiation. Another product of L-ornithine metabolism is L-proline, which 
affects collagen production (109). Helminthes can cause extensive tissue damage, resulting in released of proteolytic enzymes with the potential to damage surround cells (Kreider et al., 2007). Increased production of collagen, along with increased fibronectin and matrix metalloproteinase are associated with tissue repair mechanisms (111), which have been observed during helminth infection. These characteristics are associated with shifting inflammatory responses, as well as fibrosis and wound-repair mechanisms of M2 macrophages.

Resistance to helminth infections has been linked to Arg-1, not only for its contribution to macrophage polarization and ability to limit immune responses through $\mathrm{T}$ cell activation, but it also has physiologic roles in clearance mechanisms. Inhibition of arginase during infection with H. polygyrus resulted in increased adult worm burden (73). Metabolites, L-ornithine and polyamines, can reduce larval motility and migration of $H$. polygyrus (112). Similarly, inhibition of Arg-1 prevented larval trapping in the skin of mice infected with $N$. brasiliensis (113). In the absence of IL-13 signaling, Arg-1 expression was inhibited in mice infected with $H$. polygyrus had impaired gut motility, smooth muscle function and mucus production, and were unable to polarize macrophages towards an M2 phenotype (114). Together, these data highlight critical contribution of both Arg-1 expression and alternative activation in development of protective immunity. However, to date, little is known about macrophages or Arg-1 expression during $H$. contortus infection in sheep. Potential differences may exist between resistant and susceptible breeds, though it remains to be explored.

\section{Alternatively activated macrophages are critical during helminth infection}

While little is known about ovine monocytes and macrophages, many studies have demonstrated a critical role of M2 macrophages promoting the development of Th2 type responses in the clearance of helminth parasites in murine models. Production of Th2 cytokines, 
such as IL-4 and IL-13, trigger differentiation of M2 macrophages, which are distinguished by increased expression of Arg-1 and IL-4ra (73). Signaling through IL-4ra and activation of M2 down-regulate pro-inflammatory pathways, decreasing IL-17 and other Th1 type cytokines (66). Alternatively activated macrophages interact with innate cells, recruiting populations which maintain Th2 signaling, drive CD4+ T cell polarization and suppress Th1 inflammation (73). Furthermore, during helminth infection, M2 macrophages contribute to tissue repair, fibrosis and clearance of debris $(115,116)$. Proteolytic enzymes from tissue damage due to migrating helminthes triggers M2 activation, increasing production of fibronectin, collagen and matrix metalloproteinase (111). Owing much to their plasticity in response to environmental stimuli, macrophages link innate and adaptive immunity and influence cellular responses. Thus, macrophages are important players driving appropriate effector responses and overall clearance of helminth infection. These data further highlight the complexity of macrophage involvement, spanning innate and adaptive responses. M2 macrophage-derived cytokines and chemokines may function by inducing differentiation of naive $\mathrm{T}$ cells into Th2 cells, limiting expansion of type-1 responses, recruiting other immune cells to the site of infection and promoting Th2associated effector function (117).

Recruitment of innate cells occurs through M2 macrophage secreted chemokine production, such as CCL11, CCL17, CCL22, and CCL24 (118). Chemokines CCL17 and CCL22 produced by M2 macrophages are chemotactic factors for T cells. Chemokine CCL24 is an eosinophil and neutrophil chemotactic protein, where eosinophils are commonly linked with helminth infection, promoting tissue remodeling and clearance of debris (56). Studies using murine gastrointestinal nematode, $N$. brasiliensis, demonstrated macrophages collaborate with neutrophils, enhancing in vitro killing of helminth parasites (9). Infection with S. stercoralis 
induced M2 macrophages capable of killing larvae, both in vivo and in vitro when neutrophils were present (119), demonstrating collaborative mediation between cell types. Similarly, during $N$. brasiliensis infection in mice, neutrophils primed macrophages, inciting rapid healing of nematode-induced damage and reduced larval ATP in vitro (9), directly mediating larval killing.

While macrophages rely on CD4+ Th2 cells expressing IL-4 to promote Arg-1 expression (120), M2 macrophages also exert effects on CD4+ T cells, modulating or suppressing immune responses (121). Multiple mechanisms serve to regulate $\mathrm{T}$ cell activation during infection such as cell-to-cell contact and enzyme metabolism. Helminth-induced macrophages display an upregulation of programmed death ligand 1 (PD-L)1 and PD-L2, which regulate T cell function and may have implications during infection $(122,123)$. Activation of $\mathrm{T}$ cells requires cell-to-cell communication, between antigen presenting cell (APC) expression of MHC-II and TCR. Engagement of PD-L1, expressed on activated macrophages during helminth infection, with PD1 on $\mathrm{T}$ cell surfaces can inhibit downstream and proliferative responses (122). An additional mechanism of $\mathrm{T}$ cell inhibition by M2 macrophages is through metabolic starvation. The requirement of arginase by M2 is depleted by increased expression of Arg-1, which limits availability to $\mathrm{T}$ cells, which also require arginine for proliferation $(124,125)$. Together, M2 macrophages are essential in controlling Th2 phenotype and stabilizing the immune response. It is thought that these control mechanisms serve to limit effector $\mathrm{T}$ cell toxicity against healthy tissues (126). These data suggest maintenance of Th2 response requires alternative activation, but M2 macrophages also require input from Th2 cells. While these ideas seem contradictory, taken in the context of the development of an early response progressing to an adaptive response, M2 macrophages may take on distinctive functions at each stage. 


\section{Macrophages are plastic cells and display a spectrum of phenotypes}

Numerous studies have provided evidence in support of macrophages switching phenotype, regardless of priming, and retaining functionality. Macrophages with an alternative phenotype taken from mice infected with Brugia malayi, altered gene expression when treated with LPS and IFN $\gamma$, also taking on bactericidal activity (127). Another study demonstrated IL-4 pretreatment of macrophages enhanced TNFa and IL-12 in response to LPS (128), which are cytokines not associated with M2 macrophages. A co-infection model, using immune opposing H. polygyrus and Salmonella enterica, demonstrated macrophages adapt to changing stimulus and are uninhibited on a transcriptional level (129). However, despite their plasticity, functional analysis indicated tissue origin - either blood-recruited or tissue resident - limited response (129).

Conversely, some data demonstrate polarized macrophages become unresponsive or functionally altered after initial stimulation. Response to LPS by macrophages treated with IL-10 were altered on a transcriptional level, revealed by microarray analysis, with suppression of genes normally induced by LPS (130). Phagocytic uptake of Neisseria meningitidis by mouse macrophages treated with IL-4 or IL-13 was significantly reduced, suggesting functional impairment (131). Interestingly, although phagocytosis was impaired, IL-4 treated macrophages increased secretion of pro-inflammatory cytokines during challenge infection (131), suggesting altered, but not completely impaired responses.

Because macrophage effector functions are wide ranging, from homeostasis and regulating immunity to phagocytosis, macrophage activation can be considered a spectrum. Classification of M1 and M2, two opposites of polarization, have been useful while delineating macrophage function and associated pathologies. However, macrophage activation is not 
terminally differentiated and changing environmental stimuli evolve as infection progresses, which may heavily influence macrophage activation state. Even within these classifications, M1 and M2, macrophages may take on a spectrum of phenotypes. For example, macrophages induced by LPS, immune complexes, apoptotic cells and IL-1Ra produce IL-10 and TGF $\beta$, which are distinct from M1 macrophages, yet fall within M2 phenotypically though they do not elicit a Th2 response (118). A large number of genes regulate macrophage phenotype and function; therefore, it is not unreasonable for patterns of expression to be transient given a changing environment. Discrepancies in experiments may be due to different lengths and amount of stimulus, as macrophage response is not static, rather macrophages differentiation depends upon sequence of stimulus and temporal activity of cytokine signal. Flexibility of macrophages may be attributed to their long-lived nature, since they do not experience high turnover like many innate cells (127) and thus, benefits host immunity. Furthermore, complete polarization or full activation, particularly during in vivo studies, rarely occurs in an entire macrophage population $(92,129)$.

\section{Cytokine interleukin-13 is critical during helminth infection}

Concerted signaling of Th2 cytokines, such as IL-4 and IL-13, drives parasite expulsion.

Of these cytokines, IL-13 signals through non-immune cells increasing mucus production and contraction of intestinal epithelium, resulting in clearance of infection (56). Effector functions of IL-13 make it a unique cytokine, driving cell-mediated immunity (132) and promoting gut motility. Diverse effector functions are mediated by IL-13, as it is involved in airway hyperresponsiveness, allergy, tissue eosinophilia, class switching to IgE Ab production, goblet cell hyperplasia, tissue remodeling and fibrosis (132). Therefore, many hallmarks of Th2 responses are shared with IL-13 effector function. 
Cytokine IL-4 has long been recognized as the canonical Th2 marker during helminth infection; however more recent studies have begun to highlight a critical role of IL-13 in resistance to intestinal nematode infection. Interleukin-13 shares many biologic functions with IL-4, including cell surface receptor IL-4ra. In mice, IL-13 is positioned near IL-4 on chromosome 11 (133). Amino acid homology, however, is low between IL-4 and IL-13, though tertiary structure is conserved (134). Unlike IL-4, IL-13 stimulates MHC-II on monocytes and macrophages, down-regulates inflammatory cytokines IL-6 (135) and IFN $\gamma$, protecting mice from LPS-induced endotoxemia (136). Despite similarities, IL-13 is non-redundant in the immune system and has a distinct, independent role in helminth infection.

Cytokines IL-4 and IL-13 are the only proteins known to bind IL-4ra, such that sharing a receptor serves as an initial basis of their overlapping physiologic functions (137). The IL-4ra complex contains IL-4R $\alpha$ and $\gamma c$ (type 1 receptor) or IL-13R $\alpha 1$ (type 2 receptor) chains, but formation is dependent on sequence of ligand binding, whether it be IL-4 or IL-13 (137). Conjugation with IL-4 forms type 1 receptor, responsible for T cell signaling, but both IL-4 and IL-13 can induce type 2 receptor formation (137), whereas IL-4 and IL-13 are seemingly in competition for IL-13R $\alpha 1$ (138). Cross-linking studies demonstrated that IL-4 binds more effectively for IL-13r than IL-13 and IL-4 can even neutralize some of the effects of IL-13 (138). Moreover, receptor structure have been shown to differ on different cell types (138), which may influence immune response and signaling pathways. Type 1 complex is found on $\mathrm{T}$ cells, B cells and myeloid cells, whereas Type 2 complexes are found on myeloid cells and non-hematopoetic cell types (139). Ligation of IL-13 or IL-4 to its receptor induces phosphorylation of Janus tyrosine kinases (JAK) and recruiting STAT-6. Activation of STAT-6 results in translocation to the nucleus, where it binds DNA, initiating transcription of downstream genes (140). 
Alterations in receptor binding may account for differences in susceptible and resistant hosts during infection with helminths, though it has not yet been explored in the context of $H$. contortus.

Mice given an infection of Trichuris muris were unable to clear infection in the absence of IL-13, when compared to their wild-type (WT) counterparts that were highly resistant (133). Here IL-13 KO mice were compared to IL-4 KO mice to determine relative contribution of each cytokine. These data demonstrated that IL-13 KO mice were able to generate a Th2 response, but had impaired clearance mechanisms, whereas IL-4 KO mice were also susceptible to $T$. muris, but could not mount a full Th2 protective response, including an inability to generate IL13 (133). Both IL-4 and IL-13 are necessary during infection with $T$. muris, however, these data suggest each have distinct roles.

Another study using IL-4ra KO mice, IL-4 KO and RAG KO revealed IL-13 regulates Th2 responses to $N$. brasiliensis infection. While IL-4 KO mice had higher worm burden and FEC, these mice were still able to mount a protective response and expel worms similar to control mice (141). In comparison, IL-4ra KO mice were unable to recover fully, failing to expel worms (141). Interestingly, this study also revealed that IL-4ra KO macrophages were functionally impaired, unable to respond to either IL-4 or IL-13, and resulted in failure to block NO production (141). Because IL-4 and IL-13 share IL-4ra, these data next led to determine the contribution of IL-13 to worm expulsion. Mice deficient in RAG developed chronic infection with $N$. brasiliensis, yet exogenous treatment with IL-13 alone was sufficient to elicit expulsion of $N$. brasiliensis in those mice (141). Thus, in the absence of lymphocytes, non-lymphoid cells were activated by IL-13 to mediate parasitic infection. 
IL-13 deficient mice have normal development of lymphoid organs and cell numbers, with the expression of immunoregulatory molecules associated with Th2 responses such as CD4, CD8 and B220, in the context of $N$. brasiliensis infection (142). No differences were observed in levels of IL-4, IL-5 and IL-10 in IL-13 deficient mice during infection, suggesting intact Th2 responses (142). Others have reported IL-13 KO mice were unable to clear infection with $N$. brasiliensis, despite development of Th2 response. Absence of IL-13 did not alter IgE levels, however IgA increased in KO mice compared to WT (142). Furthermore, IL-13 KO mice failed to develop goblet cell hyperplasia (142). Mucin secreting goblet cells in intestinal villi of KO mice were both fewer in number and reduced in size as compared to WT (142), impairing mucus secretion and gut contractility.

Response to enteric parasite $H$. polygyrus demonstrated IL-13R $\alpha 1$ is critical in host protection and clearance. Here, mice deficient in IL-13R $\alpha 1$ were used to examine the contribution of IL-13 during primary and secondary infection. In the absence of IL-13R $\alpha 1$, mice were unable to expel worms and had higher worm fecundity (114). Despite up-regulation of Th2 cytokines, IL-25 production was absent in intestines of deficient mice, which also had fewer goblet cells (114). Furthermore, during secondary infection, IL-13R $\alpha 1$ deficient mice experienced attenuated mucosal permeability and altered smooth muscle function (114). Differences between primary and secondary infection also indicated a necessity of IL-13 in the development of type 2 memory responses, which drive tissue responses to $H$. polygyrus larvae penetrating submucosa (114). Lack of IL-13 signaling through IL-13R $\alpha 1$ prevented polarization of M2 macrophages and inhibited STAT-6 signaling pathways essential during infection (114).

The involvement of IL-4r $\alpha$ in non-bone-marrow derived cells, such as intestinal epithelium cells, goblet cells and smooth muscle cells rather than immune cells was 
demonstrated using $N$. brasiliensis and Trichinella spiralis models in mice. Mice only expressing IL-4ra on non-bone marrow-derived cells were able to clear $N$. brasiliensis, whereas T. spiralis required signaling on both (143). While not a direct impact of IL-13, these data emphasize the role of non-immune cell signaling which occurs through IL-4 and IL-13, linking cytokine to physiologic outcome. Th2 responses are critical in worm expulsion, generating both IL-4 and IL-13 needed to signal gastrointestinal cells. Together, these data demonstrate that even in the absence of IL-4, a Th2 response can be mounted, initiating IL-13 signaling through IL-4ro sufficient to mediate worm expulsion.

Limited data has been generated on the exact role of IL-13 during $H$. contortus infection in sheep, but numerous studies have shown resistant breeds of sheep highly express IL-13 mRNA in abomasal lymph nodes, tissue and mucosa $(7,50,144,145)$. With the contribution of macrophages, IL-4r $\alpha$ and IL-13, it is reasonable to hypothesize that IL-13 contributes to resolution of $H$. contortus in resistant sheep like St. Croix, though mechanism and involvement remain unknown.

\section{Concluding remarks}

Development of full host protective immunity and expulsion of $H$. contortus relies on orchestrated responses including cellular recruitment and signaling via Th2 cytokines. Circulating PBMC are a heterogeneous population of cells. During infection, migration into tissues initiates differentiation of a spectrum of phenotypes, responding to signaling and eliciting an appropriate immune response. Of these, monocytes are plastic cells, important directors of inflammation and regulation. Classification of macrophages, however, has relied on categorization based on expression of cell-surface markers associated with mouse models, diving macrophages into two general types - M1 and M2 - with distinct physiologic roles. Disparities 
exist between markers for mouse and human monocytes, where the majority of human monocytes would be categorized as M1, while M1 and M2 phenotypes are equally represented in blood (146). The role of macrophage differentiation in sheep models remains unclear. Thus the aim of this research is to understand and characterize macrophages during development of natural resistance in St. Croix hair sheep during H. contortus infection. Our central hypothesis is that ovine monocytes contribute to larval morbidity, previously associated with PBMC, and monocytes preferentially display markers associated with alternatively activated macrophages, which are essential in development of full protective host immunity.

Clearance of $H$. contortus in susceptible hosts currently requires use of anthelmintics. Nicotinic agonists for deworming, such as levamisole, cause muscle contraction and spastic paralysis (147), resulting in increased passage rate from the abomasum. With the emergence of drug-resistant $H$. contortus strains, a critical need exists to develop alternative control strategies. Since St. Croix sheep develop an early and strong Th2 response in response to $H$. contortus L3 and the potent role of IL-13, we hypothesize that IL-13 produced by M2 may contribute to paralytic activity, directly inhibiting larvae in addition to its established role in gut contractility.

Therefore, aims of the current study are (i) to identify which cell type contributes to observed morbidity elicited by PBMC, (ii) to characterize ovine monocyte phenotype associated with larval morbidity and (iii) to evaluate functional mechanisms contributing to increased morbidity and decreased larval motility induced by monocytes. An additional aim is to understand the role and contribution of IL-13 signaling in alternative activation of monocytes. Understanding the role of monocytes in addition to the role of IL-13 in this system highlights the importance of Th2 immunity, connecting immune cells and non-immune cells driving the physiologic response of parasite clearance. Further understanding these mechanisms will aid in 
defining key differences between resistant and susceptible breeds, providing evidence and foundation for development of advanced anthelmintics and alternative treatments against haemonchosis.

\section{Literature cited}

1. USDA-APHIS-VS. Reference of 1996 U.S. Sheep Health and Management Practices. 1996.

2. Howell SB, Burke JM, Miller JE, Terrill TH, Valencia E, Williams MJ, et al. Prevalence of anthelmintic resistance on sheep and goat farms in the southeastern United States. J Am Vet Med Assoc. 2008;233(12):1913-9.

3. Bowdridge SA, Zajac AM, Notter DR. St. Croix sheep produce a rapid and greater cellular immune response contributing to reduced establishment of Haemonchus contortus. Vet Parasitol. 2015;208(3-4):204-10.

4. Gamble HR, Zajac AM. Resistance of St. Croix lambs to Haemonchus contortus in experimentally and naturally acquired infections. Vet Parasitol. 1992;41(3-4):211-25.

5. Courtney CH, Parker CF, McClure KE, Herd RP. Resistance of exotic and domestic lambs to experimental infection with Haemonchus contortus. Int J Parasitol. 1985;15(1):101-9.

6. Jacobs JR, Sommers KN, Zajac AM, Notter DR, Bowdridge SA. Early IL-4 gene expression in abomasum is associated with resistance to Haemonchus contortus in hair and wool sheep breeds. Parasite Immunol. 2016;38(6):333-9.

7. Lacroux C, Nguyen THC, Andreoletti O, Prevot F, Grisez C, Bergeaud JP, et al. Haemonchus contortus (Nematoda: Trichostrongylidae) infection in lambs elicits an 
unequivocal Th2 immune response. Vet Res. 2006;37(4):607-22.

8. Holt RM, Shepherd EA, Ammer AG, Bowdridge SA. Effects of peripheral blood mononuclear cells on Haemonchus contortus larval motility in vitro. Parasite Immunol. 2015;37(10):553-6.

9. Chen F, Wu W, Millman A, Craft JF, Chen E, Patel N, et al. Neutrophils prime a longlived effector macrophage phenotype that mediates accelerated helminth expulsion. Nat Immunol. 2014;15(10):938-46.

10. Shepherd EA, Garza JJ, Greiner SP, Bowdridge SA. The effect of ovine peripheral blood mononuclear cells on Haemonchus contortus larval morbidity in vitro. Parasite Immunol. 2017;39(4):e12424.

11. Rowe A, McMaster K, Emery D, Sangster N. Haemonchus contortus infection in sheep: Parasite fecundity correlates with worm size and host lymphocyte counts. Vet Parasitol. 2008 May;153(3-4):285-93.

12. Miller JE, Bahirathan M, Lemarie SL, Hembry FG, Kearney MT, Barras SR. Epidemiology of gastrointestinal nematode parasitism in Suffolk and Gulf Coast Native sheep with special emphasis on relative susceptibility to Haemonchus contortus infection. Vet Parasitol. 1998;74(1):55-74.

13. Hoberg EP, Zarlenga DS. Evolution and Biogeography of Haemonchus contortus: Linking Faunal Dynamics in Space and Time. Vol. 93, Advances in Parasitology. Elsevier Ltd; 2016. 1-30 p.

14. Alba-Hurtado F, Muñoz-Guzmán MA. Immune responses associated with resistance to 
haemonchosis in sheep. Biomed Res Int. 2013;2013.

15. Besier RB, Kahn LP, Sargison ND, Wyk JA Van. The Pathophysiology, Ecology and Epidemiology of Haemonchus contortus Infection in Small Ruminants. Vol. 93, Advances in Parasitology. Elsevier Ltd; 2016. 95-143 p.

16. Barger IA, Siale KI, Banks DJD, Le Jambre LF. Rotational grazing for control of gastrointestinal nematodes of goats in a wet tropical environment. Vet Parasitol. 1994;53:109-16.

17. Van Dijk J, Sargison ND, Kenyon F, Skuce PJ. Climate change and infectious disease: helminthological challenges to farmed ruminants in temperate regions. Animal. 2010;4:377-92.

18. Waller PJ, Chandrawathani P. Haemonchus contortus: parasite problem No. 1 from tropics - polar circle. Problems and prospects for control based on epidemiology. Trop Biomed. 2005;22:131-7.

19. Gibbs HC. Mechanisms of survival of nematode parasites with emphasis on hypobiosis. Vet Parasitol. 1982;11(1):25-48.

20. Tak I-R, Dar SA, Dar JS, Ganai BA, Chishti MZ, Ahmand F. A brief study of morphology of Haemonchus contortus and its hematophagous behaviour. Glob Vet. 2014;13(6):960-5.

21. Boughton IB, Hardy WT. Stomach worms (Haemonchus contortus) of sheep and goats. Report of the Texas Agricultural Experimental Station. 1935.

22. Clark CH, Kisel GK, Goby CH. Measurements of blood loss caused by Haemonchus contortus infection in sheep. Am J Veternary Res. 1962;23:977-80. 
23. Albers GA, Le Jambre LF. Erythrocyte potassium concentration: a simple parameter for erythropoiesis in sheep infected with Haemonchus contortus. Res Vet Sci. 1983;35:273-6.

24. Shamansky LM, Pratt D, Boisvenue RJ, Cox GN. Cuticle collagen genes of Haemonchus contortus and Caenorhabditis elegans are highly conserved. Mol Biochem Parasitol. 1989;37(1):73-85.

25. Fetterer RH, Rhoads ML. Biochemistry of the nematode cuticle: relevance to parasitic nematodes of livestock. Vet Parasitol. 1993;46(1-4):103-11.

26. Maizels RM, Philip M, Ogilvie BM. Molecules on the surface of parasitic nematodes as probes of the immune response in infection. Immunol Rev. 1982;61:109-36.

27. Maizels RM, Selkirk ME. Immunobiology of nematode antigens. Englund PT, Sher A, editors. The Biology of Parasitism. New York: Alan R. Liss, Inc.; 1988. 285-308 p.

28. Roberts LS, Janovy J. Foundations of Parasitology. 7th ed. New York; 2005. 425-427 p.

29. Dineen JK, Donald AD, Wagland BM, Offner J. The dynamics of the host-parasite realtionship: I II. The response of sheep to primary infection with Haemonchus contortus. Parasitology. 1965;55:515-25.

30. Blitz NM, Gibbs HC. Morphological characterization of the stage of arrested development of Haemonchus contortus in sheep. Can J Zool. 1971;49:991-5.

31. Gibbs HC. Hypobiosis and the periparturient rise in sheep. Vet Clin North Am Food Anim Pract. 1986;2(2):345-53.

32. Gatongi P., Prichard R., Ranjan S, Gathuma J., Munyua W., Cheruiyot H, et al. 
Hypobiosis of Haemonchus contortus in natural infections of sheep and goats in a semiarid area of Kenya. Vet Parasitol. 1998;77(1):49-61.

33. Dargie JD, Allonby EW. Pathophysiology of single and challenge infections of Haemonchus contortus in Merino sheep: Studies on red cell kinetics and the "self-cure" phenomenon. Int J Parasitol. 1975;5(2):147-57.

34. Georgi, J.R. and Whitelock JH. Erythrocyte loss and resitution in ovine haemonchosis. Estimation of erythrocyte loss in lambs following natural exposure. Cornell Vet. 1967;57(1):44-53.

35. Le Jambre LF. Relationship of blood loss to worm numbers, biomass and egg production in Haemonchus infected sheep. Int J Parasitol. 1995;25(3):269-73.

36. Scallan J, Huxley VH, Korthuis RJ. Capillary Fluid Exchange: Regulation, Functions, and Pathology. San Rafael: Morgan and Claypool Life Sciences; 2010. Chapter 4.

37. Gray D. Genetic Variation in resistance to parasites. Gray GD, Woolaston RR, Eaton BT, editors. Breeding for resistance to infectious diseases in small ruminants. Canebarra: ACIAR Monograph Series; 1995. 43-52 p.

38. Woolaston RR. Selection of Merino sheep for increased and decreased resistance to Haemonchus contortus: Peri-parturient effects on faecal egg counts. Int J Parasitol. 1992;22(7):947-53.

39. Ortolani EL, Leal ML do R, Minervino AHH, Aires AR, Coop RL, Jackson F, et al. Effects of parasitism on cellular immune response in sheep experimentally infected with Haemonchus contortus. Vet Parasitol. 2013;196(1-2):230-4. 
40. Vanimisetti HB, Greiner SP, Zajac AM, Notter DR. Performance of hair sheep composite breeds: Resistance of lambs to Haemonchus contortus. J Anim Sci. 2004;82:595-604.

41. Greer AW, Hamie JC. Relative maturity and the development of immunity to gastrointestinal nematodes in sheep: An overlooked paradigm? Parasite Immunol. 2016;38(5):263-72.

42. MacKinnon KM, Zajac AM, Kooyman FNJ, Notter DR. Differences in immune parameters are associated with resistance to Haemonchus contortus in Caribbean hair sheep. Parasite Immunol. 2010;32(7):484-93.

43. MacKinnon KM, Burton JR, Zajac AM, Notter DR. Microarray analysis reveals difference in gene expression profiles of hair and wool sheep infected with Haemonchus contortus. Vet Immunol Immunopathol. 2009;130:210-20.

44. Ingham A, Reverter A, Windon R, Hunt P, Menzies M. Gastrointestinal nematode challenge induces some conserved gene expression changes in the gut mucosa of genetically resistant sheep. Int J Parasitol. 2008;38:431-42.

45. Romagnani S. Type $1 \mathrm{~T}$ helper and type $2 \mathrm{~T}$ helper cells: Functions, regulation and role in protection and disease. Int J Clin Lab Res. 1992;21:152-8.

46. Oliphant CJ, Hwang YY, Walker JA, Salimi M, Wong SH, Brewer JM, et al. MHCIImediated dialog between group 2 innate lymphoid cells and CD4+ T cells potentiates type 2 immunity and promotes parasitic helminth expulsion. Immunity. 2014;41:283-95.

47. Else KJ, Finkelman FD. Intestinal nematode parasites, cytokines and effector mechanisms. Int J Parasitol. 1998;28(8):1145-58. 
48. Bancroft AJ, Else KJ, Grencis RK. Low-level infection with Trichuris muris significantly affects the polarization of the CD4 response. Eur J Immunol. 1994;24(12):3113-8.

49. Balic A, Bowles VM, Meeusen ENT. Cellular profiles in the abomasal mucosa and lymph node during primary infection with Haemonchus contortus in sheep. Vet Immunol Immunopathol. 2000;75(1-2):109-20.

50. Terefe G, Lacroux C, Andreoletti O, Grisez C, Prevot F, Bergeaud JP, et al. Immune response to Haemonchus contortus infection in susceptible (INRA 401) and resistant (Barbados Black Belly) breeds of lambs. Parasite Immunol. 2007;29(8):415-24.

51. Neill DR, Wong SH, Bellosi A, Flynn RJ, Daly M, Langford TKA, et al. Nuocytes represent a new innate effector leukocyte that mediates type-2 immunity. Nature. 2010;464(7293):1367-70.

52. Saenz SA, Siracusa MC, Perrigoue JG, Spencer SP, Urban JF, Tocker JE, et al. IL-25 elicits a multipotent progenitor cell population that promotes $\mathrm{TH} 2$ cytokine responses. Nature. 2010;464(7293):1362-6.

53. Maizels RM, Hewitson JP, Smith KA. Susceptibility and immunity to helminth parasites. Curr Opin Immunol. 2012;24:459-66.

54. Fallon PG, Ballantyne SJ, Mangan NE, Barlow JL, Dasvarma A, Hewett DR, et al. Identification of an interleukin (IL)-25-dependent cell population that provides IL-4, IL-5, and IL-13 at the onset of helminth expulsion. J Exp Med. 2006;203(4):1105-16.

55. Guo Z, González JF, Hernandez JN, McNeilly TN, Corripio-Miyar Y, Frew D, et al. Possible mechanisms of host resistance to Haemonchus contortus infection in sheep 
breeds native to the Canary Islands. Sci Rep. 2016;6:1-14.

56. Anthony RM, Rutitzky LI, Urban JF, Stadecker MJ, Gause WC. Protective immune mechanisms in helminth infection. Nat Rev Immunol. 2007;7(12):975-87.

57. Prussin C, Metcalfe DD. IgE, mast cells, basophils, and eosinophils. J Allergy Clin Immunol. 2010;125(2 SUPPL. 2):486-94.

58. Rainbird MA, Macmillan D, Meeusen ENT. Eosinophil-mediated killing of Haemonchus contortus larvae: effect of eosinophil activation and role of antibody, complement and interleukin-5. Parasite Immunol. 1998;20(2):93-103.

59. Reinhardt S, Scott I, Simpson H V. Neutrophil and eosinophil chemotactic factors in the excretory/secretory products of sheep abomasal nematode parasites : NCF and ECF in abomasal nematodes. Parasitol Res. 2011;109(3):627-35.

60. Balic A, Bowles VM, Meeusen ENT. The immunbiology of gastrointestinal nematode infections in ruminants. Advances in Parasitology. Elsevier; 2000. 181-241 p. (Advances in Parasitology; vol. 45).

61. Gill HS, Altmann K, Cross ML, Husband AJ. Induction of T helper 1- and T helper 2-type immune responses during Haemonchus contortus infection in sheep. Immunology. 2000;99(3):458-63.

62. Shakya KP, Miller JE, Horohov DW. A Th2 type of immune response is associated with increased resistance to Haemonchus contortus in naturally infected Gulf Coast Native lambs. Vet Parasitol. 2009;163(1-2):57-66.

63. Herndon FJ, Kayes SG. Depletion of eosinophils by anti-IL-5 monoclonal antibody 
treatment of mice infected with Trichinella spiralis does not alter parasite burden or immunologic resistance to reinfection. J Immunol. 1992;149(11):3642-7.

64. Brunei LR, Sabin EA, Cheever AW, Kopf MA, Pearce EJ. Interleukin 5 (IL-5) is not required for expression of a Th2 response or host resistance mechanisms during murine schistosomiasis mansoni but does play a role in development of IL-4-producing non-T, non-B cells. Infect Immun. 1999;67(6):3014-8.

65. Bass DA, Szejda P. Eosinophils versus neutrophils in host defense. Killing of newborn larvae of Trichinella spiralis by human granulocytes in vitro. J Clin Invest. 1979;64(5):1415-22.

66. Chen F, Liu Z, Wu W, Rozo C, Bowdridge S, Millman A, et al. An essential role for TH2type responses in limiting acute tissue damage during experimental helminth infection. Nat Med. 2012;18(2):260-6.

67. Schallig HD, Van Leeuwen MA, Cornelissen AW. Protective immunity induced by vaccination with two Haemonchus contortus excretory secretory proteins in sheep. Parasite Immunol. 1997;19(10):447-53.

68. Huntley J., Patterson M, Mackellar A, Jackson F, Stevenson L., Coop R. A comparison of the mast cell and eosinophil responses of sheep and goats to gastrointestinal nematode infections. Res Vet Sci. 1995;58(1):5-10.

69. Madden KB, Urban JF, Ziltener HJ, Schrader JW, Finkelman FD, Katona IM. Antibodies to IL-3 and IL-4 suppress helminth-induced intestinal mastocytosis. Jounral Immunol. 1991;147:1387-91. 
70. O'Garra A, Murphy K. Role of cytokines in determining T-lymphocyte function. Curr Opin Immunol. 1994;158:1085-94.

71. Gill HS, Watson DL, Brandon MR. Monoclonal antibody to CD4+ T cells abrogates genetic resistance to Haemonchus contortus in sheep. Immunology. 1993;78(1):43-9.

72. Peña MT, Miller JE, Horohov DW. Effect of CD4+ T lymphocyte depletion on resistance of Gulf Coast Native lambs to Haemonchus contortus infection. Vet Parasitol. 2006;138(3):240-6.

73. Anthony RM, Urban JF, Alem F, Hamed HA, Rozo CT, Boucher JL, et al. Memory TH2 cells induce alternatively activated macrophages to mediate protection against nematode parasites. Nat Med. 2006;12(8):955-60.

74. Bradley LM, Harbertson J, Biederman E, Zhang Y, Bradley SM, Linton P-J. Availability of antigen - presenting cells can determine the extent of CD4 effector expansion and priming for secretion of Th2 cytokines in vivo. Eur J Immunol. 2015;32(8):1-2.

75. Meeusen ENT, Balic A, Bowles V. Cells, cytokines and other molecules associated with rejection of gastrointestinal nematode parasites. Vet Immunol Immunopathol. 2005;108(1-2 SPEC. ISS.):121-5.

76. Schallig HD. Immunological responses of sheep to Haemonchus contortus. Parasitology. 2000;120 Suppl:S63-72.

77. Schallig HD, Van Leeuwen MA, Bernadina WE, Hendrikx WM. Serum antibody responses of Texel sheep experimentally infected with Haemonchus contortus. Res Vet Sci. 1994;57(1):63-8. 
78. Liu Q, Kreider T, Bowdridge SA, Liu Z, Song Y, Gaydo AG, et al. B cells have distinct roles in host protection against different nematode parasites. J Immunol. 2010;184(9):5213-23.

79. Gordon S. The macrophage: Past, present and future. Eur J Immunol. 2007;37(SUPPL. 1):9-17.

80. Merien F. A Journey with Elie Metchnikoff: From Innate Cell Mechanisms in Infectious Diseases to Quantum Biology. Front Public Heal. 2016;4:1-5.

81. Guilliams M, Mildner A, Yona S. Developmental and Functional Heterogeneity of Monocytes. Immunity. 2018;49(4):595-613.

82. van Furth R, Cohn ZA. The origin and kinetics of mononuclear phagocytes. J Exp Med. $1968 ; 128: 415-35$.

83. Ginhoux F, Jung S. Monocytes and macrophages: developmental pathways and tissue homeostasis. Nat Rev Immunol. 2014;14(6):392-404.

84. Bonnardel J, Guilliams M. Developmental control of macrophage function. Curr Opin Immunol. 2018;50:64-74.

85. Nichols BA, Bainton DF, Farquhar MG. Differentiation of monocytes Origin, Nature, and Fate of Their Azurophil Granules. J Cell Biol. 1971;50:498-515.

86. Swirski FK, Nahrendorf M, Etzrodt M, Wildgruber M, Cortez-Retamozo V, Panizzi P, et al. Identification of Splenic Reservoir Monocytes and Their Deployment to Inflammatory Sites. Sci Rep. 2009;325:612-7. 
87. Wynn TA, Chawla A, Pollard JW. Macrophage biology in development, homeostasis and disease. Nature. Nature Publishing Group; 2013;496:445-55.

88. Epelman S, Lavine KJ, Randolph GJ. Origin and Functions of Tissue Macrophages. Immunity. 2014;41(1):21-35.

89. Murray PJ, Wynn TA. Protective and pathogenic functions of macrophage subsets. Nat Rev Immunol. 2011;11(11):723-37.

90. Hopkinson-Woolley J, Hughes D, Gordon S, Martin P. Macrophage recruitment during limb development and wound healing in the embryonic and foetal mouse. J Cell Sci. 1994;107:1159-67.

91. Hashimoto D, Chow A, Noizat C, Teo P, Beasley MB, Leboeuf M, et al. Tissue-resident macrophages self-maintain locally throughout adult life with minimal contribution from circulating monocytes. Immunity. 2013;38(4):792-804.

92. Jenkins SJ, Ruckerl D, Cook PC, Jones LH, Finkelman FD, Rooijen N Van, et al. Local macrophage proliferation, rather than recruitment from the blood, is a signature of Th2 inflammation. Science. 2011;332:1284-8.

93. Fleetwood AJ, Lawrence T, Hamilton JA, Cook AD. Granulocyte-macrophage colonystimulating factor (CSF) and macrophage CSF-dependent macrophage phenotypes display differences in cytokine profiles and transcription factor activities: implications for CSF blockade in inflammation. J Immunol. 2007;178:5245-52.

94. Boettcher S, Manz MG. Regulation of Inflammation- and Infection-Driven Hematopoiesis. Trends Immunol. 2017;38(5):345-57. 
95. Verreck FAW, de Boer T, Langenberg DML, Hoeve MA, Kramer M, Vaisberg E, et al. Human IL-23-producing type 1 macrophages promote but IL-10-producing type 2 macrophages subvert immunity to (myco)bacteria. PNAS. 2004;101(13):4560-5.

96. Metcalf D. Hematopoietic regulators: Redundancy or subtlety. Blood. 1993;82(12):351523.

97. Smith BR. Regulation of hematopoiesis. Yale J Biol Med. 1990;63(5):371-80.

98. Huber S, Hoffmann R, Muskens F, Voehringer D. Alternatively activated macrophages inhibit T-cell proliferation by Stat6-dependent expression of PD-L2 Alternatively activated macrophages inhibit T-cell proliferation by Stat6-dependent expression of PDL2. Blood. 2010;116(17):3311-20.

99. Kaplan MH, Schindler U, Smiley ST, Grusby MJ. Stat6 is required for mediating responses to IL-4 and for the development of Th2 cells. Immunity. 1996;4(3):313-9.

100. Martinez FO, Gordon S. The M1 and M2 paradigm of macrophage activation: time for reassessment. Vol. 6, F1000Prime Reports. 2014.

101. Brunet LR. Nitric oxide in parasitic infections. Int Immunopharmacol. 2001 Aug;1(8):1457-67.

102. Bogdan C. Of microbes, macrophages and nitric oxide. Behring Inst Mitt. 1997;99:58-72.

103. Fang FC. Mechanisms of nitric oxide-related antimicrobial activity. J Clin Invest. 1997;100:2818-25.

104. MacMicking J, Xie Q, Nathan C. Nitric Oxide and Macrophage Function. Annu Rev 
Immunol. 1997;15(1):323-50.

105. Nascimento M, Huang SC, Smith AM, Everts B, Lam W, Bassity E, et al. Ly6Chi Monocyte Recruitment Is Responsible for Th2 Associated Host-Protective Macrophage Accumulation in Liver Inflammation due to Schistosomiasis. PLoS Pathog. 2014;10(8):e1004282.

106. Alonso-Trujillo J, Rivera-Montoya I, Rodríguez-Sosa M, Terrazas LI. Nitric oxide contributes to host resistance against experimental Taenia crassiceps cysticercosis. Parasitol Res. 2007;100(6):1341-50.

107. Ruano A., Lopez-Aban J, Fernandez-Soto P, Lane de Melo A, Muro A. Treatment with nitric oxide donors diminishes hyperinfection by Strongyloides venezuelensis in mice treated with dexamethasone. Acta Trop. 2015;152:90-5.

108. Suwanpradid J, Shih M, Pontius L, Yang B, Birukova A, Guttman-Yassky E, et al. Arginase1 deficiency in monocytes/macrophages upregulates inducible nitric oxide synthase to promote cutaneous contact hypersensitivity. J Immunol. 2017;199:1827-34.

109. Wu G, Morris SMJ. Arginine metabolism: nitric oxide and beyond. Biochem J. 1998;336:1-17.

110. Kreider T, Anthony RM, Urban JF, Gause WC. Alternatively activated macrophages in helminth infections. Curr Opin Immunol. 2007;19(4):448-53.

111. Gratchev A, Kzhyshkowska J, Utikal J, Goerdt S. Interleukin-4 and dexamethasone counterregulate extracellular matrix remodelling and phagocytosis in type-2 macrophages. Scand J Immunol. 2005;61(1):10-7. 
112. Esser-von Bieren J, Mosconi I, Guiet R, Piersgili A, Volpe B, Chen F, et al. Antibodies trap tissue migrating helminth larvae and prevent tissue damage by driving IL-4raindependent alternative differentiation of macrophages. PLoS Pathog. 2013;9:e1003771.

113. Obata-Ninomiya K, Ishiwata K, Tsutsui H, Nei Y, Yoshikawa S, Kawano Y, et al. The skin is an important bulwark of acquired immunity against intestinal helminths. J Exp Med. 2013;210:2583-95.

114. Sun R, Urban JF, Notari L, Vanuytsel T, Madden KB, Bohl J, et al. Interleukin-13 receptor $\alpha 1$-dependent responses in the intestina are critical to parasite clearance. Infect Immun. 2016;84:1032-44.

115. Martin P, Leibovich SJ. Inflammatory cells during wound repair: The good, the bad and the ugly. Trends Cell Biol. 2005;15(11):599-607.

116. Wynn TA, Barron L. Macrophages: Master regulators of inflammation and fibrosis. Liver. 2011;30(3):245-57.

117. Goerdt S, Orfanos CE. Other functions, other genes: Alternative activation of antigenpresenting cells. Immunity. 1999;10:137-42.

118. Duque GA, Descoteaux A. Macrophage cytokines: Involvement in immunity and infectious diseases. Front Immunol. 2014;5:1-12.

119. Bonne-Année S, Kerepesi LA, Hess JA, O’Connell AE, Lok JB, Nolan TJ, et al. Human and mouse macrophages collaborate with neutrophils to kill larval strongyloides stercoralis. Infect Immun. 2013;81(9):3346-55.

120. Maizels RM, Balic A, Gomez-Escobar N, Nair M, Taylor MD, Allen JE. Helminth 
parasites - Masters of regulation. Immunol Rev. 2004;201:89-116.

121. Liu Z, Liu Q, Pesce JT, Anthony RM, Lamb E, Whitmire J, et al. Requirements for the development of IL-4-producing T cells during intestinal nematode infections: what it takes to make a Th2 cell in vivo. Immunol Rev. 2004;201:57-74.

122. Loke P, MacDonald AS, Robb A, Maizels RM, Allen JE. Alternatively activated macrophages induced by nematode infection inhibit proliferation via cell-to-cell contact. Eur J Immunol. 2000;30:2669-78.

123. Terrazas LI, Montero D, Terrazas CA, Reyes JL, Rodriguez-Sosa M. Role of the programmed death-1 pathway in the suppressive activity of alternatively activated macrophages in experimental cysticercosis. Int J Parasitol. 2005;35:1349-58.

124. Munder M, Eichmann K, Modolell M. Alternative metabolic states in murine macrophages reflected by nitric oxide synthase/arginase balance: Competitive regulation by CD4+ T cells correlates with Th1/Th2 phenotype. J Immunol. 1998;160(11):5347-54.

125. Pesce JT, Ramalingam TR, Mentink-Kane MM, Wilson MS, Kasmi KCE, Smith AM, et al. Arginase-1-expressing macrophages suppress Th2 cytokine-driven inflammation and fibrosis. PLoS Pathog. 2009;5(4):e1000371.

126. King SB, Knorn AM, Ohnmacht C, Voehringer D. Accumulation of effector CD4 T cells during type 2 immune responses is negatively regulated by Stat6. J Immunol. 2008;180(2):754-63.

127. Mylonas KJ, Nair MG, Prieto-Lafuente L, Paape D, Allen JE. Alternatively Activated Macrophages Elicited by Helminth Infection Can Be Reprogrammed to Enable Microbial 
Killing. J Immunol. 2009;182(5):3084-94.

128. Major J, Fletcher JE, Hamilton TA. IL-4 Pretreatment Selectively Enhances Cytokine and Chemokine Production in Lipopolysaccharide-Stimulated Mouse Peritoneal Macrophages. J Immunol. 2002;168(5):2456-63.

129. Ruckerl D, Campbell SM, Duncan S, Sutherland TE, Jenkins SJ, Hewitson JP, et al. Macrophage origin limits functional plasticity in helminth-bacterial co-infection. PLoS Pathog. 2017;13:e1006233.

130. Lang R, Patel D, Morris JJ, Rutschman RL, Murray PJ. Shaping Gene Expression in Activated and Resting Primary Macrophages by IL-10. J Immunol. 2002;169(5):2253-63.

131. Varin A, Mukhopadhyay S, Herbein G, Gordon S. Alternative activation of macrophages by IL-4 impairs phagocytosis of pathogens but potentiates microbial-induced signalling and cytokine secretion. Blood. 2012;115(2):353-62.

132. Wynn TA. IL-13 Effector Functions. Annu Rev Immunol. 2003;21(1):425-56.

133. Bancroft AJ, McKenzie AN, Grencis RK. A critical role for IL-13 in resistance to intestinal nematode infection. J Immunol. 1998;160(7):3453-61.

134. Minty A, Chalon P, Derocq JM, Dumont X, Guillemot JC, Kaghad M, et al. Interleukin13 is a new human lymphokine regulating inflammatory and immune responses. Nature. 1993;362:248-50.

135. Zurawski G, Vries JE De. Interleukin 13, an interleukin 4-like cytokine that acts on monocytes and B cells, but not on T cells. Immunol Today. 1994;(1):19-26. 
136. Muchamuel T, Menon S, Pisacane P, Howard MC, Cockayne DA. IL-13 protects mice from lipopolysaccharide-induced lethal endotoxemia: correlation with down-modulation of TNF-alpha, IFN-gamma and IL-12 production. J Immunol. 1997;158:2898-903.

137. Mueller TD, Zhang JL, Sebald W, Duschl A. Structure, binding, and antagonists in the IL4/IL-13 receptor system. Biochim Biophys Acta - Mol Cell Res. 2002;1592(3):237-50.

138. Obiri NI, Leland P, Murata T, Debinski W, Puri RK. The IL-13 receptor structure differs on various cell types and may share more than one component with IL-4 receptor. J Immunol. 1997;158(2):756-64.

139. Gadani SP, Cronk JC, Norris G, Kipnis J. IL-4 in the brain: a cytokine to remember. J Immunol. 2012;189(9):4213-9.

140. Hershey K, Gurjit K. IL-13 receptors and signaling pathways: An evolving web. J Allergy Clin Immunol. 2003;111(4):677-90.

141. Barner M, Mohrs M, Brombacher F, Kopf M. Differences between IL-4R $\alpha$-deficient and IL-4-deficient mice reveal a role for IL-13 in the regulation of Th2 responses. Curr Biol. 1998;8(11):669-72.

142. McKenzie GJ, Bancroft AJ, Grencis RK, McKenzie ANJ. A distinct role for interleukin13 in Th2-cell-mediated immune responses. Curr Biol. 1998;8(6):339-42.

143. Urban JF, Noben-Trauth N, Schopf L, Madden KB, Finkelman FD. Cutting Edge: IL-4 Receptor Expression by Non-Bone Marrow-Derived Cells Is Required to Expel Gastrointestinal Nematode Parasites. J Immunol. 2001;167(11):6078-81.

144. Shakya KP, Miller JE, Lomax LG, Burnett DD. Evaluation of immune response to 
artificial infections of Haemonchus contortus in Gulf Coast Native compared with Suffolk lambs. Vet Parasitol. 2011;181:239-47.

145. Terefe G, Lacroux C, Prévot F, Grisez C, Bergeaud JP, Bleuart C, et al. Eosinophils in Haemonchus contortus-infected resistant and susceptible breeds of sheep: Abomasal tissue recruitment and in vitro functional state. Vet Parasitol. 2009;165(1-2):161-4.

146. Strauss-Ayali D, Conrad SM, Mosser DM. Monocyte subpopulations and their differentiation patterns during infection. J Leukoc Biol. 2007;82(2):244-52.

147. Martin JR. Modes of Action of Anthelmintic Drugs. Vet J. 1997;154:11-34. 


\section{Chapter 2: Common methodologies}

\section{Animals and housing}

Sheep were born and raised at the West Virginia University Animal and Science Farm (Morgantown, WV) and were housed in the Sheep Research Barn. All animals were limit fed $16 \% \mathrm{CP}$ corn-soybean concentrate with ad libitum grass hay and water. This study was approved by the West Virginia University Animal Care and Use Committee (ACUC 160800381.1).

\section{Experimental Design}

Four weeks after weaning, ten St. Croix (STC) hair sheep and ten Suffolk (SUF) wool sheep were randomly assigned to one of two treatment groups: naïve or primed. Animals assigned to primed groups received a single oral dose of 10,000 Haemonchus contortus infective third stage (L3). Infection persisted for six weeks then animals were treated orally with levamisole (Agrilabs, St. Joseph, MO) $(8 \mathrm{mg} / \mathrm{kg}$ ) and allowed to rest for three weeks before blood collection. Animals assigned to naïve treatment groups received no infection and remained unexposed to $H$. contortus. Fecal egg counts (FEC) were performed using a modified McMaster's technique (34) on all lambs during the priming infection and after deworming until all animals had an FEC of 0 before blood collection.

\section{Sample collection}

\section{Immune cell separation from whole blood}

Whole blood samples were obtained via jugular venipuncture into $10 \mathrm{~mL}$ vacutainer tubes treated ethylenediaminetetraacetic acid (EDTA) (Tyco, Mansfield, MA), preventing coagulation. Samples were centrifuged at $1,000 \times \mathrm{g}$ for 20 minutes at room 
temperature (RT) and buffy coats were collected and pooled by treatment group into sterile $15 \mathrm{~mL}$ centrifuges tubes. Buffy coats were re-suspended in $1 \mathrm{~mL}$ of sterile phosphate buffered saline (PBS) at $\mathrm{pH}$ of 7.4. Red blood cells (RBC) were removed by lysis using ACK lysis buffer (Lonza, Walkersville, MD). White blood cells were carefully layered over sterile lymphocyte separation media (LSM) (SPG $1.077 \mathrm{~g} / \mathrm{mL}$; Corning, Manassas, VA) and centrifuged at 400 x $g$ for 20 minutes at RT. Peripheral blood mononuclear cells (PBMC) were collected and counted using Bio-Rad TC-20 automated cell counter (Hercules, CA) and then suspended in complete media containing RPMI-1640 with 2mM L-gluatmine (GE Healthcare Life Sciences, Logan, UT), 10\% fetal bovine serum (FBS) (Corning, Corning, NY) and penicillin-streptomycin antibiotic (Sigma Aldrich, St. Louis MO, USA). Suspensions were diluted to a concentration of $1 \mathrm{x}$ $10^{6}$ cells/mL for use.

Monocytes were separated from PBMC using CD14 ${ }^{+}$autoMACs magnetic beads (Miltenyi Biotec, Gladbach, Germany). Confirmation of monocyte cell purity was performed by manual cell differential by loading a Cytospin chamber with $100 \mu \mathrm{L}$ cell suspension and concentrated onto a microscope slide using Cytopsin 4 (Thermo Scientific) and then stained using CamCo Quik Stain (Cambridge Diagnostic Products, Fort Lauderdale, FL).

\section{Parasitological analysis}

\section{Haemonchus contortus larval culture}

Three castrated male Suffolk lambs were infected with $H$. contortus and used solely for purpose of larval culture. Feces were collected and mixed with sterilized peat 
moss and activated charcoal, then incubated for 7 days at $30^{\circ} \mathrm{C}$. Larvae were isolated using a Baermann apparatus and stored in PBS (pH 7.4) at $4{ }^{\circ} \mathrm{C}$ until use.

\section{Larval ATP Analysis}

Cell suspensions of $5 \times 10^{5}(500 \mu \mathrm{L})$ were added to a 24 -well plate (Greiner CellStar, Frickenhausen, Germany) with an additional $400 \mu \mathrm{L}$ of complete media and 100 L3 H. contortus larvae $(100 \mu \mathrm{L})$, for a total volume of $1 \mathrm{~mL}$ per well, in triplicate per treatment group and placed in an incubator for 18 hours at $37^{\circ} \mathrm{C}$ with $5 \% \mathrm{CO}_{2}$. After which, media was replaced with Accumax ${ }^{\mathrm{TM}}$ enzyme (Innovative Cell Technologies, San Diego, CA) to release cells from larvae and incubated for 1 hour at RT. Larvae were then rinsed over $40 \mu \mathrm{m}$ cell strainers (Greiner BioOne, Frickenhausen, Germany) to isolate larvae without cells. Larvae were transferred to sterile micro-centrifuge tubes and an equal volume of CellTiter-Glo ATP reagent (Promega, Madison, WI) was added to each larval sample. Larvae were homogenized using a BeadBug Microtube Homogenizer (Benchmark Scientific) and $100 \mu \mathrm{L}$ of supernatant was plated into opaque walled flatbottom 96-well microplate (Greiner CellStar, Frieckenhausen, Germany). Luminescence was measured using a luminometer (BioTek Instruments), with an integration time of 1 second per well.

An ATP standard curve was created using serial dilutions from $1 \mu \mathrm{M}-0.001 \mu \mathrm{M}$ of rATP (Promega, Madison, WI) and blank standard of $0 \mu \mathrm{M}$ was included. Standard values were plotted against luminescent values, and then fitted using a linear regression line. Experimental ATP concentrations were corrected by subtracting background luminescence using a blank standard and calculated using the standard curve performed for each replication. Mean ATP was calculated per treatment group. 


\section{Larval motility analysis}

Video of larvae was captured using Olympus Air wireless lens (Shinjuku, Tokyo, Japan) fixed to Motic AE2000 inverted microscope (Mars, PA). Larval motility was assessed using WormLab ${ }^{\text {TM }}$ tracking software (MBF Bioscience, Williston, VT), measuring larval movement over 50 frames of video recording.

\section{RNA isolation and CDNA}

Total RNA was isolated from $\mathrm{CD}^{+} 4^{+}$cells from each treatment group using illustra RNAspin Mini kit (GE Healthcare, Buckinghamshire, United Kingdom). Briefly, cells were homogenized in $350 \mu \mathrm{L}$ of cell lysis buffer with $3.5 \mu \mathrm{L} \beta$-mercaptoethanol. Lysate was filtered, and RNA bound a membrane before desalinization and digestion of DNA using DNase. RNA was washed and dried on a silica membrane, then eluted into RNase-free water. Samples were determined to have >1.8 OD 260:280 ratio, measured by NanoDrop 1000 Spectrophotometer (Thermo Scientific, Wilmington, Denmark).

Synthesis of cDNA was prepared using a High Capacity cDNA Reverse Transcription Kit (Thermo Fisher Scienfitic, Vilnius, LT). Reactions were prepared using $10 \mu \mathrm{l}$ of $2 \mathrm{X}$ RT master mix and $10 \mu \mathrm{l}$ RA sample, then placed in a T100 thermal cycler (Bio-Rad, Hercules, CA). Reactions were completed by heating to $25^{\circ} \mathrm{C}$ for 10 minutes, then to $37^{\circ} \mathrm{C}$ for 120 minutes, and $85^{\circ} \mathrm{C}$ for 5 minutes, then cooled to $4^{\circ} \mathrm{C}$. Final cDNA preparations were stored at $-20^{\circ} \mathrm{C}$.

\section{Gene expression assay}

Samples were analyzed in quadruplicate using CFX96 system (Bio-Rad, Hercules, CA). Reactions contained $1 \mu \mathrm{L}$ 20x TaqMan Gene Expression Assay (Applied Biosystems, Foster City, CA) (Table 1), $2 \mu \mathrm{L}$ (100 ng) cDNA template, $10 \mu \mathrm{L} 2 \mathrm{X}$ TaqMan Gene Expression Master Mix (Applied Biosystems, Foster City, CA), and $7 \mu \mathrm{L}$ 
RNase-free water for volume of $20 \mu \mathrm{L}$ per reaction. Conditions for $\mathrm{qPCR}$ were performed using the following thermal-cycling profile: 10 minute hold at $95^{\circ} \mathrm{C}$, then 40 cycles of 15 seconds at $95^{\circ} \mathrm{C}$ denaturation and 20 seconds at $60^{\circ} \mathrm{C}$ extension. Relative fold changes in gene expression were calculated using $\Delta \mathrm{Ct}$ values [Ct (test) $-\mathrm{Ct}$ (reference)], and derived using $2^{-\Delta \Delta \mathrm{Ct}}$ where the reference gene used for normalization was GAPDH.

\section{Table 1: Taqman Probes}

\begin{tabular}{lll}
\hline Gene Name & Abbr & Assay ID \\
\hline Glyceraldehyde3-phosphate & GAPDH & Bt03210913_g1 \\
Arginase 1 & Arg1 & Oa04891279_m1 \\
Inducible nitric oxide synthase & iNOS & Oa04876175_m1 \\
Interferon gamma & IFN $\gamma$ & Oa04656649_m1 \\
Interleukin-4 & IL-4 & Oa04927178_s1 \\
Interleukin-10 & IL-10 & Oa04657337_m1 \\
Interleukin-12 & IL-12 & Oa04927178_s1 \\
Interleukin-13 & IL-13 & Oa03223101_m1 \\
\hline
\end{tabular}




\title{
Chapter 3: Characterization of ovine monocyte activity when cultured with Haemonchus contortus larvae in vitro
}

\begin{abstract}
Peripheral blood mononuclear cells (PBMC) have been shown to impair Haemonchus contortus $(\mathrm{Hc})$ motility and increase larval morbidity in vitro. Separation of monocytes from lymphocytes demonstrated a clear role for monocytes increasing larval morbidity as measured by larval ATP concentration. Larval ATP after culture with St.Croix (STC)-derived monocytes was significantly lower $(0.015 \mu \mathrm{M})$ than larvae cultured with Suffolk (SUF)-derived monocytes $(0.067 \mu \mathrm{M})(\mathrm{P}<0.001)$, highlighting breed differences. No differences were observed in larvae treated with SUF-derived lymphocytes $(0.112 \mu \mathrm{M}$ ATP) compared to untreated L3 $(0.118 \mu \mathrm{M}$ ATP $)$. Monocyte gene expression was characterized over 15 hours of culture. Monocytes from SUF sheep generally had higher expression of M1 genes early, whereas STC-derived monocytes displayed markers of alternative activation throughout the $15 \mathrm{hr}$ course. To further determine ovine monocyte activation in response to Hc larvae, enzymes arginase-1 (Arg1) and inducible nitric oxide synthase (iNOS) were inhibited using BEC (S-(2boronoethyl)-I-cysteine) and 1400W (N-(3-(aminomethyl)benzyl)acetamidine), respectively. Effector function was determined to be Arg1-dependent, as both STC- and SUF-derived cells treated with BEC did not reduce larval ATP compared to control treated larvae (STC: $0.055 \mu \mathrm{M}$ and $0.029 \mu \mathrm{M}$ ATP) (SUF: $0.069 \mu \mathrm{M}$ and $0.067 \mu \mathrm{M}$ ATP). Larval ATP after culture with SUF-derived, $1400 \mathrm{~W}$-treated monocytes $(0.037 \mu \mathrm{M})$ was significantly lower than larval ATP when cultured with control $(0.059 \mu \mathrm{M})(P<$ 0.001), restoring effector function. Larval ATP of STC-derived 1400W treated cells
\end{abstract}


$(0.046 \mu \mathrm{M})$ was significantly higher than larvae cultured with STC-derived monocytes alone $(0.029 \mu \mathrm{M}$ ATP $)(P<0.001)$, suggesting an undefined role of iNOS specific to STC. Collectively, these data indicate STC monocytes preferentially become alternatively activated when exposed to Hc larvae, which is essential for monocyteinduced larval morbidity and development of full host protective response in vivo.

\section{Introduction}

Peripheral blood mononuclear cells are a heterogeneous population of cells comprised of lymphocytes and monocytes. Lymphocytes are important in generating immune responses against helminths, primarily by producing antibody $\operatorname{IgE}$ and $\operatorname{Ig} \mathrm{A}$ from B cells, along with induction of $\mathrm{CD}^{+} \mathrm{Th} 2$ cells $(1,2)$. Depletion of CD4+ T lymphocytes in naturally parasite resistant Gulf Coast Native lambs ablated resistance to $H$. contortus (3), demonstrating the importance of adaptive immunity and a potent cellular response. Monocytes, which circulate in blood are recruited to tissues during infection and differentiate into macrophages in response to stimuli. Murine models of helminth infection have demonstrated a role of macrophages in mediation of parasite Nippostrongylus brasiliensis, where monocytes directly adhere to larvae, contributing to larval killing (4). However, the contribution of monocytes during H. contortus infection in sheep has not yet been investigated.

Helminths stimulate alternatively activated macrophages (M2) that can aid in the development of Th2 driven immunity. Competition for substrate, L-arginine is critical in polarization of monocytes and is used to distinguish classically activated (M1) macrophages from M2. Nitric oxide synthase 2 (iNOS) is important in cytotoxic and antimicrobial functions of M1 (5) and the develop of Type 1 immunity against bacteria 
and viruses, whereas Arginase-1 (Arg1) activity increases with M2 (6). Competition for the L-arginine substrate down-regulates other macrophage activation states, where M2 activity suppresses M1 and vice versa (7). Thus, enzyme levels can be indicative of macrophage activation state (8). While this phenomenon is well described in murine models, there is controversy as to the role of these enzymes in macrophage differentiation in larger order mammals.

Alternatively activated macrophages have been documented to produce IL-13 in response to helminth infection. In the context of $H$. contortus infection, a study found IL-13 levels were elevated in abomasal tissue by day 3 after infection (9). Furthermore, it was also found that resistant sheep had increased circulating monocyte counts by day 5 after infection with $H$. contortus (10). Our previous data have indicated that PBMC can severely inhibit larval motility and increase larval morbidity. Therefore, the objective of this study was to determine which cell subset of PBMC contributes to larval morbidity using ATP quantification and to characterize the functional role of ovine monocytes in response to $H$. contortus $\mathrm{L} 3$ in vitro, using RT qPCR and motility analysis. These data suggest STC sheep preferentially develop alternatively activated monocytes in response to $H$. contortus infection, as compared to SUF, which may contribute to natural parasite resistance.

\section{Materials and Methods}

\section{Transmission electron microscopy}

Samples of 10,000 H. contortus L3 were cultured with $5 \times 10^{7}$ PBMC in 24-well

filtered plates (Nunc, Roskilde, Denmark) for 18 hours at $37^{\circ} \mathrm{C}$ with $5 \% \mathrm{CO}_{2}$. Supernatant was replaced with fixative (3\% glutaraldehyde in sodium cacodylate Buffer, 
$\mathrm{pH}$ 7.4) and allowed to fix for 1 week at RT. Samples were delivered to the WVU COREs imaging facility and larvae were embedded, polymerized and sectioned by facility staff.

\section{Enzyme inhibition assays}

Arginase and iNOS activity were inhibited by adding $10 \mu \mathrm{g} / \mathrm{mL}$ BEC (S-(2boronoethyl)-I-cysteine hydrochloride) or $10 \mu \mathrm{g} / \mathrm{mL} \quad 1400 \mathrm{~W} \quad$ (N-(3[Aminomethyl]benzyl)acetamidine) (Sigma-Aldrich, St. Louis, MO), respectively to $5 \times 10^{5}$ CD14+ cells from STC or SUF and cultured with $H$. contortus L3 for 9 hours at $37^{\circ} \mathrm{C}$ and $5 \% \mathrm{CO}_{2}$. Arginase activity was measured using a QuantiChrom Arginase Assay Kit (BioAssay Systems, Hayward, CA) and NO was measured using Griess Reagent System (Promega Corporation, Madison, WI).

\section{Statistical analysis}

Larval ATP and motility data were analyzed using SigmaPlot software (Systat Software). The main effects of breed and cell type were compared by two-way ANOVA using the Holm-Sidak method for mean comparisons. Gene expression data was analyzed by one-way ANOVA analysis, comparing gene by breed within each time point. Significance was accepted at $P<0.05$.

\section{Results}

Effect of mononuclear cell subset on $\boldsymbol{H}$. contortus motility and morbidity

Larvae cultured with STC-derived monocytes had significantly lower ATP concentration $(0.015 \mu \mathrm{M})$ when compared to SUF-derived monocytes $(0.067 \mu \mathrm{M}$ ATP $)$ $(P<0.001)$ (Figure 1a). When L3 were cultured with lymphocytes, STC-derived cells reduced ATP $(0.085 \mu \mathrm{M})$, whereas SUF-derived lymphocytes $(0.112 \mu \mathrm{M}$ ATP) had no effect on larval ATP reduction when compared to untreated L3 $(0.118 \mu \mathrm{M}$ ATP) $(P<$ 
0.001) (Figure 1a). Overall, monocytes from both breeds (STC: $0.015 \mu \mathrm{M}$; SUF: 0.067 $\mu \mathrm{M})$ had a greater effect on larval ATP than lymphocytes from either breed (STC: 0.085 $\mu \mathrm{M}$; SUF: $0.122 \mu \mathrm{M}$ ), implicating monocytes as the major effector cell contributing to larval morbidity in this system.

To confirm these data, larvae were cultured with STC- or SUF-derived PBMC and fixed in a pellet to be processed for transmission electron microscopy (TEM). Images revealed cellular attachment to larval cuticle. Activated macrophages were adhering to larvae, whereas lymphocytes were not. Additionally, the larval cuticle was separated from the larval body at the site of cellular attachment (Figure 1b), supporting the conclusion that monocytes are directly contributing to larval morbidity.

Tracking data further supports the role of monocytes by significantly reducing straight-line distance, when compared to lymphocytes or untreated larvae. Larvae exposed to STC-derived monocytes traveled $14 \mu \mathrm{m}$ and L3 exposed to SUF-derived monocytes traveled $15 \mu \mathrm{m}$ in distance, with no significant difference between the breeds (Figure 1c). When larvae were cultured with STC- or SUF-derived lymphocytes, straight-line distance traveled was $27 \mu \mathrm{m}$ and $23 \mu \mathrm{m}$, respectively (Figure 1c). In comparison to untreated control larvae $(39 \mu \mathrm{m})$, both monocytes and lymphocytes from either breed reduced straight-line distance. Monocytes, however, significantly reduced larval path-length in comparison to other treatments (STC: $13 \mu \mathrm{m}$; SUF: $15 \mu \mathrm{m})(P<$ $0.05)$

\section{Gene expression analysis of activated monocytes}

To understand the activation status of monocytes exposed to L3 in vitro, qPCR was performed to determine patterns of M1 and M2 gene expression over a course of 6, 
9, 12 and 15 hours of culture. While genes associated with Th1 pro-inflammatory response, considered markers of M1, were up-regulated in both breeds, SUF-derived monocytes displayed significantly higher expression of IL-12 than STC monocytes, though no differences in iNOS or IFN $\gamma$ were observed (Table 3.1), suggesting an early M1 phenotype in SUF. Again, both breeds up-regulated genes associated with a Th2 response, considered markers of M2 alternative activation. Unexpectedly, SUF-derived monocytes stimulated with L3 up-regulated IL-13 when compared to STC $(P<0.001)$ (Table 3.1). STC-derived monocytes significantly up-regulated IL-10 in response to L3, compared to SUF-derived monocytes $(P<0.05)$ (Table 3.1). No significant differences were observed in monocyte expression of Arg1, IL-4 or IL-4ra at 6 hrs of culture with L3.

At 9hr, IL-4 was not expressed by either SUF- or STC-derived monocytes. Interestingly, there were no significant differences in expression of IL-4 between breeds at 15 hours after culture of monocytes with L3 (Table 3.3). However, SUF-derived monocytes had sustained up-regulation of NOS2 and IFN $\gamma$ at 15 hours when compared to STC-derived monocytes (Table 3.3). IL-4r $\alpha$ and IL-13 was down-regulated in SUFderived monocytes at 15 hrs (Table 3.3), suggesting a switch in signaling. Notably, SUFderived monocytes significantly up-regulated IL-10 at 15 hours of culture (Table 3.3), which suggests a switch in phenotype much later than STC-derived monocytes occurring at 9 hours. Together, these data suggest transient patterns in gene expression, with sustained inflammatory signaling in SUF-derived monocytes and alternative activation of STC-derived monocytes. 


\section{Effect of arginase and nitric oxide inhibition in monocytes during culture with $\boldsymbol{H}$. contortus L3}

Murine models indicate monocyte polarization is driven by the competition for Larginine by iNOS, associated with M1 phenotype, and Arg1 associated with M2 phenotype. Therefore, a competitive inhibitor of arginase (BEC) and a selective inhibitor of iNOS (1400W) were used to determine influence of activation status on larval morbidity and motility.

When cultured with BEC-treated monocytes, larval ATP was significantly increased as compared to larvae treated with monoctyes alone. Of interest, when SUFderived monocytes were treated with BEC, all effector function was ablated and larval ATP $(0.069 \mu \mathrm{M})$ was not significantly different than untreated (untrt) L3 $(0.067 \mu \mathrm{M}$ ATP) (Figure 2a). The greatest impact on ATP was observed in STC-derived monocytes treated with BEC $(0.055 \mu \mathrm{M}$ ATP) compared to L3 treated with STC-derived monocytes alone $(0.029 \mu \mathrm{M}$ ATP $)(P<0.001)$, suggesting that inhibition of arginase ablates monocyte cell function against L3 (Figure 2a). Tracking measurements further support these data, as inhibition of arginase activity increased larval speed. Larvae cultured with BEC-treated monocytes from either breed moved at higher speeds, compared to monocytes alone $(P<0.05)$, with the greatest difference between larvae cultured with STC-derived monocytes and BEC-treated STC-derived monocytes (Figure 2b). However, distance traveled was not significantly different between breed or treatment (Figure 2c).

Inhibiting iNOS activity in SUF-derived cells enhanced effector activity, reducing larval ATP to lower levels than larvae cultured with SUF-derived monocytes alone (Figure 3a). Larval ATP after culture with 1400W-treated SUF-derived monocytes was 
$0.037 \mu \mathrm{M}$, which was significantly reduced from larvae treated with SUF-derived monocytes alone, with $0.059 \mu \mathrm{M}$ ATP $(P<0.001)$ (Figure 3a). However, when STCderived monocytes were treated with $1400 \mathrm{~W}$ larval ATP increased to $0.046 \mu \mathrm{M}$ ATP, which was significantly higher than larvae treated with STC-derived monocytes alone $(0.029 \mu \mathrm{M}$ ATP $)(P<0.001)$, which unexpectedly reveals a role of iNOS in larval morbidity (Figure 3b).

\section{Discussion}

Murine models of helminth infection have demonstrated cellular mechanisms of larval killing in vitro, with direct attachment $(4,11)$. Prior to our current study, PBMC from both St. Croix and Suffolk effectively increased larval morbidity of L3 in vitro (12) and thus, the aim of these data were to determine whether lymphocytes (CD14-) or monocytes (CD14+) in a heterogeneous population of cells had a greater impact on larval morbidity. When isolated, STC-derived monocytes had increased effector function against L3, compared to SUF-derived monocytes. These data indicate ovine monocytes induce larval killing. Furthermore, while SUF-derived monocytes were able to induce larval morbidity compared to untreated control L3, differences between STC- and SUFderived monocytes indicate an impairment of SUF-derived monocytes, although mechanisms remain unclear.

To determine if differences in breed effector function were also monocyte activation status dependent, Arg1 and iNOS were inhibited to prevent polarization towards M2 or M1 phenotype, respectively. Inhibition of Arg1, preventing an M2 phenotype, significantly reduced effector function of both STC- and SUF-derived monocytes as hypothesized. However, differences in larval morbidity were greatest 
between untreated and treated STC-derived monocytes, indicating STC-derived monocytes require Arg1 in mediation of L3 in vitro and preferentially become M2 in response to L3. Inhibition of iNOS activity promoted SUF-derived monocyte effector function, rescuing susceptibility and reducing larval ATP comparable to STC-derived monocytes, again supporting Arg1 requirement. Therefore, an overproduction of iNOS by SUF could prevent appropriate activation of monocytes during infection. Increased expression of iNOS was associated with both STC- and SUF-derived monocytes by 9 to 12 hours. However, SUF remained higher, while STC iNOS gene expression decreased overtime.

Unexpectedly, STC-derived monocytes with impaired iNOS activity lost effector function. In contrast to bacteria and protozoa, helminth parasites - adults, larval stages and their eggs - are large, intrusive, multicellular organisms, and therefore are not targeted with the same immune response. Eggs released from schistosomes incite tissue inflammation in the liver, where NO produced by macrophages aids in regulation of tissue damage (13). While macrophage phenotypes were heterogeneous in the liver during schistosome infection, alternative activation was dominant, despite high iNOS and TNFa (14), indicating both Th2 and Th1 mechanisms of clearance may be involved.

While Arg1 activity is pivotal in activation status and macrophage polarization, some studies have suggested that parasite-induced arginase may be beneficial to the parasite itself, functionally inhibiting iNOS-dependent parasite killing mechanisms (15). L-ornithine produced downstream of L-arginine hydrolysis has been shown to support parasite growth (15), whereas iNOS gene expression early during infection induces vasodilation, promoting wound healing, before environmental factors drive arginase- 
dependent production of collagen and tissue repair (16). Thus, data from this study support a role for increased iNOS in STC-derived cells early during infection, and may support a potential role for type 1 responses, such as iNOS, during $H$. contortus infection, though mechanisms remain unclear.

Gene expression was performed to characterize monocytes from STC and SUF sheep in response to L3. Markers associated with murine monocytes were used to determine activation status, whereas ovine markers of activation have not fully been explored and thus, may account for differences in expression observed in other models of helminth infection. In our current study, gene expression demonstrated a spectrum of genes activated in response to L3 over 6 to 15 hours of culture. St. Croix derived monocytes shifted profiles by hour 9 of culture, whereas SUF-derived monocytes had increased expression of Th1- throughout all time points. While differences were observed between breeds in both Th1 and Th2 associated genes, clear indicators of polarization towards alternative activation could not be detected.

Monocytes and macrophages are highly plastic cells, responding to wide ranges of stimuli. One limitation of this study was the use of whole L3, compared to use of crude larval antigen. In the current model, L3 actively excrete and secrete factors into cell culture media, which may influence gene expression. Additionally, while L3 are washed following larval culture, bacteria from feces may remain in small amounts, influencing cell activity. Furthermore, due to their plasticity, gene expression of activation markers may not be homogeneous across a single well of L3-treated cells and multiple mechanisms of larval mediation may be occurring simultaneously. 
Polarization is influenced by many factors and shaped over time, as well as by tissue (17,18). These factors may be extrinsic, intrinsic and environmental (17). Additionally, macrophage function is not limited to a given polarization state, as macrophage phenotype does not always indicate macrophage function or physiologic process (17). While L-arginine metabolism is linked with polarization of M1 and M2 macrophages, inhibition of arginase in mice did not alter numbers of M2, but did increase inflammation (19). Mice with inhibited arginase activity displayed impaired or delayed wound healing, functional properties of monocytes remained intact (19). Furthermore, macrophage activation and production of specific cytokines is graded across activation states. Production of IL-10, for example, can be linked to many immune settings and thus, macrophage functional activity is largely dependent on how much signal is being produced rather than gene expression of one factor versus another $(17,18)$.

Collectively, our current study demonstrated ovine monocytes contribute to increased larval morbidity compared to lymphocytes, requiring Arg1 activity to induce full effector function. Breed differences in response to BEC, suggest alternative activation is preferential in STC- and not SUF-derived monocytes in response to $H$. contortus L3. These data also indicate an enhanced ability of STC-derived monocytes to increase larval morbidity and reduce larval motility. Previously unknown roles of iNOS and Arg1 during $H$. contortus infection were also observed in STC-derived monocytes, suggesting mediation of L3 may not rely on highly polarized monocytes, rather on plasticity to accommodate changes in environment. However, markers of alternative activation in ovine monocytes remain unclear. 


\section{Literature Cited}

1. Lacroux C, Nguyen THC, Andreoletti O, Prevot F, Grisez C, Bergeaud JP, et al. Haemonchus contortus (Nematoda: Trichostrongylidae) infection in lambs elicits an unequivocal Th2 immune response. Vet Res. 2006;37(4):607-22.

2. Schallig HD. Immunological responses of sheep to Haemonchus contortus. Parasitology. 2000;120 Suppl:S63-72.

3. Peña MT, Miller JE, Horohov DW. Effect of CD4+ T lymphocyte depletion on resistance of Gulf Coast Native lambs to Haemonchus contortus infection. Vet Parasitol. 2006;138(3):240-6.

4. Chen F, Wu W, Millman A, Craft JF, Chen E, Patel N, et al. Neutrophils prime a long-lived effector macrophage phenotype that mediates accelerated helminth expulsion. Nat Immunol. 2014;15(10):938-46.

5. MacMicking J, Xie Q, Nathan C. Nitric Oxide and Macrophage Function. Annu Rev Immunol. 1997;15(1):323-50.

6. Munder M, Eichmann K, Modolell M. Alternative metabolic states in murine macrophages reflected by nitric oxide synthase/arginase balance: Competitive regulation by CD4+ $\mathrm{T}$ cells correlates with $\mathrm{Th} 1 / \mathrm{Th} 2$ phenotype. J Immunol. 1998;160(11):5347-54.

7. Maizels RM, Balic A, Gomez-Escobar N, Nair M, Taylor MD, Allen JE. Helminth parasites - Masters of regulation. Immunol Rev. 2004;201:89-116.

8. Lowenstein CJ. iNOS (NOS2) at a glance. J Cell Sci. 2004;117(14):2865-7. 
9. MacKinnon KM, Burton JR, Zajac AM, Notter DR. Microarray analysis reveals difference in gene expression profiles of hair and wool sheep infected with Haemonchus contortus. Vet Immunol Immunopathol. 2009;130:210-20.

10. Bowdridge SA, Zajac AM, Notter DR. St. Croix sheep produce a rapid and greater cellular immune response contributing to reduced establishment of Haemonchus contortus. Vet Parasitol. 2015;208(3-4):204-10.

11. Rainbird MA, Macmillan D, Meeusen ENT. Eosinophil-mediated killing of Haemonchus contortus larvae: effect of eosinophil activation and role of antibody, complement and interleukin-5. Parasite Immunol. 1998;20(2):93-103.

12. Shepherd EA, Garza JJ, Greiner SP, Bowdridge SA. The effect of ovine peripheral blood mononuclear cells on Haemonchus contortus larval morbidity in vitro. Parasite Immunol. 2017;39(4):e12424.

13. Brunet LR. Nitric oxide in parasitic infections. Int Immunopharmacol. 2001 Aug;1(8):1457-67.

14. Nascimento M, Huang SC, Smith AM, Everts B, Lam W, Bassity E, et al. Ly6Chi Monocyte Recruitment Is Responsible for Th2 Associated Host-Protective Macrophage Accumulation in Liver Inflammation due to Schistosomiasis. PLoS Pathog. 2014;10(8):e1004282.

15. Vincendeau P, Gobert AP, Daulouède S, Moynet D, Mossalayi MD. Arginases in parasitic diseases. Trends Parasitol. 2003;19(1):9-12.

16. Shearer JD, Richards JR, Mills CD, Caldwell MD. Differential regulation of 
macrophage arginine metabolism: a proposed role in wound healing. Am J Physiol. 1997;272:181-90.

17. Murray PJ. Macrophage polarization. Annu Rev Physiol. 2017;79:541-66.

18. Ginhoux F, Schultze J., Murray PJ, Ochando J, Biswas SK. New insights into the multidimensional concept of macrophage ontogeny, activation and function. Nat Immunol. 2015;17:34-40.

19. Campbell L, Savill C, Murray PJ, Cruickshank S, Hardman M. Local arginase 1 activity is requried for cutaneous wound healing. J Invest Dermatol. 2013;133:2461-70. 


\section{Figures}
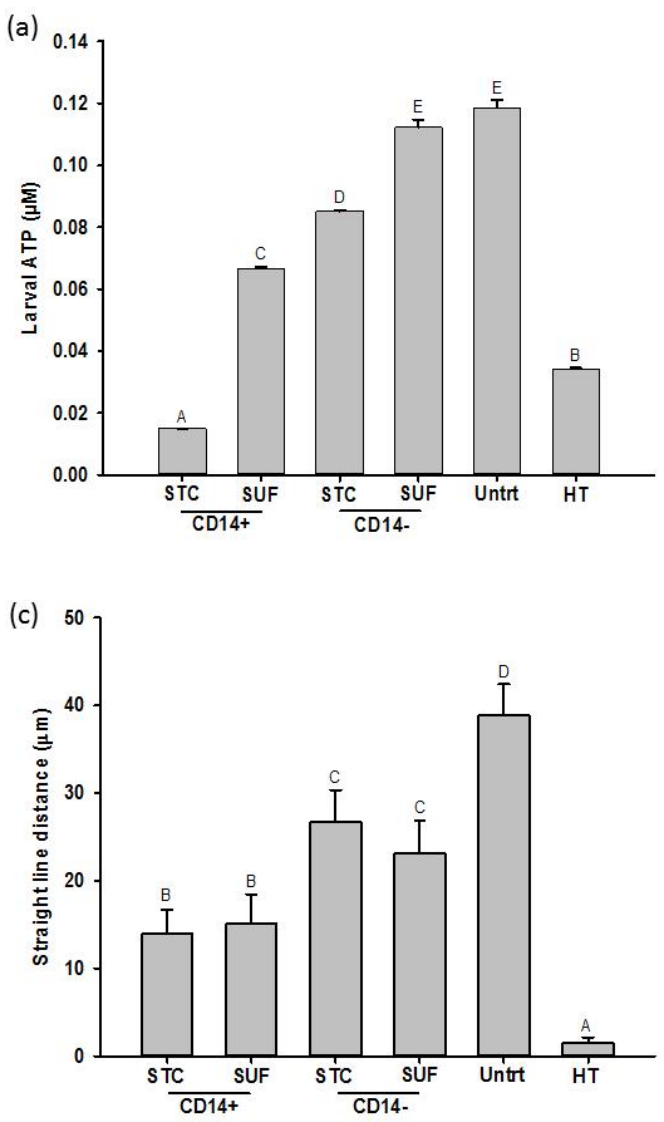

(b)

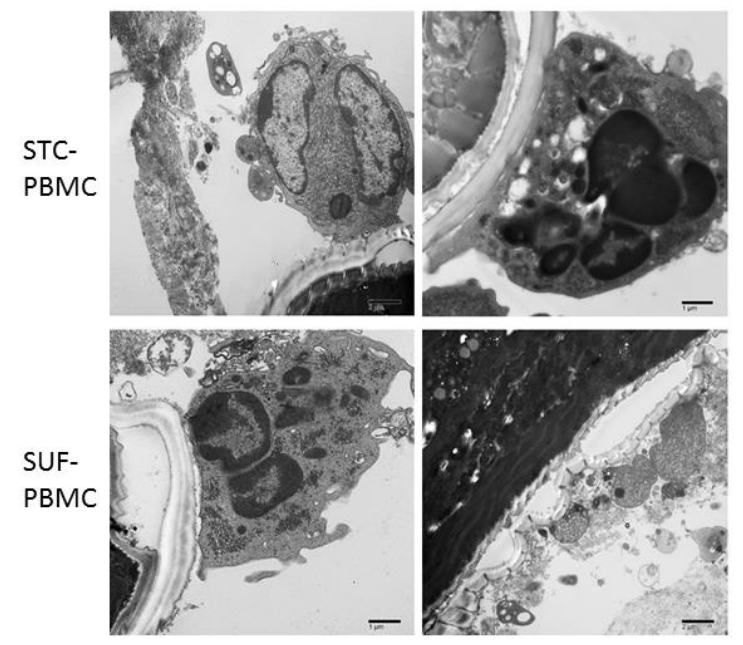

Figure 1: Monocyte and lymphocyte interaction with larvae in vitro.

(a) Monocytes $\left(\mathrm{CD} 14^{+}\right)$and lymphocytes $\left(\mathrm{CD} 14^{-}\right)$were isolated from PBMC derived from either St. Croix (STC) or Suffolk (SUF) sheep and cultured with L3 for 18 hours, and ATP was compared to untreated (Untrt) or heat treated (HT) control L3. (b) Larvae were cultured with STC- or SUF- derived PBMC and imaged using transmission electron microscopy (TEM). (c) Straight-line distance of L3 was measured over 50 frames of video using WormLab ${ }^{\mathrm{TM}}$ after 9 hours of culture with either STC- or SUF- derived CD14+ or CD14- cells. Error bars represent SEM. Different letters indicate significant differences; $P<0.001$. 
(a)

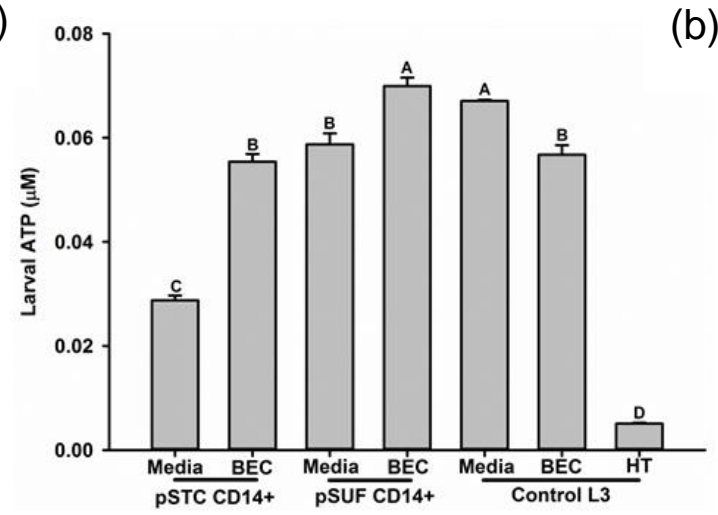

(c)

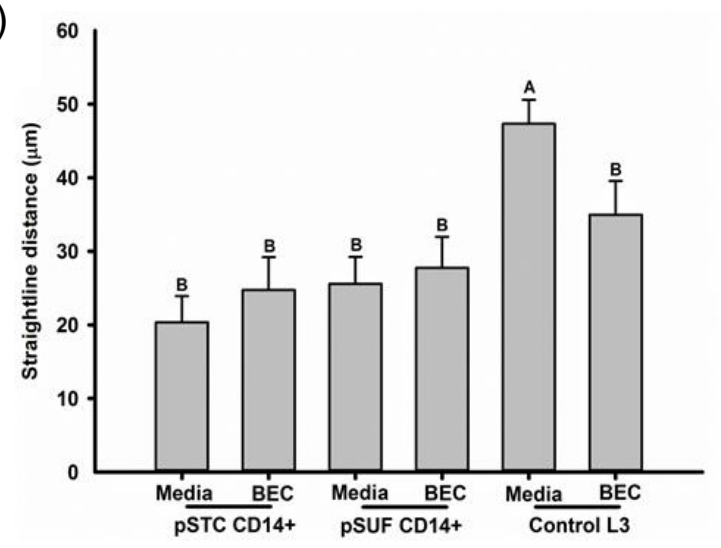

(b)

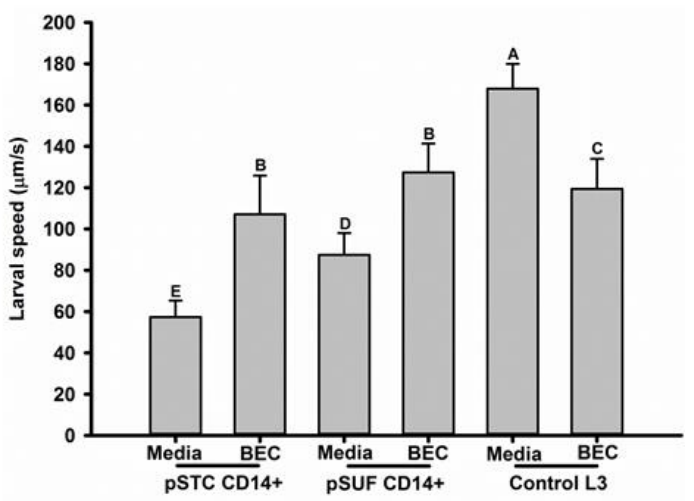

Figure 2: Inhibition of Arginase activity in monocytes.

CD14+ monocytes were isolated from PBMC derived from either St. Croix (STC) or Suffolk (SUF) sheep and cultured with $10 \mu \mathrm{g} / \mathrm{mL}$ BEC (S-(2-boronoethyl)-I-cysteine hydrochloride) for one hour, before adding L3 to culture. (a) Larval ATP was measured after 9 hours of incubation, and compared to untreated (media) and BEC treated controls. (b) Larval speed and (c) straight-line distance were measured over 50 frames of video recorded after 9 hours culture with CD14+ cells from either STC or SUF. Motility was analyzed using WormLab ${ }^{\mathrm{TM}}$ software. Each treatment was performed in triplicate. Error bars represent SEM. Different letters indicate significant differences; $P<0.001$. 
(a)

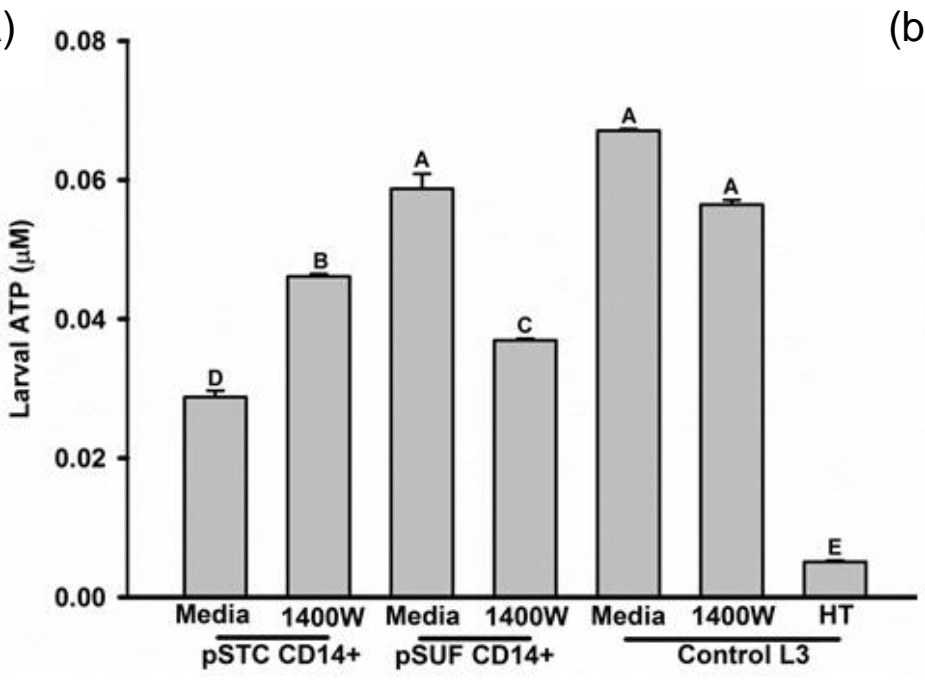

(c)

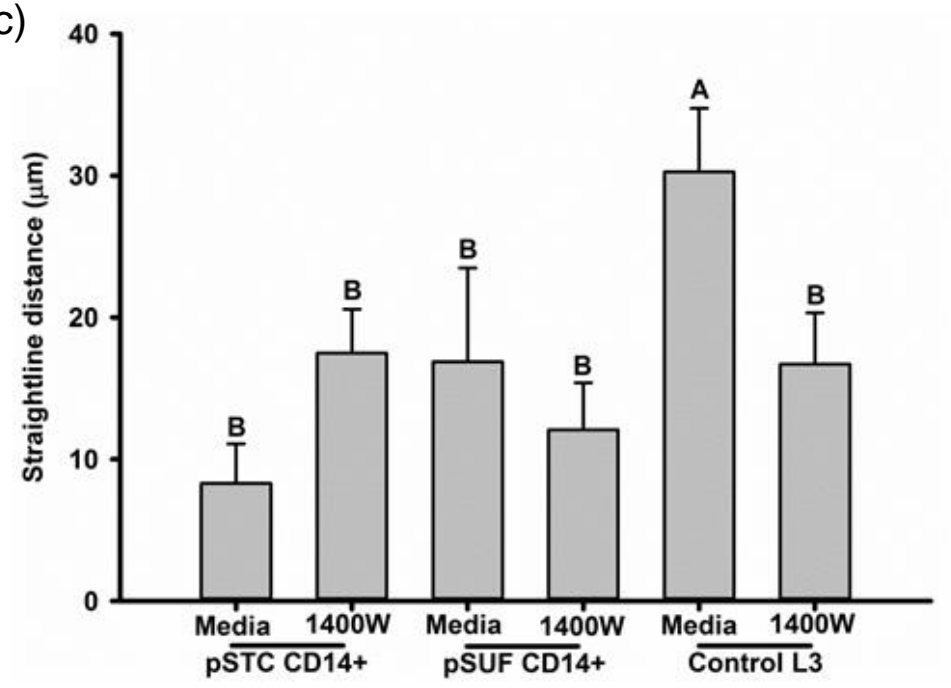

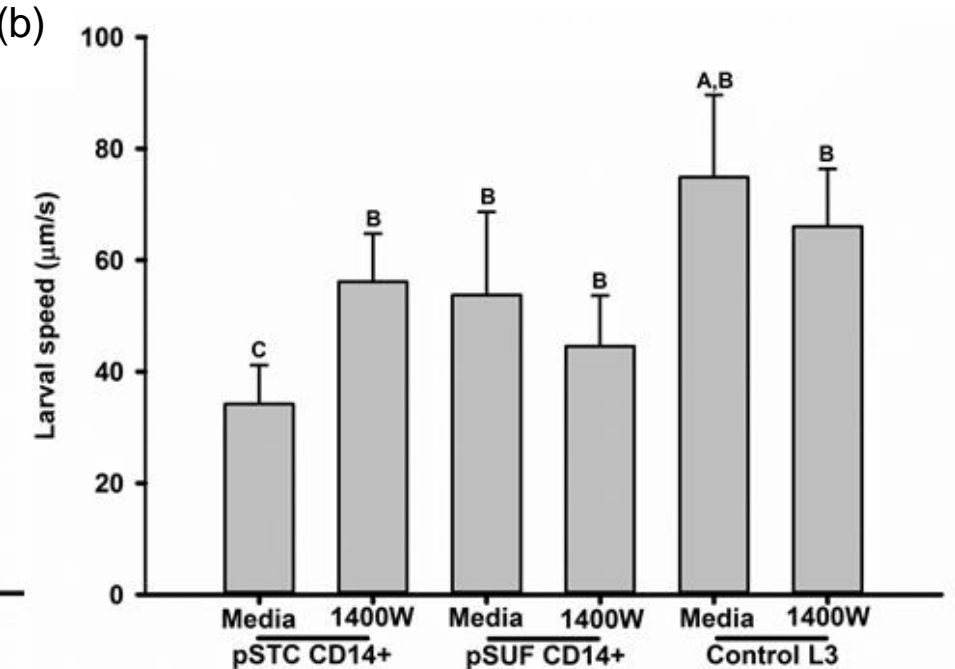

Figure 3: Inhibition of iNOS activity in monocytes.

CD14+ monocytes were isolated from PBMC derived from either St. Croix (STC) or Suffolk (SUF) sheep and cultured with $10 \mu \mathrm{g} / \mathrm{mL}$ 1400W (N-(3[Aminomethyl]benzyl)acetamidine) for one hour, before adding L3 to culture. (a) Larval ATP was measured after 18 hours of incubation, and compared to untreated (media) and 1400W treated controls. (b) Larval speed increased when STC-derived cells were treated with $1400 \mathrm{~W}$, but was reduced in SUF-derived cells treated with 1400W. (c) Treatment with $1400 \mathrm{~W}$ had no effect on straight-line distance traveled. Error bars represent SEM. Different letters indicate significant differences; $P<0.001$. 


\section{Tables}

Table 3.1: Gene expression of monocytes at 6 hours of cultures with L3

\begin{tabular}{|c|c|c|c|c|c|}
\hline \multirow[t]{2}{*}{ Gene } & \multicolumn{2}{|c|}{ STC } & \multicolumn{2}{|c|}{ SUF } & \multirow[b]{2}{*}{$P$ value } \\
\hline & FC & SEM & FC & SEM & \\
\hline \multicolumn{6}{|c|}{ Th1-related genes } \\
\hline$I L-12$ & 413.39 & 27.85 & 149.75 & 19.43 & 0.001 \\
\hline NOS2 & nd & & nd & & \\
\hline$I F N \gamma$ & 2.93 & 0.34 & 9.12 & 2.57 & ns \\
\hline \multicolumn{6}{|c|}{ Th2-related genes } \\
\hline$I L-4 r \alpha$ & 15.13 & 0.75 & 24.17 & 5.31 & ns \\
\hline$I L-4$ & 20.24 & 1.32 & 34.47 & 0.70 & ns \\
\hline $\operatorname{Arg} 1$ & 30.74 & 3.14 & 58.07 & 4.88 & ns \\
\hline$I L-10$ & 339.20 & 14.67 & 270.41 & 11.01 & 0.020 \\
\hline$I L-13$ & 35.10 & 2.38 & 141.02 & 6.47 & $<0.001$ \\
\hline
\end{tabular}

Cells were cultured with $\mathrm{L} 3$ at $37^{\circ} \mathrm{C}$ and $5 \% \mathrm{CO}_{2}$ for 6 hours then isolated from larvae to measure gene expression. Fold change (FC) was calculated using $\Delta$ ct relative to housekeeping gene GAPDH and $\Delta \Delta$ ct relative to cells cultured media. 
Table 3.2: Gene expression of monocytes at 9 hours of cultures with L3

\begin{tabular}{|c|c|c|c|c|c|}
\hline \multirow[t]{2}{*}{ Gene } & \multicolumn{2}{|c|}{ STC } & \multicolumn{2}{|c|}{ SUF } & \multirow[b]{2}{*}{$P$ value } \\
\hline & FC & SEM & FC & SEM & \\
\hline \multicolumn{6}{|c|}{ Th1-related genes } \\
\hline$I L-12$ & 29.63 & 3.87 & 87.40 & 16.01 & $\mathrm{~ns}$ \\
\hline NOS2 & 782.39 & 60.81 & 1191.71 & 46.18 & 0.006 \\
\hline$I F N \gamma$ & 69.60 & 11.64 & 546.92 & 67.17 & 0.002 \\
\hline \multicolumn{6}{|c|}{ Th2-related genes } \\
\hline$I L-4 r \alpha$ & 65.04 & 3.16 & 105.42 & 43.32 & 0.861 \\
\hline$I L-4$ & nd & & nd & & \\
\hline Argl & 53.81 & 2.48 & 164.71 & 3.01 & $<0.001$ \\
\hline$I L-10$ & 836.22 & 107.46 & 449.86 & 36.34 & 0.032 \\
\hline IL-13 & 485.81 & 35.86 & 785.70 & 56.82 & 0.11 \\
\hline
\end{tabular}

Cells were cultured with $\mathrm{L} 3$ at $37^{\circ} \mathrm{C}$ and $5 \% \mathrm{CO}_{2}$ for 9 hours then isolated from larvae to measure gene expression. Fold change (FC) was calculated using $\Delta$ ct relative to housekeeping gene GAPDH and $\Delta \Delta$ ct relative to cells cultured media. 
Table 3.3: Gene expression of monocytes at 12 hours of cultures with L3

\begin{tabular}{|c|c|c|c|c|c|}
\hline \multirow[t]{2}{*}{ Gene } & \multicolumn{2}{|c|}{ STC } & \multicolumn{2}{|c|}{ SUF } & \multirow[b]{2}{*}{$P$ value } \\
\hline & FC & SEM & FC & SEM & \\
\hline \multicolumn{6}{|c|}{ Th1-related genes } \\
\hline$I L-12$ & 58.41 & 14.20 & 47.93 & 7.41 & 0.55 \\
\hline NOS2 & 9449.88 & 407.47 & 6835.49 & 1028.28 & 0.08 \\
\hline$I F N \gamma$ & 10.04 & 0.28 & 38.18 & 12.36 & 0.98 \\
\hline \multicolumn{6}{|c|}{ Th2-related genes } \\
\hline$I L-4 r a$ & 344.76 & 0.86 & nd & & ns \\
\hline$I L-4$ & 160.17 & 18.11 & 174.96 & 4.21 & 0.47 \\
\hline Arg1 & 17.60 & 3.65 & 16.11 & 2.27 & 0.82 \\
\hline$I L-10$ & 1176.62 & 84.28 & 1427.26 & 146.15 & 0.21 \\
\hline$I L-13$ & 161.08 & 44.55 & 154.66 & 25.16 & 0.91 \\
\hline
\end{tabular}

Cells were cultured with $\mathrm{L} 3$ at $37^{\circ} \mathrm{C}$ and $5 \% \mathrm{CO}_{2}$ for 12 hours, then isolated from larvae to measure gene expression. Fold change (FC) was calculated using $\Delta$ ct relative to housekeeping gene GAPDH and $\Delta \Delta$ ct relative to cells cultured media. 
Table 3.4: Gene expression of monocytes at 15 hours culture with L3

\begin{tabular}{|c|c|c|c|c|c|}
\hline \multirow[t]{2}{*}{ Gene } & \multicolumn{2}{|c|}{ STC } & \multicolumn{2}{|c|}{ SUF } & \multirow[b]{2}{*}{$P$ value } \\
\hline & FC & SEM & FC & SEM & \\
\hline \multicolumn{6}{|c|}{ Th1-related genes } \\
\hline$I L-12$ & 64.41 & 6.13 & 33.51 & 3.93 & 0.035 \\
\hline NOS2 & 974.39 & 498.80 & 3931.81 & 102.53 & 0.004 \\
\hline$I F N \gamma$ & 3.67 & 0.39 & 19.49 & 1.90 & 0.001 \\
\hline \multicolumn{6}{|c|}{ Th2-related genes } \\
\hline$I L-4 r \alpha$ & 7.51 & 0.86 & 0.66 & 0.022 & 0.001 \\
\hline$I L-4$ & 245.52 & 65.17 & 73.33 & 32.21 & 0.144 \\
\hline Arg1 & 2.64 & 0.31 & 33.64 & 2.55 & $<0.001$ \\
\hline$I L-10$ & 552.58 & 37.33 & 1261.02 & 20.32 & $<0.001$ \\
\hline$I L-13$ & 47.18 & 6.22 & 0.04 & 0.01 & 0.002 \\
\hline
\end{tabular}

Cells were cultured with $\mathrm{L} 3$ at $37^{\circ} \mathrm{C}$ and $5 \% \mathrm{CO}_{2}$ for 15 hours, then isolated from larvae to measure gene expression. Fold change (FC) was calculated using $\Delta$ ct relative to housekeeping gene GAPDH and $\Delta \Delta$ ct relative to cells cultured media. 


\title{
Chapter 4: A novel role for Interleukin-13 inducing paralysis in Haemonchus contortus larvae
}

\begin{abstract}
The cytokine interleukin-13 (IL-13) is common to Th2 responses and exerts effects through host immune and non-immune cells. Typically, IL-13 induces gut contractility and mucus secretion after infection with helminth parasites to eliminate parasites from the digestive tract. A "weep and sweep" response could be enhanced by larval paralysis, therefore the objective of this study was to determine pleiotropic effects of IL-13 on $H$. contortus larvae directly. To test this hypothesis, L3 were treated with ovine recombinant $(\mathrm{r}) \mathrm{IL}-13(1 \mu \mathrm{g} / \mathrm{ml})$ and motility was analyzed using Wormlab $^{\mathrm{TM}}$ software. Treatment with rIL-13 reduced larval speed $(27 \mu \mathrm{m} / \mathrm{s})$ and distance $(7.5 \mu \mathrm{m})$ compared to untreated L3 (speed: $94 \mu \mathrm{m} / \mathrm{s}$; distance: $27 \mu \mathrm{m})(P<0.001)$. To confirm paralysis L3 were treated with levamisole (LEV), a known paralytic chemotherapeutic, which was not significantly different from rIL-13 treatment $(23 \mu \mathrm{m} / \mathrm{s}$ and $27 \mu \mathrm{m} / \mathrm{s}$, respectively). Neither LEV nor rIL-13 had an effect on larval morbidity. Addition of rIL13 to isolated monocytes did not enhance effector activity. However, blocking IL-13 reduced monocyte-driven larval morbidity $(0.13 \mu \mathrm{M}$ ATP $)$ and larval motility was significantly increased $(88 \mu \mathrm{m} / \mathrm{s} ; 27 \mu \mathrm{m})$ compared to larvae treated with STC-monocytes alone $(0.07 \mu \mathrm{M}$ ATP; $34 \mu \mathrm{m} / \mathrm{s} ; 8 \mu \mathrm{m})(P<0.05)$, though not to levels of untreated control L3 $(0.2 \mu \mathrm{M}$ ATP; $130 \mu \mathrm{m} / \mathrm{s} ; 30 \mu \mathrm{m})$. These data indicate that IL-13 has a dual capability by paralyzing L3 and aiding development of monocyte-driven larval morbidity.
\end{abstract}




\section{Introduction}

Cytokines are a fundamental aspect of immune response (1) as they recruit immune cells, influence immune cell differentiation and signal non-immune cells. Signaling from and to non-immune cells can affect host physiologic responses necessary to eliminate some types of pathogenic infection $(1,2)$. During helminth infection cytokine production induces increased mucus production by goblet cells, increased luminal flow and contractility of gut smooth muscle (2). Collectively, these actions result in removal of parasites from the gastrointestinal tract and are known as the "weep and sweep" response.

Concerted signaling of Th2 cytokines, such as IL-4, IL-5, and IL-13, promote IgE antibody production and drives parasite expulsion from the gastrointestinal tract. Of these cytokines, IL-13 signals through non-immune cells increasing mucus production and contraction of intestinal epithelium, resulting in clearance of infection (2). Effector functions of IL-13 make it a unique cytokine, driving cell-mediated immunity (3) and gut motility, as IL-13 directly interacts with enteric nerves (3). Though IL-4 and IL-13 share a receptor and are functionally related, IL-13 has a non-redundant role in host immunity (3). Previous studies have demonstrated a dominant and critical role of IL-13 in the control of $N$. brasiliensis infection using RAG knockout mice $\left(\mathrm{RAG}^{-1}\right)$. In the absence of lymphocytes, treatment with recombinant IL-13 stimulated parasite expulsion by directly activating non-lymphoid cells (4). These data are supported by evidence of increased expression of IL-4r $\alpha$ (receptor for IL-13) by non-immune gastrointestinal cells, such as smooth muscle cells, goblet cells and intestinal epithelium, inducing physiologic 
changes sufficient to clear $N$. brasiliensis in mice (5). However, these effects have not been investigated during infection with $H$. contortus in sheep.

Clearance in susceptible hosts currently requires use of anthelmintics. Nicotinic agonists used for deworming, such as levamisole, cause muscle contraction and spastic paralysis of larvae (6), resulting in increased passage rate from the abomasum. With the emergence of drug-resistant $H$. contortus strains, a critical need exists to develop alternative control strategies. Parasite-resistant STC sheep develop a strong Th2 response and display preferential alternative activation of macrophages in response to infective L3 in vitro, a hypothesis was developed whereby IL-13 has larval paralytic activity. The objectives of these experiments were to understand the direct effects of IL-13 on $H$. contortus L3 and how it may contribute to clearance of $H$. contortus in resistant sheep. Understanding natural mechanisms associated with resistance to $H$. contortus are essential to develop of advanced therapeutics.

\section{Materials and Methods}

\section{Inhibition assays}

To determine the effect of IL-13 on larval morbidity, IL-13 was inhibited in $\mathrm{CD}_{14}{ }^{+}$and $H$. contortus $\mathrm{L} 3$ co-cultures using $\alpha \mathrm{IL}-13 \mathrm{mAb}(0.1 \mu \mathrm{g} / \mathrm{mL})$. Cultures were incubated for $9 \mathrm{hr}$ at $37^{\circ} \mathrm{C}$. Motility and ATP were measured as outlined in the common methodologies section of this manuscript. To further validate paralytic activity of IL-13, $\mathrm{CD}_{1} 4^{+}$cell culture supernatant was collected after stimulation with crude larval antigen (HcLA) for $18 \mathrm{hr}$ at $37^{\circ} \mathrm{C}$. Supernatant was then added to $100 \mathrm{H}$. contortus $\mathrm{L} 3$ and

incubated at $37^{\circ} \mathrm{C}$ for $9 \mathrm{hr}$. Larval motility was assessed after culture using Wormlab ${ }^{\mathrm{TM}}$ 
Software, measuring speed and distance. To determine if rIL-13 could rescue susceptibility, rIL-13 $(1 \mu \mathrm{g} / \mathrm{mL})$ was added to CD14 ${ }^{+}$cells with L3 and incubated for $9 \mathrm{hr}$ at $37^{\circ} \mathrm{C}$. Again, motility and ATP were measured.

\section{Interleukin-13 protein quantification}

Culture supernatant was plated in pre-coated ovine-specific IL-13 ELISA (Genorise Scientific, Berwyn, PA) plates and protein quantification was performed according to manufacturer protocol. Briefly, $100 \mu 1$ of culture supernatant was plated in triplicate and incubated for $1 \mathrm{hr}$ at room temperature (RT). Liquid was aspirated from each well and washed before adding $100 \mu$ biotinylated detection antibody to each well and incubated for $1 \mathrm{hr}$ at RT. Again, solution was aspirated from each well and washed twice before adding $100 \mu \mathrm{l}$ horseradish peroxidase (HRP) conjugate was added to each well, incubating for $20 \mathrm{~min}$. Following two washes, $100 \mu \mathrm{l}$ of substrate reagent was added to each well, incubated for 20 min protected from light, before adding $50 \mu 1$ stop solution to each well. Optical density was read at 450nm and 540nm for wavelength correction. Assay detection range of $7-500 \mathrm{pg} / \mathrm{ml}$.

\section{Larval antigen preparation}

Crude larval antigen was prepared by homogenization of one $\mathrm{mL}$ centrifuged pellet of $H$. contortus L3 on ice using a tissue homogenizer. Lysate was centrifuged at $15,000 \times \mathrm{g}$ at $4^{\circ} \mathrm{C}$ for 1 hour. Supernatant was removed and filtered through a $0.22 \mu \mathrm{m}$ filter to sterilize. Protein was determined using micro-BCA assay (Pierce, Rockford, IL). Protease inhibitor cocktail (Sigma Aldrich, St. Louis, MO) was added at a rate of $1 \mu \mathrm{L}$ cocktail per $\mu \mathrm{g}$ of protein. Sterile $H$. contortus crude larval antigen (HcLA) was aliquoted into $1.5 \mathrm{~mL}$ microcentrifuge tubes and stored at $-80^{\circ} \mathrm{C}$ until use in experiments. 


\section{Fluorescent localization of interleukin-13}

Interaction of IL-13 with L3 was analyzed using fluorescent imaging. ReadiLink 594/610 Ab labeling kit (Biorad Laboratories, Hercules, CA) was used to label rIL-13 (Kingfisher Biotech, St. Paul, MN) according to manufacturer's protocol. Larvae were incubated with or without $1 \mu \mathrm{g} / \mathrm{mL}$ labeled rIL-13 for $6 \mathrm{hr}$ at $37^{\circ} \mathrm{C}$. Larvae were fixed to a slide by loading a Cytospin chamber with $100 \mu \mathrm{L} \mathrm{L3}$ suspension and concentrated onto

a microscope slide using Cytopsin 4 (Thermo Scientific) and mounted with DAPI Fluoromount-G (Southern Biotech, Birmingham, AB). Images were obtained on Zeiss Axio Imager M1 (Oberkochen, Germany) fluorescent microscope, using Cy5 filter cube. Micrographs were taken with Axiocam Mrc5 microscope camera (Oberkochen, Germany) mounted on the Imager M1. Composite images from fluorescence were overlaid using Zeiss software.

\section{Statistical analysis}

Data were analyzed using SigmaPlot software (Systat Software). Experiments in Figure 1 were analyzed with a one-way ANOVA for mean comparison. The Main effects of breed and treatment were compared in Figure 2 by two-way ANOVA using the HolmSidak method for mean comparison. Significance was accepted at $P<0.05$.

\section{Results}

\section{Larval motility following treatment with recombinant interleukin-13}

Larval motility was tracked following incubation with rIL-13 or levamisole (LEV), a known paralytic chemotherapeutic, and compared to motility of untreated control L3. When treated with rIL-13 larval speed $(28 \mu \mathrm{m} / \mathrm{s})$ was not significantly 
different from LEV treated larvae $(23 \mu \mathrm{m} / \mathrm{s})$, whereas both rIL-13 and LEV significantly reduced larval speed from untreated control $(94 \mu \mathrm{m} / \mathrm{s})(P<0.001)$ (Figure 1a). Straightline distance traveled by larvae was also significantly reduced when treated with rIL-13 (7.5 $\mu \mathrm{m})$ as compared to control $(27 \mu \mathrm{m})$, but was higher than LEV-treated larvae (1.8 $\mu \mathrm{m})(P<0.05)$ (Figure 1a). Larval morbidity was unaffected by treatment with either rIL-13 (0.047 $\mu \mathrm{M}$ ATP) or LEV (0.043 $\mu \mathrm{M} \mathrm{ATP)} \mathrm{compared} \mathrm{to} \mathrm{untreated} \mathrm{control} \mathrm{L3} \mathrm{(0.05}$ $\mu \mathrm{M}$ ), as measured by ATP concentration (Figure 1c).

To confirm the role of IL-13 inhibiting larval motility, L3 were treated with cytokines IL-4 and IFNy to compare to rIL-13 treated larvae. No differences were observed in speed or distance when L3 were treated with IFN $\gamma$ or IL-4, compared to control untreated L3 (Figure 1a). To confirm IL-13 is paralytic and not inducing larval morbidity, larval ATP was measured following each treatment and no differences were observed compared to untreated control L3 (Figure 1b). Furthermore, these results were not concentration dependent, as no differences were observed between concentrations of rIL-13, IL-4 and IFN $\gamma$ using 10-fold dilutions from 0.01 to $1 \mu \mathrm{g} / \mathrm{ml}$ (Figure 1c). Together, these data suggest that cytokine IL-13, specifically, may have a direct effect on L3, which is independent of cellular mechanisms and not due to cytokine "stickiness."

\section{Role of IL-13 in monocyte-larval interaction}

To understand the contribution of IL-13 from monocytes on L3 in culture, IL-13 was blocked using a monoclonal antibody (mAb) anti-IL-13 ( $\alpha$ IL-13). Monocytes from both breeds were incubated with $\alpha \mathrm{IL}-13$ when L3 were added to culture and incubated for 9 hr. Larvae cultured with monocytes treated with $\alpha \mathrm{IL}-13(0.13 \mu \mathrm{M}$ ATP $)$ had significantly higher ATP than L3 cultured with STC-derived monocytes alone (0.07 $\mu \mathrm{M}$ 
ATP), however $\alpha$ IL-13 treated monocytes were able to induced larval morbidity below untreated control L3 $(0.21 \mu \mathrm{M}$ ATP $)(P<0.001)$ (Figure 2a). No differences were observed between SUF-derived monocytes $(0.13 \mu \mathrm{M}$ ATP $)$ and SUF-derived monocytes treated with $\alpha \mathrm{IL}-13(0.12 \mu \mathrm{M}$ ATP), however both groups were significantly lower than untreated control larvae $(0.21 \mu \mathrm{M}$ ATP) $(P<0.001)$ (Figure 2a). Blocking IL-13 significantly increased larval speed (STC: $89 \mu \mathrm{m} / \mathrm{s}$; SUF: $91 \mu \mathrm{m} / \mathrm{s}$ ) compared to L3 treated with monocytes in media from either breed (STC: $34 \mu \mathrm{m} / \mathrm{s}$; SUF: $44 \mu \mathrm{m} / \mathrm{s})(P<$ 0.001) (Figure 2b), consistent with previous findings. Effects on straight-line distance were similar, where $\alpha \mathrm{IL}-13$ of cells significantly increased motility (STC: $27 \mu \mathrm{m} / \mathrm{s}$; SUF $33 \mu \mathrm{m} / \mathrm{s}$ ), compared to L3 cultured with monocytes in media alone (STC: $8 \mu \mathrm{m}$; SUF: 20 $\mu \mathrm{m})(P<0.001)$ (Figure $2 \mathrm{~b})$. These data suggest a role of IL-13 in monocyte effector activity.

Due to the observed effects of $\alpha$ IL-13 it was hypothesized that additional IL-13 could enhance effector function of SUF-derived monocytes. To determine the effects of IL-13 on monocytes activity, rIL-13 was added to STC- and SUF-derived monocytes and incubated overnight before adding L3 to culture. Larval morbidity was not enhanced by addition of rIL-13 in monocyte cell culture from either breed, as ATP was not reduced to levels comparable to L3 cultured with STC- or SUF-derived monocytes in media alone (Figure 2a). Furthermore, larval speed following addition of rIL-13 cytokine to STC- or SUF-derived monocytes was significantly higher (STC: $52 \mu \mathrm{m} / \mathrm{s}$; SUF: $68 \mu \mathrm{m} / \mathrm{s}$ ), as was straight-line distance (STC: $16 \mu \mathrm{m} / \mathrm{s}$; SUF: $21 \mu \mathrm{m} / \mathrm{s}$ ) when compared to L3 cultured with monocytes alone (STC: $34 \mu \mathrm{m} / \mathrm{s}, 8 \mu \mathrm{m}$; SUF: $44 \mu \mathrm{m} / \mathrm{s}, 20 \mu \mathrm{m})(P<0.001)$ (Figure $2 \mathrm{~b}$ ), though motility was still decreased from untreated controls $(130 \mu \mathrm{m} / \mathrm{s} ; 30 \mu \mathrm{m})(P<$ 
0.001) (Figure 2b). These data suggest that IL-13 does not heighten monocyte effector function against L3 in vitro.

To quantify IL-13 produced by monocytes, ovine-specific IL-13 ELISA was performed after culture of STC-and SUF-derived monocytes with or without L3 for 9 hours. No differences were observed in IL-13 production between breeds (STC: 13 pg/ml; SUF: $14 \mathrm{pg} / \mathrm{ml}$ ) (Figure 2c). Interestingly, both STC- and SUF-derived cells significantly reduced detectable IL-13 production with L3 in culture (STC: $6 \mathrm{pg} / \mathrm{ml}$; SUF: $7 \mathrm{pg} / \mathrm{ml}$ ), and IL-13 was not significantly different between breeds.

To further understand monocyte dynamics in culture with L3, and to determine if monocytes are secreting factors to inhibit larval motility, monocytes from both breeds were stimulated with Haemonchus contortus crude larval antigen (HcLA) overnight. Larvae were then treated with supernatant from monocytes in media or monocytes treated with HcLA and incubuated for 9 hours before measuring larval motility. Media from monocyte cell culture from either breed reduced larval speed (STC: $46 \mu \mathrm{m} / \mathrm{s}$; SUF: 38 $\mu \mathrm{m} / \mathrm{s})$ compared to untreated L3 $(54 \mu \mathrm{m} / \mathrm{s})(P<0.05)$ (Figure $2 \mathrm{~d})$, however no differences were observed in straight-line distance compared to control L3 (Figure 2d). Larvae treated with supernatant from STC-derived monocytes cultured with HcLA had the greatest reduction in speed $(28 \mu \mathrm{m} / \mathrm{s})(P<0 \quad .05)$ compared to all other treatment groups (Figure 2d). These data suggest monocytes produce factors capable of inhibiting larval motility, similar to that observed by IL-13 alone.

Because IL-13 production by monocytes was significantly reduced when L3 were in culture, yet monocytes secreted factors able to reduce larval motility, it was 
hypothesized that L3 were interacting with IL-13 in such a way as to neutralize its detection with ELISAs. Therefore, larvae were treated with or without fluorescently labeled-rIL-13 overnight and imaged to determine if IL-13 localized on L3. Imaging revealed IL-13 is present inside L3 (Figure 2e), suggesting IL-13 may be ingested by L3. These data support the mechanism of IL-13 acting as a paralytic, while IL-13 is reduced in cell culture medium with L3 present.

\section{Discussion}

Parasites secrete inhibitory factors or cytokine-mimics to modulate host immune response (7). However, little is known about whether cytokines can direct their effects against parasites, either in vivo or in vitro. Due to the nature of IL-13 exerting effects on both immune and non-immune cells, we hypothesized that this critical Th2 cytokine may have an additional anti-parasitic role that can directly interact in an inhibitory manner with L3. Culturing L3 with IL-13 in vitro demonstrated paralytic properties of IL-13 against L3, reducing overall motility, but did not affect larval morbidity when L3 were cultured with IL-13 in the absence of cells. Additional cytokines such as IL-4, another key Th2 cytokine, and IFN $\gamma$, an opposing Th1 related cytokine, were used to eliminate the possibility that observed effects of IL-13 were due to cytokine stickiness and therefore, specific to IL-13. Furthermore, these data suggest a previously unknown interaction of IL-13 directly with L3 and thereby having multiple, complimentary roles in parasite resistance in the host.

Studies have demonstrated macrophage adherence to $N$. brasiliensis larvae in vitro, inducing larval killing, where blocking IL-13 reduced larvicidal activity of macrophages (8). In our current study, blocking IL-13 in cell culture media with $\alpha$ IL-13 
had the greatest effect on STC-derived monocytes, which impaired cell effector mechanisms against L3. Though statistical difference was observed, $\alpha$ IL-13 had minor effects on SUF-derived monocyte effector function. While blocking IL-13 had significant effects on cellular activity against L3, larval morbidity was not entirely dependent on IL-13, as $\alpha$ IL-13-treated monocytes were still capable of reducing larval morbidity compared to untreated control L3. These data suggest that while IL-13 alone does not contribute to larval morbidity, its absence prevents full monocyte-driven morbidity and therefore, other monocyte-derived factors must be involved in larval morbidity. Evidence using S. stericoralis in mice demonstrated a role of macrophages and neutrophils surrounding larvae in vitro, but larval killing relied on soluble factors (9). Similar to our study, these data support independent mediators play a role in parasite resistance. Overall, these experiments support the importance of IL-13 in cell culture, where blocking IL-13 in both STC- and SUF-derived monocyte culture impaired cellmediated reduction in larval motility. Again, these differences were strongest in larvae cultured with STC-derived monocytes, highlighting breed differences and heightened ability of STC to mediate L3.

Due to increased motility and a decrease in monocyte-driven morbidity when Il13 was blocked in cell culture, we hypothesized that IL-13 could rescue susceptibility in SUF-derived monocytes. Surprisingly, however, supplementation of cell culture media with rIL-13 did not have a positive effect on larval morbidity or function to reduce larval motility as well as untreated monocytes from either breed. Thus, no additive effects were observed with addition of exogenous IL-13 in this model. In a mouse model, IL-4 knock out $\left(\mathrm{IL}-4^{-/-}\right)$mice were able to clear $N$. brasiliensis infection, whereas IL-13 ${ }^{-/-}$mice had 
higher worm burdens and unable to clear infection (10). When IL-13 ${ }^{-/-}$mice were given exogenous IL-13, worm burden was significantly reduced due to effects on goblet cell hyperplasia in the gut (10). Therefore, while administration with exogenous IL-13 did not enhance monocyte effector function in vitro, it is reasonable to hypothesize that exogenous IL-13 may have a greater capacity to rescue susceptibility in vivo, contributing to non-immune intestinal cells.

In our present study, we showed IL-13 had direct effects on $H$. contortus L3 in vitro, independent of cellular immunity. IL-13 is a potent inducer of larval paralysis, similar to that of some current anthelmintics, which also act as paralytic agents and do not have larvicidal properties. Paralysis prevents larval establishment and larvae are more susceptible to immune modulated clearance mechanisms induced in the local environment. Our study also demonstrated monocyte contribution to larval morbidity, which was independent of IL-13 and greater in STC. However, monocyte-derived IL-13, and not exogenous rIL-13, was necessary for full monocyte effector function in STC. These differences were emphasized in STC compared to SUF, where SUF monocytes were not affected by either blocking IL-13 or addition of IL-13 to cell culture media.

Together, these data support a cellular-derived role of IL-13 in vitro and an independent, direct role of IL-13 against $H$. contortus L3. Furthermore, these data suggest an enhanced ability of STC-derived monocytes to limit L3 motility and increased capacity to increase larval morbidity, compared to SUF, which may be reflective of mechanisms of STC natural resistant phenotype. While, these data do not implicitly demonstrate monocyte-IL-13-larval interactions in either STC or SUF sheep in vivo, previous studies have shown STC increase IL-13 gene expression during $H$. contortus 
infection (11) and increase circulating white blood cells (12). Thus, it is not unreasonable to associate our observed differences in IL-13-monocyte action with differences in parasite resistance between STC and SUF. Nevertheless, these data demonstrate a previously unknown effect of IL-13 and the potential exists for these data to be translated into development of future chemotherapeutic treatments or therapeutics in animals susceptible to $H$. contortus.

\section{Literature cited}

1. Stanley AC, Lacy P. Pathways for Cytokine Secretion. Physiology. 2010;25(4):218-29.

2. Anthony RM, Rutitzky LI, Urban JF, Stadecker MJ, Gause WC. Protective immune mechanisms in helminth infection. Nat Rev Immunol. 2007;7(12):975-87.

3. Wynn TA. IL-13 Effector Functions. Annu Rev Immunol. 2003;21(1):425-56.

4. Barner M, Mohrs M, Brombacher F, Kopf M. Differences between IL-4R $\alpha-$ deficient and IL-4-deficient mice reveal a role for IL-13 in the regulation of Th2 responses. Curr Biol. 1998;8(11):669-72.

5. Urban JF, Noben-Trauth N, Schopf L, Madden KB, Finkelman FD. Cutting Edge: IL-4 Receptor Expression by Non-Bone Marrow-Derived Cells Is Required to Expel Gastrointestinal Nematode Parasites. J Immunol. 2001;167(11):6078-81.

6. Martin JR. Modes of Action of Anthelmintic Drugs. Vet J. 1997;154:11-34.

7. Ouaissi A. Regulatory cells and immunosuppressive cytokines: Parasite-derived factors induce immune polarization. J Biomed Biotechnol. 2007;2007(94971). 
8. Chen F, Wu W, Millman A, Craft JF, Chen E, Patel N, et al. Neutrophils prime a long-lived effector macrophage phenotype that mediates accelerated helminth expulsion. Nat Immunol. 2014;15(10):938-46.

9. Bonne-Année S, Kerepesi LA, Hess JA, O’Connell AE, Lok JB, Nolan TJ, et al. Human and mouse macrophages collaborate with neutrophils to kill larval strongyloides stercoralis. Infect Immun. 2013;81(9):3346-55.

10. McKenzie GJ, Bancroft AJ, Grencis RK, McKenzie ANJ. A distinct role for interleukin-13 in Th2-cell-mediated immune responses. Curr Biol. 1998;8(6):339_ 42.

11. MacKinnon KM, Zajac AM, Kooyman FNJ, Notter DR. Differences in immune parameters are associated with resistance to Haemonchus contortus in Caribbean hair sheep. Parasite Immunol. 2010;32(7):484-93.

12. Bowdridge SA, Zajac AM, Notter DR. St. Croix sheep produce a rapid and greater cellular immune response contributing to reduced establishment of Haemonchus contortus. Vet Parasitol. 2015;208(3-4):204-10. 


\section{Figures}

(a)

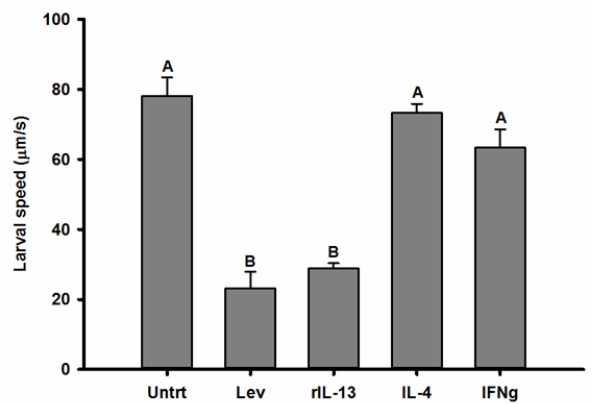

(b)

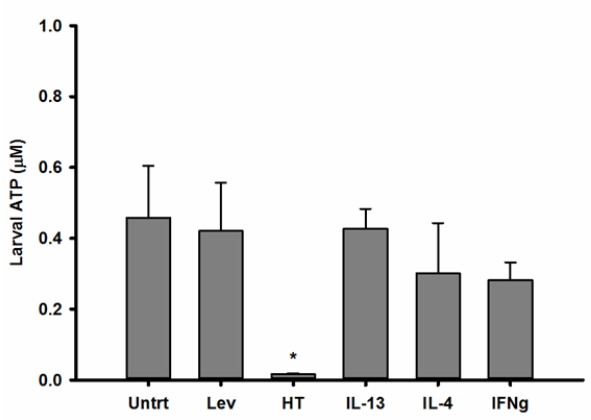

(c)

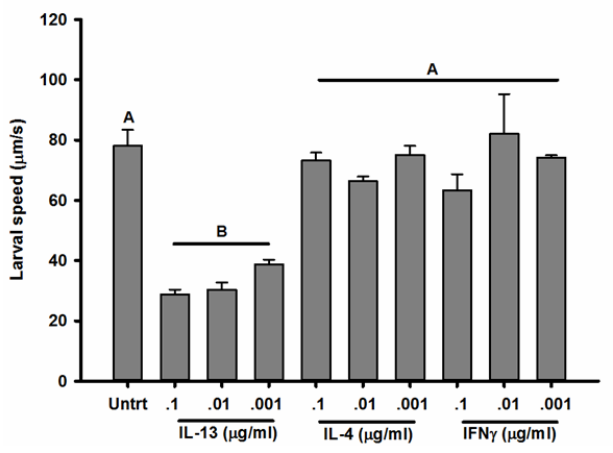

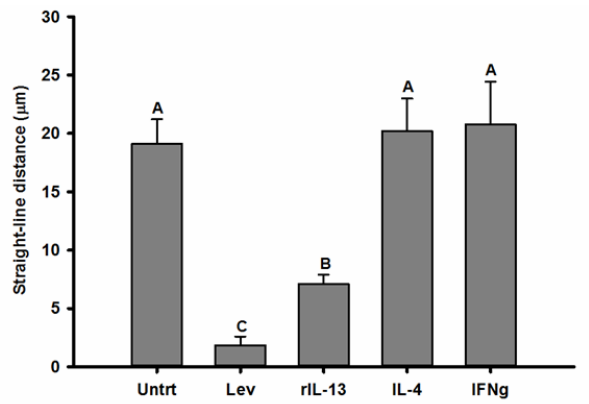

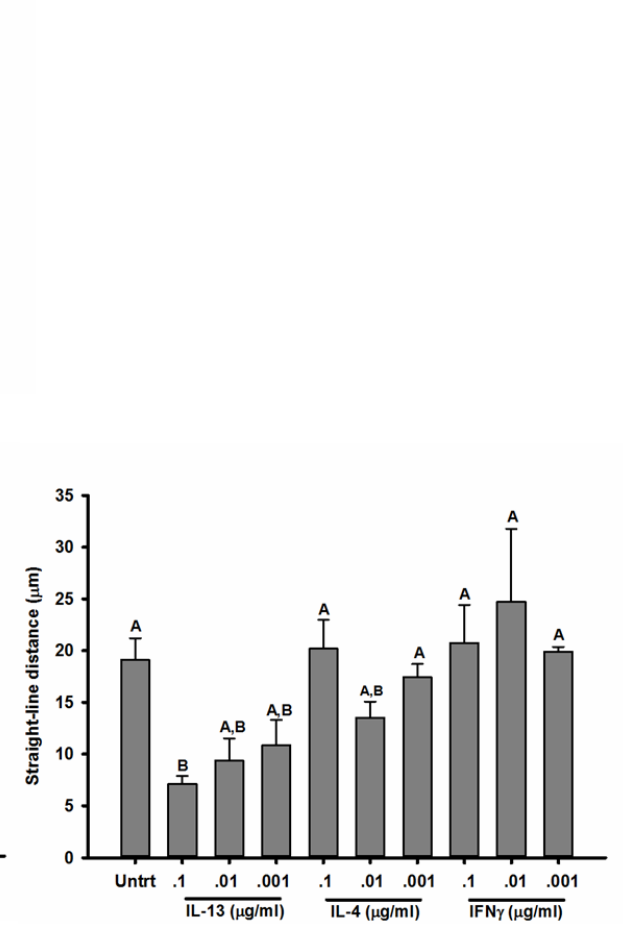

\section{Figure 1: Larval motility measured after cytokine treatment in vitro.}

Larvae were treated with $0.1 \mu \mathrm{g} / \mathrm{ml}$ ovine recombinant IL-13 (rIL-13), IL-4 or IFN $\gamma$ (IFNg), or anthelmintic levamisole (LEV) and cultured in 24 -well plates for $9 \mathrm{hrs}$ at $37^{\circ} \mathrm{C}$ $5 \% \mathrm{CO}_{2}$. Treatments were plated in triplicate. (a) Larval speed and straight-line distance was measured using WormLab ${ }^{\mathrm{TM}}$ tracking software, over 50 frames of video per well. (b) Larval ATP was measured across each treatment group. Data represents the average of 
three independent experiments. (c) Larvae were treated with $0.1,0.01$ or $0.001 \mu \mathrm{g} / \mathrm{ml}$ of rIL-13, IL-4 or IFN $\gamma$ and cultured for 9 hours at 9 hrs at $37^{\circ} \mathrm{C} 5 \% \mathrm{CO}_{2}$. Treatments were plated in triplicate. Videos were recorded and motility was measured as a function of speed and straight-line distance, using WormLab ${ }^{\mathrm{TM}}$ software over 50 frames of video per well. Error bars represent SEM. Different letter indicate significant differences; $P<$ 0.001. $* P<0.05$. 
(a)

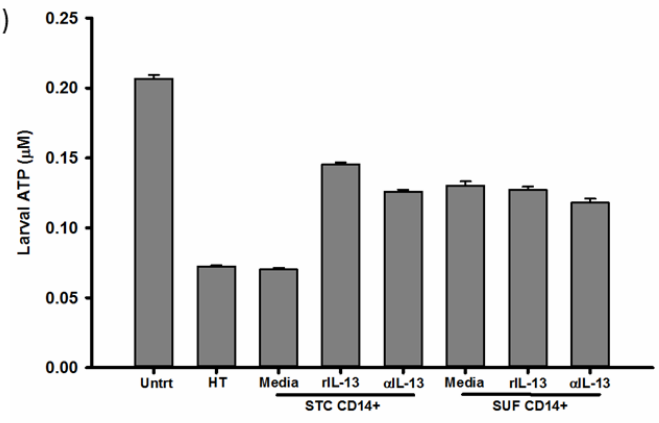

(b)
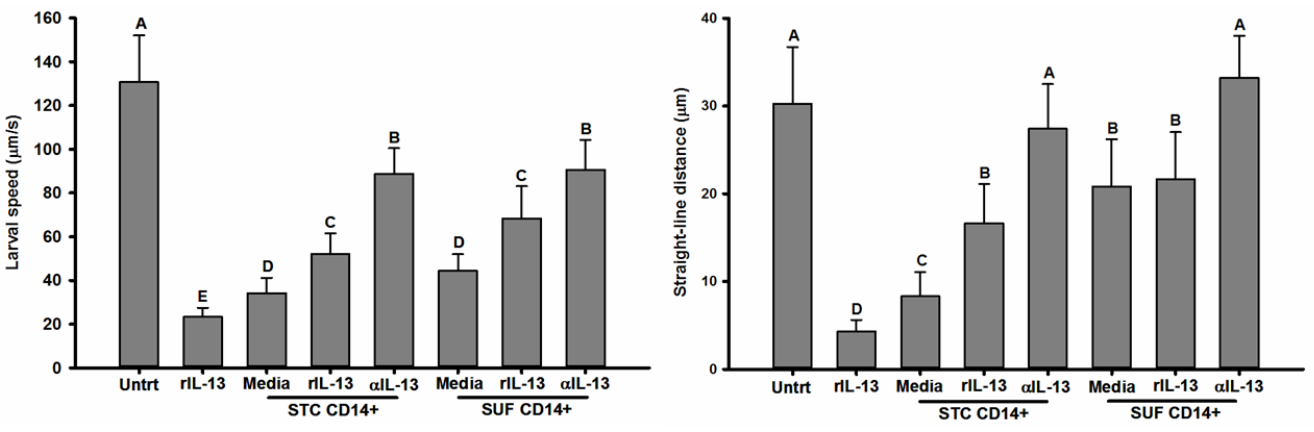

(c)

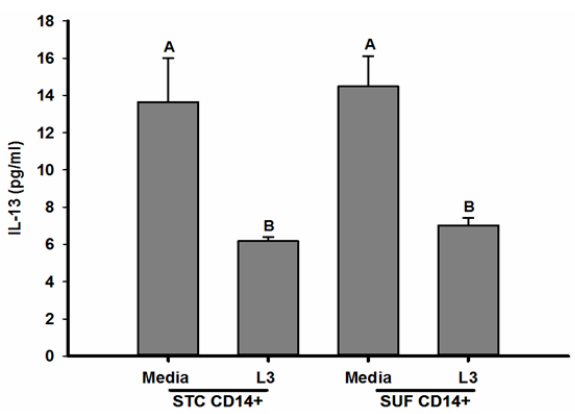

(d)

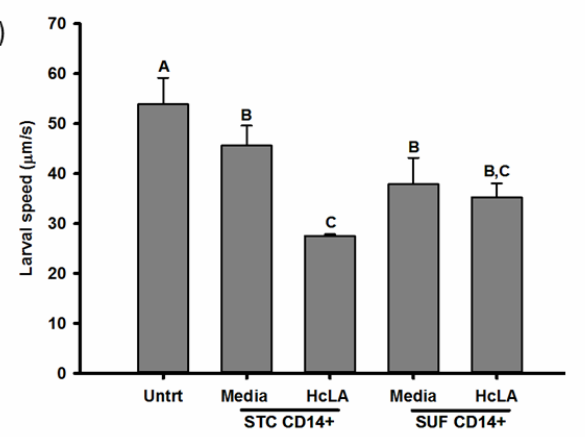

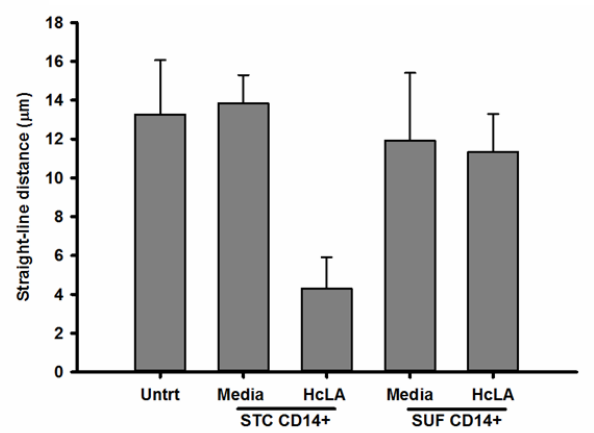


(e)

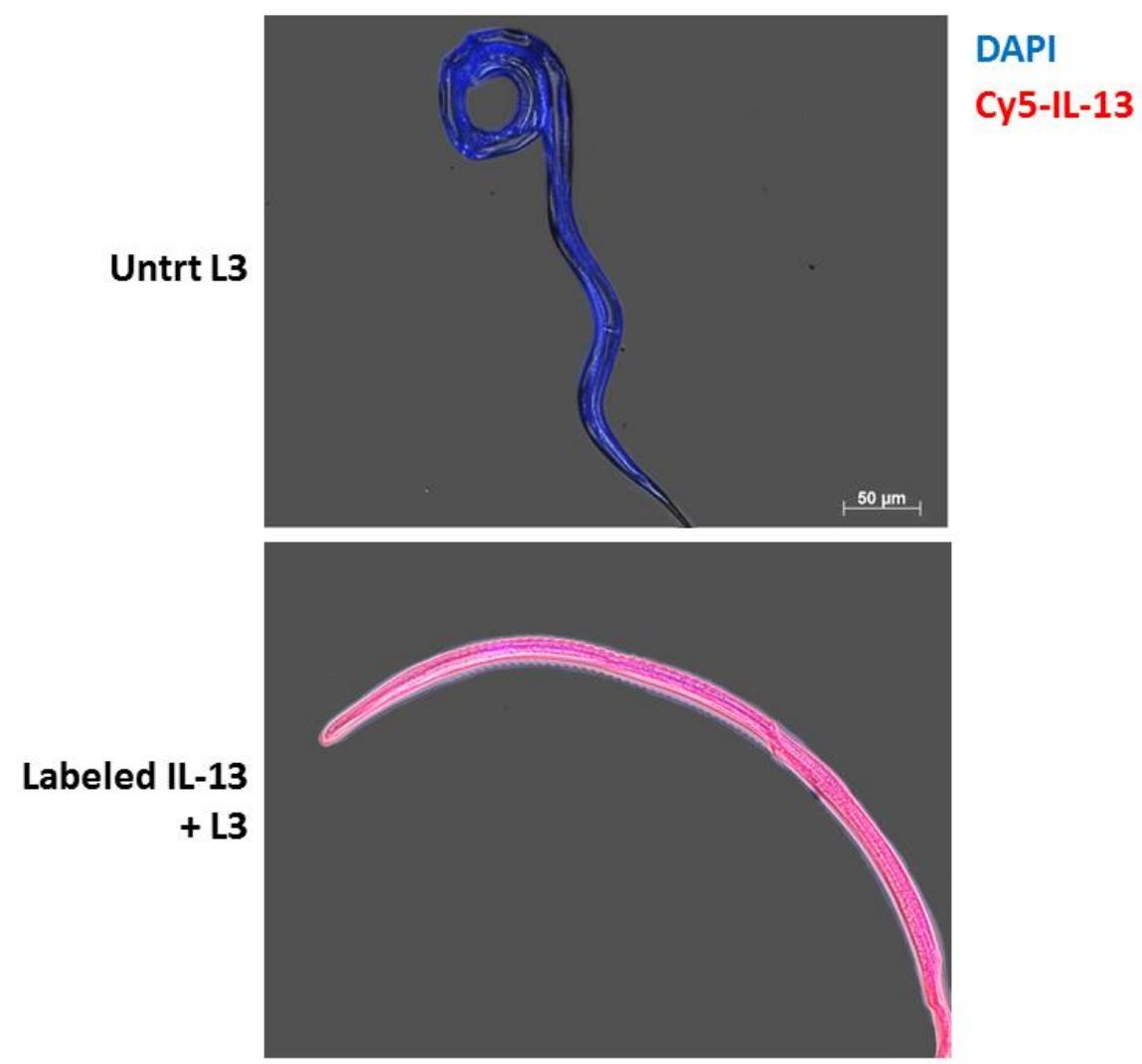

\section{Figure 2: Role of IL-13 in monocyte-larval interaction.}

(a) Larvae were cultured with monocytes (CD14+) from St. Croix (STC) or Suffolk (SUF) sheep either in media or monocytes treated with $0.1 \mu \mathrm{g} / \mathrm{ml}$ anti-IL-13 monoclonal antibody ( $\alpha \mathrm{IL}-13)$ in 24-well plates for $9 \mathrm{hrs}$ at $37^{\circ} \mathrm{C} 5 \% \mathrm{CO}_{2}$ before measuring larval ATP. (b) Larvae were treated with monocytes cultured either with media, rIL-13 or $\alpha$ IL$13(0.1 \mu \mathrm{g} / \mathrm{ml})$ for $9 \mathrm{hrs}$ at $37^{\circ} \mathrm{C} 5 \% \mathrm{CO}_{2}$. Untreated (Untrt) L3 were cultured in media and negative control L3 were culture in media supplemented with rIL-13 $(0.1 \mu \mathrm{g} / \mathrm{ml})$. Larval speed and straight-line distance was measured using WormLab $^{\mathrm{TM}}$ tracking software, over 50 frames of video per well. (c) Culture supernatant was collected from monocyte cell culture in media or treated with L3 and IL-13 quantification was performed using an ovine-specific ELISA. (d) Larvae were treated with supernatant from monocytes cultured with or without $H$. contortus crude larval antigen (HcLA) $(20 \mu \mathrm{g} / \mathrm{ml})$ 
and cultured for 9 hours before measuring motility using WormLab ${ }^{\mathrm{TM}}$ tracking software, over 50 frames of video per well. (e) Untreated L3 and L3 treated with fluorescently labeled IL-13 were imaged at 20x in brightfield Cy5 (red) and DAPI (blue) then overlaid. All treatments were performed in triplicate. Error bars represent SEM. Different letter indicate significant differences; $P<0.001$. 


\section{Chapter 5: Discussion}

Together, these studies aimed to characterize ovine monocytes in response to $H$. contortus L3 and to understand pleiotropic effects of cytokine IL-13, as both monocytes and IL-13 are critical in development of a protective Th2 type response associated with natural resistance observed in St. Croix sheep. Monocytes produce IL-13 and respond to IL-13, making it a potent modulator of monocyte function. Therefore, positive feedback of IL-13 was hypothesized to be key in monocyte activation status. Despite the requirement of IL-13 in many models of helminth clearance, direct larvae-to-cytokine interaction has not previously been described or recorded.

In mice, infection with nematodes $H$. polygyrus, $T$. spiralis or $T$. muris clearance require IL-4, whereas expulsion of $N$. brasiliensis is mediated by IL-13, and does not require IL-4 (1). Both IL-4 and IL-13 increased gut hypercontractility in response to nerve stimulation in mice infected with $H$. polygyrus or $N$. brasiliensis, however, IL-13 treatment had a greater effect on nerve response than IL-4 (2). Additionally, IL-13, but not IL-4, increased contractility in response to acetylcholine, involving enteric nerves in $N$. brasiliensis infected mice (2). Together, these data highlight functional differences in cytokine-mediated clearance and may be parasite specific. However, the individual contribution of IL-4 and IL-13 have not been evaluated in the context of $H$. contortus in sheep. Thus, the relative contribution of each cytokine specific to $H$. contortus clearance remains unclear.

Suffolk derived monocytes did not alter response to IL-13 inhibition and do not generate an inhibitory response to L3 as great as St. Croix sheep derived monocytes. 
However, these data may not account for differences in vivo, such as signaling and cellular recruitment, either through the production of IL-13 or through receptor signaling pathways. Previous research has demonstrated that St. Croix sheep have increased cellular influx to abomasal tissues during $H$. contortus infection $(3,4)$ and increased IL-13 expression by STC-derived PBMC (5). Therefore, IL-13 signaling pathways may be dampened in Suffolk sheep and may contribute to reduced ability of Suffolk sheep to mount full host protective responses, either due to lower or delayed cellular recruitment to abomasal tissue.

Despite many non-redundant functions, IL-4 and IL-13 share some biologic and structural homology, most notably sharing receptor IL-4ra (6). Sharing a receptor also leads to competition between IL-13 and IL-4 to bind to IL-4ra, where IL-4 promotes T cell differentiation to Th2 cells and IL-13 promotes M2 activation and B cell class switching (7). Increased IL-4ra expression on cell surfaces also increases sensitivity to IL-4 and IL-13, which influences M2 differentiation (8). Specifically, changes in IL-10 production are linked to IL-4ra cell surface expression (8). For example, M1 macrophages produce IL-10, but M2 macrophages produce more (9) and thus, influence sensitivity towards IL-13 polarization, which depends on timing and amount of cytokine in local tissues.

Expression of IL-10 was significantly higher in STC-derived monocytes in the current study, and occurred earlier compared to SUF-derived monocytes. Previous studies indicated STC-derived PBMC up-regulated IL-4ra in response to H. contortus L3, compared to SUF-derived PBMC (5), in accordance with data from the current study. In murine models, $T$. spiralis required IL-4ra expression on non-bone marrow-derived cells 
for parasite clearance, whereas mice infected with N. brasiliensis did not (10). Therefore, expression of IL-4r $\alpha$ on immune and non-immune cells could also account for observed differences in IL-13 activity and response to helminth infection. However, the effects of IL-10 and IL-4r $\alpha$ expression on IL-13 signaling were beyond the scope of these experiments and have yet to be explored in context of $H$. contortus. Thus, differences between St. Croix and Suffolk IL-10 signaling, up-stream of IL-13, could account for differences in IL-4ra signaling through IL-13-mediated pathways of larval expulsion.

As spread of anthelmintic resistance increases globally, advanced therapeutics are necessary to mediate $H$. contortus in small ruminant production. Data gathered in these studies indicate IL-13 is a potent inducer of larval paralysis similar to effects observed using levamisole, a known chemotherapeutic paralytic. Levamisole is a nicotinic agonist, which disrupts the neuromuscular system by binding to nicotinic acetylcholine receptors necessary for neurotransmitters in $H$. contortus locomotion (11). While immunologic mechanisms of IL-13 have been well-documented in context of helminth infection, mechanisms of IL-13 interaction with L3 are not yet understood.

While IL-13 provides protection against helminth parasites through immune and non-immune mechanisms, triggering IL-13 is attributed to disease pathologies in atopic dermatitis, allergic rhinitis, and asthma $(12,13)$. Activated mast cells and Th2 cells release IL-13, resulting in degranulation of accumulated eosinophils and lead to airway constriction in eosinophilic esophagitis, causing difficulty swallowing (14). Similarly, IL-13 expression is increased in sputum of allergen challenged mice and in sputum from asthmatics causing restrictive airway hyper-responsiveness (12). In the context of asthma, neutralization of IL-13 with anti-IL-13 antibodies reduced pathologies in both mouse and 
sheep models of airway hypersensitivity, similar to mice deficient in IL-13 $(15,16)$. Thus, administration of IL-13 should be carefully considered and localized towards abomasal tissue, in sheep.

Despite breed differences in monocyte-mediated responses and the capacity of monocytes to secrete factors inhibitory to larval motility, specific differences in signaling between St. Croix sheep and Suffolk sheep remain unclear. Data from the current studies suggest Suffolk sheep monocytes are not completely impaired, as Suffolk sheepderived monocytes expressed genes associated with Th2 type responses and can generate a response to L3, though reduced, occurring later when compared to St. Croix sheep. Measuring gene expression over 6 to 12 hours of culture was aimed to determine differences in timing of gene expression, however these data failed to elucidate differences in key markers. Nevertheless, previous studies have shown abomasal tissue from St. Croix sheep had greater expression of monocyte chemo-attractant protein-1 (MCP1), Arg1 and IL-4 when compared to susceptible, wool lambs infected with $H$.

contortus (17). Together, these data support a role for monocyte-mediated mechanisms of resistance.

\section{Literature cited}

1. Bancroft AJ, McKenzie AN, Grencis RK. A critical role for IL-13 in resistance to intestinal nematode infection. J Immunol. 1998;160(7):3453-61.

2. Zhao A, Mcdermott J, Urban JF, Gause W, Madden KB, Yeung KA, et al. Dependence of IL-4, IL-13, and Nematode-Induced Alterations in Murine Small Intestinal Smooth Muscle Contractility on Stat6 and Enteric Nerves. Jounral Immunol. 2019;171(2):948-54. 
3. Bowdridge SA, Zajac AM, Notter DR. St. Croix sheep produce a rapid and greater cellular immune response contributing to reduced establishment of Haemonchus contortus. Vet Parasitol. 2015;208(3-4):204-10.

4. MacKinnon KM, Burton JR, Zajac AM, Notter DR. Microarray analysis reveals difference in gene expression profiles of hair and wool sheep infected with Haemonchus contortus. Vet Immunol Immunopathol. 2009;130:210-20.

5. Jacobs JR, Greiner SP, Bowdridge SA. Impaired interleukin-4 signalling promotes establishment of Haemocnhus contortus in sheep. Parasite Immunol. 2018;40(12):e12597.

6. Muchamuel T, Menon S, Pisacane P, Howard MC, Cockayne DA. IL-13 protects mice from lipopolysaccharide-induced lethal endotoxemia: correlation with downmodulation of TNF-alpha, IFN-gamma and IL-12 production. J Immunol. 1997;158:2898-903.

7. Mueller TD, Zhang JL, Sebald W, Duschl A. Structure, binding, and antagonists in the IL-4/IL-13 receptor system. Biochim Biophys Acta - Mol Cell Res. 2002;1592(3):237-50.

8. Lang R, Patel D, Morris JJ, Rutschman RL, Murray PJ. Shaping Gene Expression in Activated and Resting Primary Macrophages by IL-10. J Immunol. 2002;169(5):2253-63.

9. Murray PJ. Macrophage polarization. Annu Rev Physiol. 2017;79:541-66.

10. Urban JF, Noben-Trauth N, Schopf L, Madden KB, Finkelman FD. Cutting Edge: IL-4 Receptor Expression by Non-Bone Marrow-Derived Cells Is Required to Expel Gastrointestinal Nematode Parasites. J Immunol. 2001;167(11):6078-81. 
11. Robertson SJ, Martin RJ. Levamisole-activated single-channel currents from muscle of the nematode parasite Ascaris suum. Br J Pharmacol. 1993;108(1):1708.

12. May RD, Fung M. Strategies targeting the IL-4/IL-13 axes in disease. Cytokine. 2015;75:89-116.

13. Wang Y, McCusker C. Interleukin-13-dependent bronchial hyper-responsiveness following isolated upper-aiway allergen challenge in murin model of allergic rhinitis and asthma. Clin Exp Allergy. 2005;35:1104-11.

14. Akiho H, Ihara E, Motomura Y, Nakamura K. Cytokine-induced alterations of gastrointestinal motility in gastrointestinal disorders. World J Gastrointest Pathophysiol. 2011;2(5):72-81.

15. Kasaian MT, Donaldson DD, Tchistiakova L, Marquette K, Tan Z-Y, Ahmed A, et al. Efficacy of IL-13 neutralization in a sheep model of experimental asthma. Am J Respir Cell Mol Biol. 2007;36:368-76.

16. Kasaian MT, Miller DK. IL-13 as a theraputic target for respiratory disease. Biochem Pharmacol. 2008;76(2):147-55.

17. Jacobs JR, Sommers KN, Zajac AM, Notter DR, Bowdridge SA. Early IL-4 gene expression in abomasum is associated with resistance to Haemonchus contortus in hair and wool sheep breeds. Parasite Immunol. 2016;38(6):333-9. 